University of San Diego

Digital USD

2004-05-01

\title{
The Relationship between Leadership Styles and Labour Disputes in British Columbia's Public Schools
}

Yanping Wang EdD

University of San Diego

Follow this and additional works at: https://digital.sandiego.edu/dissertations

Part of the Leadership Studies Commons

\section{Digital USD Citation}

Wang, Yanping EdD, "The Relationship between Leadership Styles and Labour Disputes in British Columbia's Public Schools" (2004). Dissertations. 740.

https://digital.sandiego.edu/dissertations/740

This Dissertation: Open Access is brought to you for free and open access by the Theses and Dissertations at Digital USD. It has been accepted for inclusion in Dissertations by an authorized administrator of Digital USD. For more information, please contact digital@sandiego.edu. 
THE RELATIONSHIP

BETWEEN LEADERSHIP STYLES AND LABOUR DISPUTES

IN BRITISH COLUMBIA'S PUBLIC SCHOOLS

\author{
By \\ Yanping Wang \\ A dissertation submitted in partial fulfillment \\ of the requirements for the degree of \\ Doctor of Education \\ University of San Diego
}

May 2004

Dissertation Committee

Fred J. Galloway, Ed.D., Chair

Daniel M. Miller, Ph.D., Member

Ron W. Germaine, Ed.D., Member 
(C) Copyright by Yanping Wang 2004

All Rights Reserved 


\begin{abstract}
For the last decade, adversarial relationships between teachers' associations and district administrators in the British Columbia public school system have been commonplace, frequently resulting in formal grievances and arbitration. Since dealing with these issues imposes enormous costs on both teachers' unions and school boards, this study used hierarchical regression analysis to explain why some schools have fewer grievances filed than other schools in the province. Specifically, this study used data gathered from 160 principals in the British Columbia public school system to examine the extent to which school demographics and principal leadership style helped explain variation in the rate of filed grievances per one hundred teachers.

Results suggest that both demographic factors and principal leadership style were key determinants of filed grievances. Specifically, two aspects of principals' leadership styles were important - those that reported engaging in Charisma/Inspirational leadership had more grievances files against them, while those with higher levels of Individualized Consideration had fewer grievances filed against them. Three demographic factors were also found to be important, with the most significant being that K-9 and K-12 schools had approximately 18 more grievances filed per one hundred teachers than elementary schools. In addition, those schools with a considerable number of office referrals $(92-225)$ tended to have more filed teacher grievances, as did schools that had a comparatively large percentage of their student population from lower income families.
\end{abstract}


To Yuluo Wang, my beloved father,

for being a great model $\&$ inspiration to me in my life 


\section{ACKNOWLEDGEMENTS}

This dissertation is the product of nearly six years of study and toil. And the work could not have been done had it not been for many people who had played significant roles in various aspects of my life. It would be almost impossible for me to thank each one of those who have contributed to the completion of my research, as there were numerous people and organizations that generously helped me. However, I wish to thank the B.C. School Superintendents' Association, B.C. Principal and Vice Principal Association, and all those from the sixty B.C. school districts that provided support and/or participated in the data collection. I also wish to thank the many B.C. local teachers' associations that willingly participated in the survey.

I wish to extend my most sincere thanks to Dr. Galloway, my committee Chair, who has contributed enormously in terms of intellectual, methodological, and editorial thoughtfulness. I have learnt much about what it takes to bring out the best in quantitative research through his guidance in this study. For his continuous support and encouragement, his sacrifice of countless Saturdays, holidays and family time for supervising this project, for his dedication to quality scholarship, for his ongoing openness to question, I feel sincerely and deeply indebted to Dr. Galloway. It was also Dr. Galloway who rightfully and persistently challenged me to rewrite over and over until it was methodologically sound and logically readable.

My many thanks and gratitude go to Dr. Dan Miller, my committee supervisor and course professor, who positively influenced and encouraged me throughout my doctoral study. I sincerely thank him for his advice in the study design and very kind 
support to me. His contribution was vital to the completion of this study. Dr. Miller's profound scholarship also made a significant influence on me through his teaching.

A special word of thanks to Dr. Germaine, my committee supervisor and former cohort member, for his significant experience and insights into the B.C. education system. I wish to thank his invested talent and energy in reading the manuscript and providing precious feedback. Although this work took so long to finish, Dr. Germaine was quick to get feedback to me each time the draft was sent to him for review. I sincerely thank Dr. Germaine for his friendship, his editorial suggestions and many proofreading chores.

A huge thank-you goes to Dr. Fred Renihan, CEO and Superintendent of Surrey School District, for his ongoing support throughout this research, especially for his generous offer for me to use the district website for the research, and for allowing me to obtain technical support from the research department. In addition, I would like to acknowledge the contributions of Dr. Barbara Holms, director of Research and Safe Schools for the Surrey School District, who provided me with intellectual support in the process of data collection. I also want to say a special thank-you to Kathryn Peterson, the research analyst for the Survey School District, who painstakingly set and reset the websites for electronic surveys for many times, downloaded completed responses, and converted data into workable data files.

Finally, I wish to thank my family for their understanding and sacrifice of many vacations and missed family fun due to time needed for this work. I am especially indebted to my husband Nian who, by the nature of our friendship and life-long companionship, has provided me with concrete support, encouragement and inspiration at 
every step of the journey. As my former classmate in the same doctoral cohort and as one who graduated three years earlier, Nian was always my first reader, non-compromising critic, and one who encouraged me to continue on the right track. My son Shane was so quiet and supportive waiting for me to finish. He never complained about a meal skipped or a trip to nowhere, though at times he had reason to do so.

It is my wish to dedicate this work to my late father who unexpectedly passed away only a couple of months before I finally finished the last sentence of this dissertation. Although he did not have the opportunity to see me complete this doctoral journey, he must be pleased to know his daughter finally made it. For over fourteen years he waited, never demanding our family reunion, and, always, he sacrificed for me with parental love and understanding till the very end. As an adult, a daughter, and a mother, I have long understood the value and virtue of personal sacrifice, which is often underrated but should be fully recognized and appreciated. This is the very reason that I present this completed work in memory of my dear father. May he rest in peace forever.

I express my deep appreciation for the many named, unnamed, and nameless that have contributed to my research, my growth, and my joy and success in bringing this work finally to an end!

God bless!

Yanping Wang 


\section{TABLE OF CONTENTS}

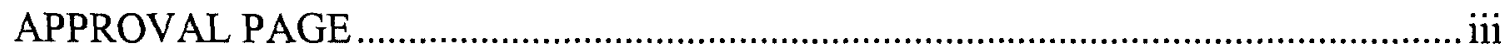

INSTITUTIONAL REVIEW BOARD CLEARANCE .................................................... iv

ACKNOWLEDGEMENTS.

CHAPTER II REVIEW OF THE LITERATURE................................................. 10

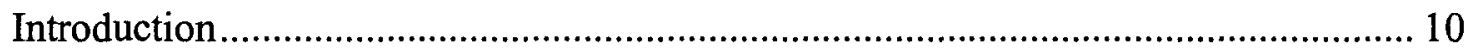

Leadership and Leadership Styles ......................................................................... 11

Definition of Leadership ..................................................................................... 11

Theoretical Perspectives ................................................................................... 12

Motivation Theories...................................................................................... 12

Theories X, Y, and Z ................................................................................ 14

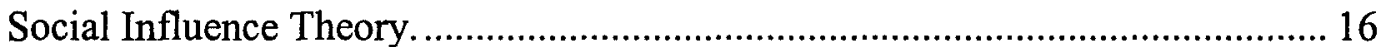

Contingency Theories. ............................................................................... 18

Pragmatic Perspectives ................................................................................... 21

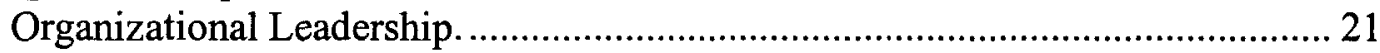

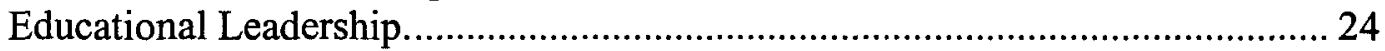

Leadership Styles of Educational Leaders ............................................................ 26

Transactional Leadership.......................................................................... 26

Transformational Leadership......................................................................... 27

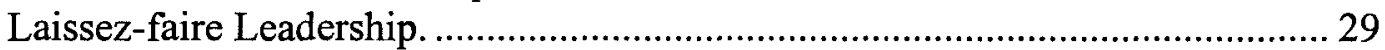

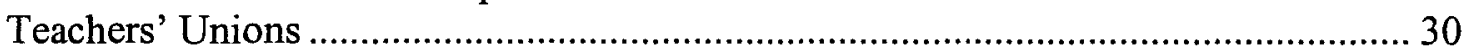

Historical Perspective ........................................................................................ 30

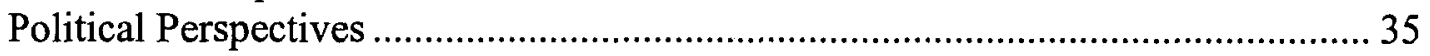

Socioeconomic and Professional Perspectives ........................................................ 39

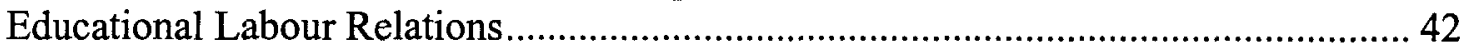


The Collective Bargaining and the British Columbia Legislation

Factors in Labour-Management Relations: Findings that Support the Theoretical

Basis for the Study

Leadership Style as a Key Factor................................................................. 49

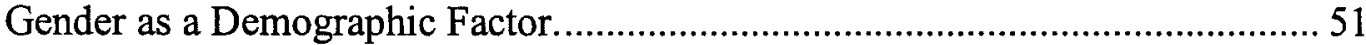

Leadership Experience as Demographic Factors................................................ 54

School Type, School Level and School Size as Contextual Factors. ................... 55

Years of Teaching Experience as a Contextual Factor. ................................... 57

Student Socio-Economic Status (SES) and Discipline as Factors...................... 58

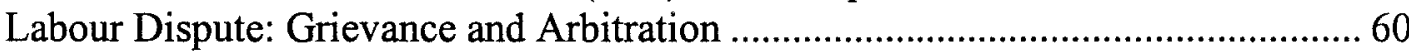

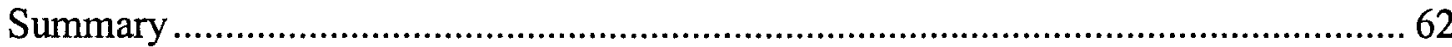

CHAPTER III RESEARCH DESIGN AND METHODOLOGY ................................ 64

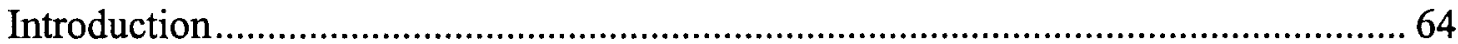

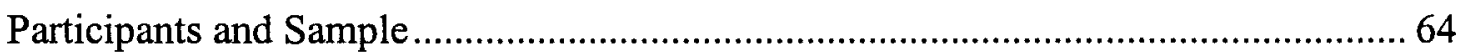

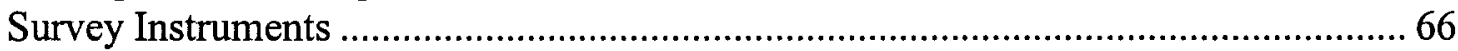

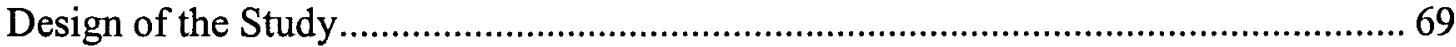

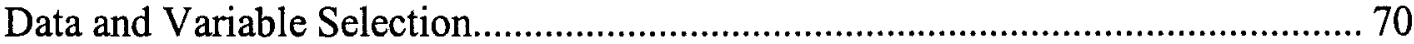

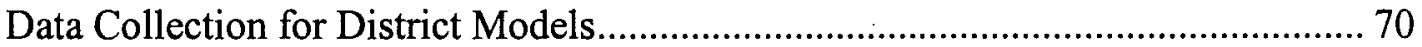

Hierarchical Regression Models and Variables ................................................... 71

Basic School Demographic Model. ................................................................ 72

Independent Variables and Measures: Demographics..................................... 73

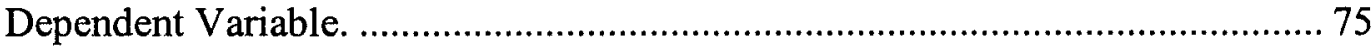

School Demographic/Leadership Model. ........................................................ 76

Additional Independent Variables and Measures: Leadership. .......................... 77

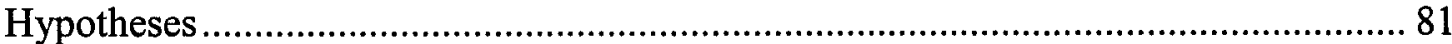

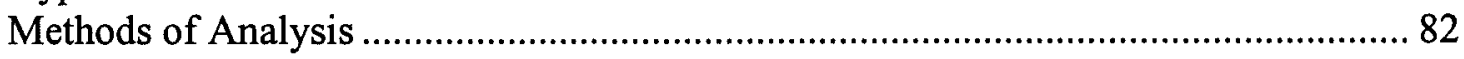

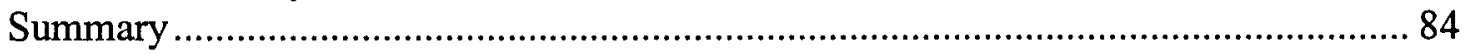

CHAPTER IV DISCUSSION AND INTERPRETATION OF THE FINDINGS .......... 85

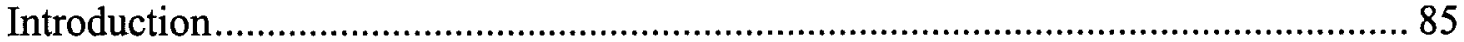

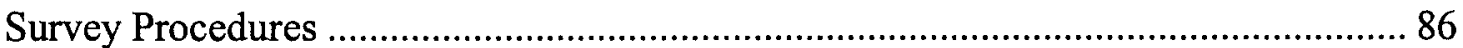

Classification and Measurement of All Variables ................................................. 87

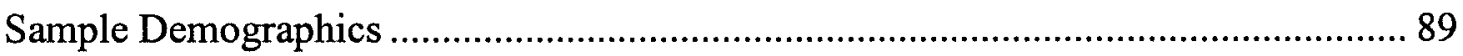

Findings from the Hierarchical Regression Analyses.............................................. 93

School Models: Demographics ............................................................................ 94

School Models: Demographics and Leadership Variables ...................................... 99

Core Demographic and Leadership Model........................................................ 99

Core Demographic and Core Leadership Model. ......................................... 103

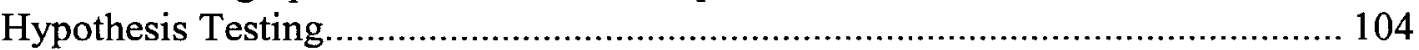

Discussion and Interpretation of the Findings .................................................. 107

Effects of School Demographic and Contextual Predictors ................................ 107

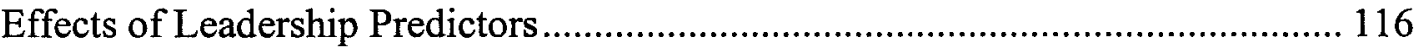

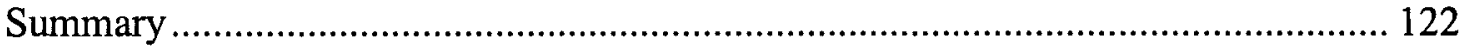


CHAPTER V CONCLUSION AND RECOMMENDATIONS OF THE STUDY $\ldots . .124$

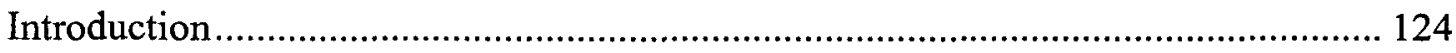

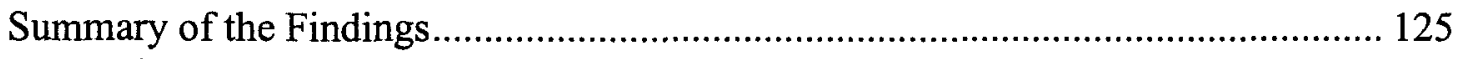

Theoretical Implications of the Findings .............................................................. 127

Recommendations for Change in Practice and Policy ........................................... 129

Recommendations for Future Research .......................................................... 133

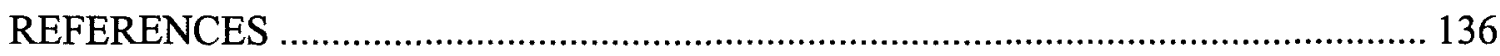

APPENDIX A: Cover Letter the Principal Survey ................................................. 149

APPENDIX B: Principal Electronic Survey ...................................................... 151

APPENDIX C: Frequency and Valid Percent of the Dummy Variables...................... 154

APPENDIX D: Correlation Coefficients, Means, and Standard Deviations of All the

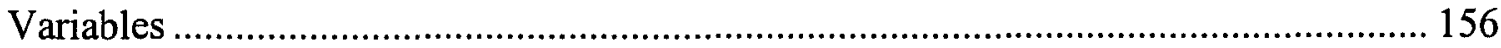

APPENDIX E: Regression Coefficients of All Independent Variables in Various Model

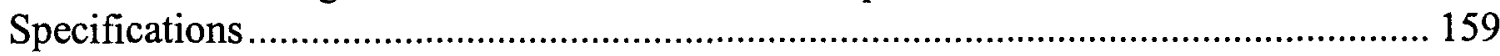




\section{LIST OF TABLES}

Table 1. Classification and Measurement of All the Variables in Hierarchical Models p. 88

Table 2. Means and Standard Deviations of All the Variables p. 90

Table 3. Regression Coefficients of Independent Variables for the Basic Demographic Model, Model 1 p. 95

Table 4. Regression Coefficients of Independent Variables for the Core Demographic Model, Model 2

Table 5. Regression Coefficients of All Independent Variables for the Core Demographic and Leadership Model, Model 3

p. 100

Table 6. Regression Coefficients of All Independent Variables for the Core Demographic and Core Leadership Model, Model 4

Table 7. Comparison of the Restricted and Unrestricted Hierarchical Multiple Regression Models

p. 105

Table 8. General Effect by Two Groups of Independent Variables

p. 106 


\section{LIST OF FIGURES}

Figure 1. Basic Demographic Model

p. 72

Figure 2. School Demographic/Leadership Model

p. 77

xiv 


\section{CHAPTER I}

\section{THE PURPOSE OF THE STUDY}

Introduction

Over the last decade, the topic of labour relations in public education systems has drawn the attention of researchers advocating education reform. It has been widely recognized that teachers' unions are powerful influences not only in the work lives of teachers, but also in school governance and operations, as well as in the formulation of educational policies and programs. Labour relations, therefore, provide a significant perspective on educational change (Shedd, 1990; Kerchner \& Koppich, 1993a; Lieberman, 1997).

However, opinions about teachers' unions are also deeply divided. The public views teachers' unions primarily as obstacles to educational reform (Fullan, 1998a; Kerchner et. al., 1998; Lieberman, 1997). Teachers' unions are often seen as part of the problem, resisting effective changes in public schooling (Haar, 1996, 1998; Kerchner et al., 1997; Lieberman, 1997). Union control, obtained through collective agreement, is perceived as a negative influence on the functioning of schools, restricting principals' leadership in schools (Haar, 1998; Lieberman, 1997). Teachers' unions are quite often 
portrayed as "self-interested and incapable of considering the true needs of students and schools" (Kerchner \& Caufman, 1993).

Others have quite a different perspective. They regard teachers' unions as productive agents for change. For some, unions are considered a critical element in educational reform (Bascia, 1991; Chase, 1997; Cooper, 1992; Kerchner et al., 1997; Steinberger, 1990). Evidence shows that teachers' associations have become involved in forming new working relationships with administrators and school boards in promoting school based management and participative decision-making. More importantly, teachers' unions are believed to have a valuable role to play in students' learning. For example, smaller class size and lower teacher/pupil ratios gained through collective bargaining have not simply improved teachers' working conditions, but have improved students' learning and the quality of their education (Hendricks-Lee \& Mooney, 1998). Studies have also shown that students in unionized districts scored significantly higher on achievement tests than students in non-unionized districts in the United States (Eberts \& Stone, 1986; Nelson \& Rosen, 1996).

In British Columbia, Canada, teachers' unions have been a very strong force in the public education system. The British Columbia Teachers' Federation (BCTF) and affiliated local teachers' associations, representing almost one hundred percent of public school teachers, play a significant role in the political and educational platforms in the province. Separated into a different "camp"1, many school principals and district administrators feel constrained by the numerous provisions and rights that teachers have obtained through collective bargaining. They generally see unions as disrupting their

\footnotetext{
${ }^{1}$ Principals and vice-principals in British Columbia belong to a different union than do teachers. Most administrators are members of the British Columbia Principals' and Vice- Principals' Association.
} 
ability to run schools and districts. School boards typically regard unions as restricting the boards' authority to develop policy and operate schools efficiently and economically, especially in times of financial difficulty (Bacharach \& Mitchell, 1983; Lawton et al., 1999). Despite such tension, positive educational labour relations exist in schools and school districts where cooperative and collaborative relationships enhance the school/district culture and support the improvement of students' learning. As Kerchner and Caufman (1993) assert, unions and administration working together require stronger, not weaker, leadership.

\section{Statement of the Problem}

Teachers' unions have increasingly gained power through collective bargaining in the past two decades. Their gain in power has often brought frustration and distress to educational administrators (Bacharach \& Mitchell, 1983; Haar, 1996, 1998; Lieberman, 1997). The traditional hierarchical power system has been challenged and changed. Consequently, redefinition of the roles played by school boards, administrators, teachers and their union representatives in the management of the school system has led to unavoidable changes in administrative procedures and decision-making processes. As a result, resistance, tension, and conflict have often developed in the implementation of collective agreements. Frequently, grievances result and arbitration is required. The resolution of grievances and arbitration costs both school boards and unions thousands of education dollars. In addition, both parties expend considerable time and energy that could otherwise be directed toward improving student achievement.

Like many other labour/management interactions in Canada, the fundamental system of labour relations in British Columbia public school districts has been based on 
an adversarial industrial model (Cole, 2000; Hoyle et al., 1990; Maple Ridge \& PittMeadows School District No. 42, 2000; Seder, 1998; Straut, 1998). As Kerchner et al., (1998) and Herdricks-Lee and Mooney (1998) contend, this model no longer meets the challenges of an era of new information and knowledge. Raham (2000) also supports this perspective and argues that, "Many policymakers and education leaders now agree the old labour relations model cannot assist in meeting the expectations for today's schools" (p. 4).

Various studies of educational leadership have focused upon the effects of district or school administrators' leadership style on school organization climate, school effectiveness, and school improvement (Jantzi \& Leithwood, 1996; McAdams \& Zinck, 1998; Uline, Miller \& Tschannen-Moran, 1998). The limited amount of research that focuses on teachers' unions has investigated theories of professional unionism and functions of unions in educational reform (Kerchner \& Koppich, 1993; Kerchne et al., 1997; Kerchne et al., 1998). However, the research in the area of teachers' unions is so sparse that it has been described as "education's dark continent" (Podgursky, 2002). There is even less research that explores the relationship between leadership styles and labour relations, even though the results of such studies may contribute to establishing more positive and productive labour relations between public school employers and teachers' unions.

\section{Purpose of the Study}

The purpose of this study was to determine the relationship between measures of leadership style and labour dispute in the British Columbia's public school system. Although there are a number of types of labour disputes, for this investigation, grievance 
was treated as the sole indicator of a labour dispute. (Grievance will be used interchangeably with labour dispute in the following text). It was hoped that this study would provide valuable insights for both administrators and teacher union leaders so that both might reexamine labour dispute from different perspectives. It was also hoped that this study would contribute to the literature on leadership and educational labour relations.

\section{Background of the Study}

Facing the changes and challenges in the post-information era, public school systems have been under continuous societal pressure to reform (Lieberman, 1993; Fullan, 1998). At the same time, the growing power base of teachers' associations has presented a challenge to the traditional hierarchy of power in education, and has added political pressure. Straut (1998) notes, "...an undeniably influential component of the 'system itself' is the relationship which exists between teacher unions and school boards and administrators; known colloquially as the 'labour relationship'. Therefore, a key to systemic reform in education may lie in restructuring labour relationships." (p. 1)

The British Columbia Teachers' Federation (BCTF) is the union that represents all the public school teachers at the provincial level with the government. A local teacher union represents all the full-time teachers, part-time teachers and teachers-on-call (TOCs) in each school district. Historically, the BCTF has been a strong force in negotiating improvements in teachers' working conditions and in negotiating improvements in their economic wellbeing. As well, the union has been a strong advocate for public education. The BCTF also frequently supports other unions in their causes. For example, when the 
Canadian Union of Public Employees' (CUPE) went on a week-long strike across the province in March 2000, the BCTF executive asked teachers to honour CUPE picket lines. Over half of the public schools in the province were shut down and over 25,100 teachers stayed off their teaching jobs in support of CUPE (BCTF, 2001a). In the past 10 years, more than four million student days have been lost due to labour disputes (BCPSEA, 2001).

A significant point in history is worthy of mention here. In 1995, the structure of collective bargaining was changed from district-by-district negotiation with individual school boards to bargaining on behalf of all teachers at the provincial level. Since then, three separate rounds of negotiation have been conducted between two provincial bargaining units, namely, the British Columbia Public School Employers Association (BCPSEA) on behalf of all the public school boards, and the BCTF on behalf of local teachers' associations. No agreement through negotiation has been reached between the two parties thus far. Each round of the provincial bargaining ended with government intervention and an imposed settlement.

In the first two rounds, the provincial bargaining model alleviated confrontations between local districts and teachers, but at the same time limited the abilities of local authorities to address issues specific to their geographic and demographic needs. Both school districts and local teachers' associations encountered numerous problems when implementing the imposed Provincial Agreement. The latest round of bargaining (April 2001-January 2002) resulted in a legislated collective agreement that redistributed power between the teachers' union and the school boards, creating new challenges in educational labour relations. At that time, teachers' formal job action was ended by an act 
of the legislature, and the BCTF began "informal job action". In most of the British Columbia schools, business was not "as usual" by the end of the 2001-02 school year. Teachers withdrew their participation from extra curricular activities and school committees. Relationships between teachers and others in their school community were strained.

Although the government was able to change the power structure in the public school system by legislation, it could not change the relationships within the system. In the same way, the government could not ensure the success of the change it initiated through legislation. As Fullan notes, "Ultimately, for reform to be successful we will need to coordinate and otherwise establish rapport between simultaneous topdown/bottom-up strategies" (1998a, p. 6).

This study ventured to explore bottom-up strategies that could improve labour relations from within so as to reflect and enhance system changes and educational reform. Thus, the current changes and challenges in British Columbia educational labour relations made this study even more timely and significant.

\section{Research Questions}

Based on the purpose of the study, the overarching research question was: What is the relationship between measures of leadership style and labour dispute in British Columbia public schools? Specifically, this study sought to answer-why do some schools have fewer teacher grievances filed than other schools in British Columbia?

In answering the above questions, the researcher gathered data by surveying school principals, and then analyzing the effects of the following variables on labour dispute: Leadership Styles, Quality of Leadership, Gender, Years of leadership 
Experience, School Type, School Level, School Size, Average Years of Teachers' Experience at the School, School Discipline, and Socio-Economic Status for Student Population. The emphasis was on the relationship between measures of the Leadership Style of the site administrator and the number of labour disputes filed at the school site. Delimitations of the Study

This study had several delimitations:

1. This study focused on investigating the relationship between leadership styles and labour dispute through analysis of eight contextual or demographic variables and seven leadership variables. Not included in the analysis were some other measures of labour disputes, such as collective bargaining and/or negotiation, the number of times arbitration was required or rewarded, measures of some other potential influential factors such as personality traits and negotiation skills. However, based on the literature review and the reality in British Columbia educational labour relations, I selected the strongest and most appropriate indicator, grievances, as a measure of labour dispute at school level as well as the most appropriate sets of independent variables.

2. The study was limited to the public school system in British Columbia. It was possible, however, that its findings might have some relevance for other provinces in Canada and the United States as well.

3. Since leadership styles in this study were classified as dimensions of transactional, transformational and laissez-faire, the effects of other leadership styles on labour dispute were not taken into consideration in the analysis.

4. Due to the lack of resources, this study was limited to the leadership assessment method employed—leaders rating their leadership styles according to their 
own perceptions of themselves rather than being rated by others. According to Avolio (2003), "There have been numerous studies using self-rated MLQ scores. Generally, they are inflated somewhat when compared with ratings by others."

5. Grievance data for the study could not be categorized according to the nature of the grievance, such as harassment, posting and hiring, class size, etc. This was due to the lack of resources for proper record keeping/tracking at the district level and the lack of consistency in the language of the local collective agreements across the province.

6. Since this study was quantitative in nature, no interview data were gathered. Such qualitative data would be likely to produce more nuanced findings.

\section{Summary}

This chapter presented the purpose of the study and provided information on the general context of labour/management relationships in education, specifically information about labour/management relationships in British Columbia. Although this study had several delimitations, the scarcity of literature and research addressing the relationship between leadership and educational labour relations underscores the value and significance of the current study. This chapter also stated the research questions and emphasized the relationship of measures of leadership styles and labour dispute. The following chapter will review the current literature and research related to leadership/leadership styles, teachers' unions, and educational labour relations, particularly in the province of British Columbia. 


\section{CHAPTER II \\ REVIEW OF THE LITERATURE \\ Introduction}

Although an abundance of literature on leadership theory exists, there is a paucity of data examining the relationship between leadership behaviour of educational leaders and educational labour relations. This is somewhat unusual since no organization can be truly successful without effective leadership. Leadership is the key factor "that empowers the work force and ultimately determines which organizations succeed or fail" (Bennis \& Nanus, 1997, p. 12). As such, the purpose of this study was to determine the relationship between measures of leadership style and labour dispute in B. C. public schools.

In this chapter, I will derive a working definition of leadership from a brief review of the major definitions on leadership. Then, leadership and leadership styles will be scrutinized in the light of related literature from theoretical perspectives as well as pragmatic perspectives, particularly those of educational leaders. Next, teachers' unions will be discussed from the following perspectives--historical, political, socioeconomic and professional. The history of educational labour relations in British Columbia public school system will be delineated and analyzed by looking at related British Columbia legislation from different historical stages. Finally, various influential factors will be examined through a review of current empirical research. Overall, the literature drawn from industrial organizations and education on relevant themes - leadership, leadership 
styles, teachers' unions, and educational labour relations - will provide a conceptual framework for the design of this study.

\section{Leadership and Leadership Styles}

\section{Definition of Leadership}

Leadership is a popular and broad topic that is widely studied. However, it is hard to find a definition of leadership that is agreed upon by all, as there are literally hundreds of definitions of leadership available. Some definitions distinguish management from leadership. For example, Kotter (1988) views management as coordinating diverse activities to achieve desired results through planning, organizing, staffing, directing, and controlling. In contrast, he regards leadership as a process of visioning, networking, and relationship building. Bennis and Nanus (1985) describe the difference between management and leadership as follows, "managers do things right, and the leaders do the right thing" (p. 21). A manager may not be a leader. By the same token, a leader does not necessarily hold a management position or have to be an authoritative figure. Turvey (1999) believes that leadership is the influence that leaders have on their followers rather than an exertion of power by commanders over their subordinates. Other definitions of leadership emphasize leaders' abilities to inspire a shared vision and to reach group goals by influencing others.

Two dimensions are encompassed in defining task-oriented and people oriented leadership. Both task and people are incorporated in Hersey and Blanchard's (1977) situational leadership model. Leaders who score high on both dimensions are considered the best leaders. At its core, leadership involves people. Pejza (1994) describes it concisely, "You lead people; you manage things" (p. 3). This is, according to Pejza, the 
fundamental difference between leadership and management. Along the same line, Kouzes and Posner (1993) define leadership succinctly as a relationship between employers and employees. This relationship manifests itself as a bond between the leader and followers. The leader plays a facilitative role to support the need of the constituents to reach the common goals.

"Leadership is a reciprocal relationship between those who choose to lead and those who decide to follow. Any discussion of leadership must attend to the dynamics of this relationship. Strategies, tactics, skills, and practices are empty unless we understand the fundamental human aspirations that connect leaders and their constituents. If there is no underlying need for the relationship, then there is no need for leaders." (Kouzes \& Posner, 1993, p. 1)

Since this study targets labour relations, which involve the human relationship between employers and employees, I will use Kouzes and Posner's definition to serve as the working definition for leadership in this study.

\section{Theoretical Perspectives}

\section{Motivation Theories.}

The practices and concepts of leadership have evolved from a rich theoretical base. Abraham Maslow (1954) developed one of the most influential theories called Motivation Theory. It laid a foundation for the development of leadership as well as educational theory and practice. According to Maslow, human behavior is driven by a hierarchy of individual needs. Basic needs, such as food, shelter and safety, have to be at least partially satisfied before the higher level needs of belonging, esteem and selfactualization become effective and dominant drives. In this sense, a satisfied need is not a 
motivator. Once a need is satisfied, another higher level need surfaces, which can be satisfied in a wide variety of ways.

However, Maslow's motivation theory is limited in its ability to explain all of the variation inherent in human behaviors (Bolman \& Deal, 1997). As such, many exceptions to the theory exist, particularly in terms of the sequence of motivations. For instance, job satisfaction and achievement can be viewed as continuous, not sequential motivators. Nevertheless, Maslow's theory is widely accepted and enormously influential in the field of human motivation.

Maslow's theory has been extended through the work of Frederick Herzberg (1966). Herzberg asserts in his findings that tangible rewards such as better pay, fringe benefits, and improved working conditions are not motivators, but only hygienic or maintenance factors that keep employees from being dissatisfied, whereas job achievement and job enrichment are key factors that motivate employees. According to Herzberg, maintenance factors and motivation factors are basically independent, not in opposition with each other, and affect employees' behavior in profoundly different ways (as cited in Hoyle et al., 1990). When employees are given more responsibility and freedom to do their job, as well as given greater challenges and recognition for their achievements, they tend to be more motivated and produce higher levels of performance. In this way, Herzberg has further developed Maslow's hierarchy of needs into motivators and non-motivators. He believes that only psychological needs-self-esteem and selffulfillment needs—are true motivators, while the lower level needs—-physical, safety and social needs—are non-motivators, or hygienic factors (Bolman \& Deal, 1997; Costley \& Todd, 1991; Hoyle et al., 1990). Herzberg's findings have complemented Maslow's 
motivation theory and provided a theoretical foundation for the development of leadership and leadership research (Bolman \& Deal, 1997).

\section{Theories $X, Y$, and $Z$.}

Douglas McGregor (1960) formulates the concepts of Theory X and Theory Y. According to McGregor, Theory $\mathrm{X}$ espouses the belief that human beings dislike hard work and are lazy by nature. They lack initiative and creativity. Therefore, they need to be pushed and require close supervision and direction. Theory $\mathrm{X}$ reflects the conventional view of management. In McGregor's view, most conventional management practices utilize either hard or soft Theory X approaches. The hard approach stresses coercion, tight controls, constant threats and punishments over employees in order to get them to work for the organizational objectives. However, it often results in low productivity, hostility, and combative or even destructive relationships. On the other hand, the soft approach of Theory X aims to avoid conflict and satisfy everyone's physiological needs. However, managers still find that workers are never satisfied and just don't seem to care. McGregor contends that managers' assumptions and beliefs about employees are actually self-fulfilling prophesies: if you believe people are lazy and lack initiative, they will become passive, hostile, and refuse to accept responsibility just as you expected. Those behaviors are not the results of their inherent human nature, but the consequences of the deprivation of their higher-level needs in organizations as a result of management styles based on Theory X.

From Maslow's theory of human needs and from behavioral science findings, McGregor establishes Theory Y, which takes the position that, under proper conditions, people generally have a positive attitude towards work and learn to accept and seek 
responsibilities. They are intelligent, creative, and capable of solving organizational problems. Management practices derived from Theory Y rely heavily on self-control and self-direction and promote mutual responsibility, authority delegation and structure decentralization (Costley \& Todd, 1992). Employees' commitment to organizational objectives is a function of the rewards for their achievement that satisfies individual motives. McGregor asserts that, " the essential task of management is to arrange organizational conditions so that people can achieve their own goals best by directing their efforts toward organizational rewards" (1960, p. 61). When employees' selfinterests are aligned with organizational goals, productivity will be increased, through the initiative and innovations of motivated employees.

The underlying assumptions of McGregor's Theory X and Theory Y, however, capture only the two extremes of the human nature spectrum. As human beings are complex and variable, the beliefs about human nature represented by Theory $\mathrm{X}$ and Theory Y are arguably over-generalized and over-simplified. Human behavior may change depending on work conditions, organizational culture, management expectations and practices. A theory based on one extreme of the human nature spectrum can hardly explain or direct all human behaviors. Though it seems that the Theory $\mathrm{Y}$ approach produces better performance and productivity from employees than does Theory $\mathrm{X}$, there are times when situations and individuals do not respond positively.

Incorporating principles of Maslow's needs theory and McGregor's Theory Y, William Ouchi $(1981,1982)$ developed Theory Z, which emphasizes the development of a management team consisting of managers and employees. Its function is to solve organizational problems and achieve organizational goals through a team approach. 
Theory $\mathrm{Z}$ has as its focus the entire organizational culture in looking for ways to enhance the efficiency and productivity of the organization. Ouchi considers organizational culture as the "systems, ceremonies, and myths that communicate the underlying values and beliefs of the organization to its employees" (cited in Hoyle et al., 1998, p. 136). It is through this culture, which permeates the organization as well as the employees, that managers can elicit the support from the employees towards organizational objectives. Ouchi's Theory Z captures the essential element that explains the relationship between work climate and organizational productivity. As Hoyle et al. point out, "Organizational climate has a powerful influence on the dynamics and interpersonal relationships within the organization. It can guide behavior, affect morale, and impact the organization's identity" (p. 136).

\section{Social Influence Theory.}

Most of the postindustrial definitions of leadership have been derived from social influence theory. In this theory, leaders are described as individuals who have the loyalty of followers/constituents due to their ability to influence. It is influence which is generally believed to be the essential element in emerging leadership theories (Costley \& Todd, 1991; Kouzes \& Posner, 1993; Rinehart et al., 1998). Simply put, to lead is to influence. Leaders become effective when their constituents allow them to influence their behavior. The most effective leaders are those who can elicit cooperative effort and willing commitment from their followers. "The process of leadership involves influencing individuals to work toward achieving organizational goals. Leadership is a relationship between people in which influence is unevenly distributed" (Costley \& Todd, 
1991, p. 231). Rost (1994) contends that leadership occurs primarily in the context of an influence relationship.

How can leaders influence their constituents? Cooper and Croyle (as cited in Rinehart et al., 1998) report that two potent and persuasive elements of influence are "credibility and social attractiveness". Credibility is considered as the first element of influence. Kouzes and Posner (1993) assert that "credibility is the foundation of leadership... Without credibility, visions will fade and relationships will wither" (p. 22). According to Rinehart et al., credibility has two components: expertness and trustworthiness. Expertness is the competence, knowledge and skills of leaders as perceived by their constituents. Trustworthiness is built up through a leader's display of ethics, integrity and honesty. Covey considers expertness as part of trustworthiness, "trustworthiness is based on character, what you are as a person, and competence, what you can do" (cited in Rinehart et al., 1998, p. 633). Kouzes and Posner (1993) argue that trustworthiness is established through a leader's demonstrated care, and by effective actions that live up to their promises.

The second element of influence is social attractiveness, which is related to the perceived similarity of leaders and their constituents in terms of life experiences and background. Kouzes and Posner (1993) believe that "by getting closer to their constituents and by letting their constituents get to know them, leaders can strengthen their foundation of credibility" (p. 46). This idea implies that if leaders mingle with their constituents, the constituents will be able to discover their leaders' authentic selves beneath the leadership positions and identify the commonality they share in life 
experiences and background. As a result, the leaders' social attractiveness will be enhanced.

Leading by example is an effective way of establishing credibility. Modeling the way is one of the five leadership practices of successful leaders summed up by Kouzes and Posner (1987). Leaders lead by practicing what they preach, and setting an example. In so doing their actions are far more powerful than their words. As Andrew Grove, president of Intel Corporation, puts it, "Nothing leads like example". Sergiovanni (1987) defines those who lead by example as "symbolic forces" who define, articulate and model enduring values, beliefs and cultural standards and thus send symbolic messages to their constituents and followers. In turn, the symbolic force effects changes in attitudes and engenders employees' loyalty. As a result, the leaders' social attractiveness is strengthened as well. Qualitative data from three Pennsylvania case studies further confirm the power of symbolic force in the influence relationship as well as the importance of leaders' involvement and interactions with their constituents (McAdams \& Zinck, 1998).

\section{Contingency Theories.}

Different settings and circumstances require different leadership styles. Costley and Todd (1992) maintain that,

No one set of beliefs is valid for all people or all situations... Managers should be able to recognize the qualities that make each employee different. Flexibility is essential to meet the demands of different situations and to make use of employees' unique abilities. (p. 326) 
In reality, leaders rarely practice only one leadership style. Effective leaders adapt their leadership styles in response to the nature of the situation and the needs of their constituents. Bolman and Deal (1997) also claim that "leadership varies with situation" (p. 299). For instance, “it takes a different kind of person to lead when you're growing and adding staff than when you're cutting budgets and laying people off' (p. 297).

A number of theorists have contributed to the development of contingency theories of leadership, including Fiedler (1967), Reddin (1970), Vroom and Yetton (1973), Fiedler and Chemers (1974), Hersey and Blanchard (1977), Hersey (1984), and House (1971, 1987). Fiedler, with his contingency model of leadership effectiveness, and Hersey and Blanchard, with their situational leadership model, are the authors most frequently cited in contingency theory (Bolman \& Deal, 1997; Costley \& Todd, 1992; Lewis, 1993; Turvey, 1999).

After extensive research on a wide variety of groups, Fiedler (1967) developed "the contingency model of leadership effectiveness". He found that effective leadership results in a close match between leadership style and the demands of the group situation. According to Fiedler, there are three critical situational factors accounting for the effectiveness of leadership styles: leader-member relations, task structure, and positional power. Fiedler defines basic leadership styles as task-oriented and relationship oriented. He claims that when a leader has good relations with group members, the task is clearly defined and highly structured, and the positional power is high, the leader tends to have high influence over his followers. On the other hand, when a leader is not trusted or liked by his/her group members, the task is unstructured with vague requirements, or he/she has little control over discipline and rewards, the leader has little power to influence 
his/her constituents. Fiedler further contends that task-oriented leadership style is the most effective style when leaders have either a strong influence or little influence, whereas the relationship-oriented leadership style is the most effective in moderately favorable situations.

Fiedler's model was supported in a meta-analysis of 178 studies done by Strube and Garcia (1981). However, as the world is entering the post-informational or knowledge era, task structure and skill level/requirements of employees have all changed dramatically. What seemed to be the most favorable situation to a leader at the time of Fiedler's study - 1960 s to 1980 s—may not be the case in our current era. Leaders who have the most powerful influence over employees may not depend on positional power. Nevertheless, one of the situational factors identified by Fiedler not only remains strong, but has become more important than ever-that of leader-follower relations (Bolman \& Deal, 1997; Rinehart et al., 1998).

Hersey and Blanchard's (1977) situational leadership model, also widely cited in the leadership literature, has proven to be a model for leadership training. The underlying assumption of their model is that no one leadership style is the most effective or the best. The model begins with the same two dimensions of leadership styles as does Fiedler's model: task and people. Hersey (1984) extends these dimensions into four possible leadership styles: telling, selling, participating, and delegating. Which style a leader employs depends on the maturity level and readiness of followers. When constituents are at the lowest level, i.e. unable and unwilling, leadership should be provided through "telling", giving directions and orders. At the next level when followers are willing to do the job but lack skills and knowledge (willing but unable), leaders should "sell"- to 
explain and clarify the tasks. When constituents are able but unwilling to do the job, leaders then should provide them with opportunities to "participate" in the process to increase ownership and sense of responsibility. At the highest level when followers are both able and willing, leaders should just delegate so that the followers will take responsibility and initiative to get the job done.

Although contingency theories appear to be theoretically sound, they are "limited in their conceptualization of leadership and in the strength of the empirical support" (Bolman \& Deal, 1997, p. 300). This is definitely a major area that further research is warranted, given the widely varying and constantly changing circumstances we are in. Pragmatic Perspectives

Leadership theories, derived from previous practice, shape our reality and guide our future practice. As Sergiovanni (1992) contends, "Leadership mindscapes are shaped by what we believe and value and by our understanding of the world. They create the reality that drives our leadership practice" (p. 41). In this section, leadership styles will be examined through the results of empirical studies from two different perspectivesorganization in general, and education in particular.

Organizational Leadership.

One important yet complex aspect of leadership is leadership style. Leadership style is defined as the "consistent" behavior patterns and characteristics that leaders demonstrate when they are working with and through other people, as perceived by those people (Hersey \& Blanchard, 1977; Turvey, 1999). After the discussion on contingency theories, however, it is evident that leadership styles may not be consistent but rather are prismatic and changeable according to situations and the makeup of constituents. Lewis 
(1993) compares leadership styles to the element mercury, in that it is hard to pin down. Still, some researchers have taken on the slippery process and have conducted empirical studies on leadership styles. Until quite recently, few, if any, quantitative researches have shown which specific leadership behaviours generate positive results.

In his research, Goleman (2000) examined six distinct styles of leadership so as to identify which ones might be effective in improving employees' performance. This new research, as Goleman calls it, was conducted by the consulting firm of Hay/McBer and drew on a random sample of 3,871 executives selected from a database of more than 20,000 executives worldwide for their study. The research reveals six distinct leadership styles: coercive; authoritative; affiliative; democratic; pacesetting; and coaching. Goleman applies the emotional intelligence theory by David McClelland, a noted Harvard University psychologist. Six components of emotional intelligence are identified and each is paralleled by a distinct leadership style that leaders use to make a difference for the climate in a given organization.

Goleman's first finding is that the more styles a leader exhibits, the better. That is to say, leaders who have mastered four or more leadership styles, especially the authoritative, democratic, affiliative, and coaching styles, and applied them flexibly at the right time and in the right measure, have the very best climate and employee performance. Such leaders do not rely on only one leadership style; they use many of the six styles when dealing with one specific issue. Second, of the six leadership styles, coaching style is used least often. Many leaders who participated in the study stated that they didn't have time to teach people in a high-pressure economy. Goleman (2000) argues that "leaders who ignore this style are passing up a powerful tool; its impact on 
climate and performance are markedly positive" (p. 81). Third, Goleman states that coercive style is "...the least effective in most situations... coercive style should be used only with extreme caution... it can work with problem employees with whom all else has failed" (p. 75). This is because coercive leadership has a damaging effect on the rewards system. As Herzberg (1966) has found, most high-performing workers are motivated by more than simply money. They seek the satisfaction of work well done. And finally, based on the analysis, Goleman claims that leaders who employed leadership styles that had positive impact on the organizational climate showed definitely better financial results than those who did not.

Bolman and Deal (1997), studying an international sample of school principals, hospital administrators, and corporate executives, developed four frameworks for organizational leaders in which to categorize their leadership skills--structural, human resource, political and symbolic. These frameworks can be described as follows:

1. Structural leaders set clear goals and choose the right design for the environment. They are able to get their structural changes implemented through policies, rules and the chain of command.

2. Human Resource leaders believe in people and advocate openness, mutual respect, communication, participation and empowerment. They serve as counselors, catalysts, facilitators and servants.

3. Political leaders see the systems in which they work as "jungles" fraught with competition for scarce resources. Based on their careful assessment of the distribution of power and interests, they build up networks, create coalitions, construct power bases and 
work out compromises. Sophisticated political leaders persuade first, negotiate second, and use coercion only if necessary.

4. Symbolic leaders see organizations as both theaters and temples. People in the organizations are bounded by shared vision, beliefs, traditions, myths, rituals and ceremonies. Effective symbolic leaders are charismatic and inspiring. They lead by symbolic actions so as to stimulate their followers' enthusiasm and creativity, and elicit their support.

Bolman and Deal (1997) emphasize the rational and contextual nature of leadership. They argue that multiple perspectives and frames are needed for leaders to adapt to different situations. "Each of the frames highlights significant possibilities for leadership, but each is incomplete in capturing a holistic picture" (p. 317). Therefore, they advocate reframing leadership beyond narrow and oversimplified models.

\section{Educational Leadership.}

The education arena has its own unique context: educational purposes, educational programs and curriculum, teaching and learning. It has its distinct strata of employees: professionals and paraprofessionals; and its end products, students. Its customers include parents, students and communities. Therefore, leadership in education may show differences from the organizational leadership in the business world. The perception of effective leadership styles in business and in education may also be different even though educational administration has long borrowed from organizational theories and theories of motivation. This may be so, because the metaphor of choice for schools is that of a learning organization. 
The assumptions of an organization include legitimacy, authority, hierarchy, bureaucracy, and self-interest (Sergiovanni, 1994). According to Sergiovanni (1992), traditional notions of leadership in today's schools are incomplete and not working effectively. Educational leadership needs to be viewed through a new set of lenses.

Sergiovanni (1994) contends that the root metaphor of schools as learning organizations should be changed to schools as learning communities. He argues that the metaphor of school as an organization determines how schools should be structured and managed, what leadership is and how it works. He further asserts that, "Changing the metaphor for the school from organization to community ${ }^{2}$ changes what is true about how schools should be organized and run, about what motivates teachers and students, and about what leadership is, and how it should be practiced" (p. 218).

When schools become learning communities, he says, "they're no longer driven exclusively by the requirements of hierarchy and the clever use of personal leadership. The primary forces are our values and purposes" (cited in Lewis, 1993, p. 27). Sergiovanni $(1992,1994)$ further claims that moral authority, in the form of obligations and collegiality that emerge from bonding relationships, and professional authority, in the form of a collective commitment to virtuous practice, should serve as the primary basis for educational leadership practice. Bureaucratic authority, psychological leadership, and technical-rational authority should provide support for professional and moral authority.

Sergiovanni's idea of moral and professional authority as the center of educational leadership aligns with the essence of transformational leadership advocated

\footnotetext{
${ }^{26}$ Communities are collections of individuals who are bonded together by natural will and who are together bound to a set of shared ideas and ideals. This bonding and binding is tight enough to transform them from a collection of Is into a collective we. As a we, members are part of a tightly knit web of meaningful relationships." (Sergiovanni, 1994, p. 219)
} 
by Burns (1978), Bennis and Nanus (1985), Leithwood (1992b, 1996) and Bass (1990, 1997). They view leadership as a form of power that represents one's capacity to transform vision and ideals, and purposes and values into reality and sustain such transformation over time.

Leadership Styles of Educational Leaders

Instructional leadership was once the main focus of educational leaders and school administration in the 1980 s and early 1990 s. In the wave of educational reform, transformational leadership has now become the leading trend in educational administration research and practice (Leithwood, 1992b). Subsuming instructional leadership and complemented by transactional leadership, transformational leadership is believed to provide a wide range of practice that inspires teachers and staff to attempt improvements in their teaching practices. In this section, I will discuss transactional leadership, transformational leadership and laissez-faire leadership in the light of related literature and empirical studies.

\section{Transactional Leadership.}

Transactional leadership is an exchange process between leaders and followers. Sergiovanni (1994) describes transactional leadership as "what gets rewarded gets done". Transactional leadership has its root in Maslow's motivation theory. Various rewards (recognition, salary, good evaluation, better assignments, and chances for promotion, etc.) are given to teachers or students in exchange of services or compliance. Once rewards are no longer available or desired, teachers or students give less effort to their work. Two key characteristics of transactional leadership described by Bass (1990) are: (a) initialing and organizing with a goal to get the work done; (b) showing consideration 
for employees with a focus on satisfying the self-interest of those who have done good work. Based on his findings from a number of studies, Bass concludes, "Transactional leadership is a prescription for mediocrity" (1990, p. 19). Bass' perspective supports Herzberg's (1966) motivation theory, i.e., tangible rewards are not motivators but only hygienic or maintenance factors that keep employees from being dissatisfied, whereas job achievement and job enrichment are the key factors that motivate people. Nevertheless, transactional leadership is still viewed as central in getting the daily tasks accomplished. It is also considered complementary to transformational leadership.

\section{Transformational Leadership.}

Transformational leadership stands in contrast to transactional leadership. While transactional leadership is based on an exchange of rewards for tasks completed between a leader and followers, transformational leadership attempts to motivate followers by appealing to higher level of ideals, moral values and shared visions. Transformational leadership is regarded as a product of older and newer ideas and theories (Taylor, 1994). For example, Parker described the exact characteristic of a most successful leader early in 1941 as one, "who sees another picture not yet actualized. He sees the things which belong to his present picture but which are not yet part of it" (cited in Bennis, 1985, p. 139). In schools with transformational leaders, as Sergiovanni suggests, "What is rewarding gets done" (cited in Lewis, 1993, p. 27). Thus transformational leadership is also linked to Herzberg's hygiene/motivator theory - the real motivators are job accomplishments and satisfaction.

The concept of transformational leadership was first proposed by James McGregor Burns in his seminal work, Leadership, in 1978. He describes transformational 
leaders as those who rise beyond the recognition of needs and interests of followers to focus on satisfying higher needs in order to inspire higher levels of motivation and morality. Furthermore, according to Burns, transformational leadership "is a relationship of mutual stimulation and elevation that converts followers into leaders ... a relationship between leaders and followers of power, mutual needs, aspirations, and values" (cited in Beckner, 1990, p. 9).

Bass (1990) describes transformational leadership as superior leadership performance which "occurs when leaders broaden and elevate the interests of their employees, when they generate awareness and acceptance of the purposes and mission of the group, and when they stir their employees to look beyond their own self-interest for the good of the group" (p. 23). In essence, according to Leithwood (1992a), "transformational leadership is a leadership that facilitates the redefinition of a people's mission and vision, a renewal of their commitment, and the restructuring of their systems for goal accomplishment" (p. 10). This charismatic power of transformational leaders to influence and inspire their followers is related to social influence theory. In education, transformational leadership has effected changes to the existing power systems in public schools, which have thus resulted in schoolsite management, and participative decision making. Teachers are given the opportunity to lead and to enhance instructional capacities. Although only limited empirical studies have been done on transformational leadership in educational settings, significant relationships between transformational leadership and positive changes in teachers' instructional behavior, school improvement and student engagement have been well documented (Jantzi \& Leithwood, 1996; Leithwood, 1992a \& 1992b; Leithwood \& Jantzi, 1999). 
According to Bass (1977), transformational leaders may be autocratic and directive or democratic and participative. Which style a transformational leader displays, or how participative or directive the transformational leader can be is usually decided by the situation he or she is in. "One would expect to see more authoritative transformational leadership when policy decisions rather than workplace decisions are being made" (p. 136-137). In this respect, transformational leadership can be traced to Fiedler's contingency theories of leadership.

In summary, transformational leadership, derived from various leadership theories, tends to be both intuitively appealing and empirically applicable. Thousands of cases from numerous samples with diverse cultural, organizational, and ethical contexts have indicated that transformational leadership tends to be more effective than transactional and laissez-faire leadership styles even when cultural and organizational factors are taken into account (Bass, 1997). Thus, transformational leadership is often regarded as the leadership needed for educational change (Leithwood, 1992a, 1995; Taylor, 1994).

\section{Laissez-faire Leadership.}

Laissez-faire leadership is one of the three leadership styles presented in Avolio and Bass's (1996) leadership models. It refers to non-leadership or the negation of leadership. Laissez-faire leaders are those who evade the acceptance of responsibilities as leaders. They wait to take actions until problems are brought to their attention. They avoid addressing conflicts and resist taking a stand on controversial issues. They fail to respond to needs for assistance and let things slide. Some may argue that the other side of laissez-faire leadership could be seen as empowering followers. However, many 
empirical researchers have discovered that laissez-faire leadership almost always has a negative impact on organizational effectiveness and job satisfaction. It is considered the least effective among the three leadership styles (Bass, 1997; Bass \& Avolio, 1996).

Since transformational leadership is considered as an effective leadership style for educational change, it is treated as the focus of investigation in this study. Furthermore, this study is to investigate the relationship between leadership styles and labour dispute. Therefore, after the discussion of various leadership styles and theories, especially the association between transformational/transactional leadership and other relevant leadership theories, teachers' unions will now be examined from several perspectives in the following section.

\section{Teachers' Unions}

Simply stated, teachers' unions are professional organizations that represent teachers. In Canada such unions are known as teachers' associations or teachers' federations. To provide a background for this study, it is necessary to examine teachers' unions, specifically the British Columbia Teachers' Federation, from historical, political, socioeconomic, and professional perspectives.

\section{Historical Perspective}

Lawton et al. (1999) describe the history of teachers' unions in Canada as "a story of increasingly influential activity by groups of educators dedicated to advancing the social and economic status of teaching as an occupation" (p. 13). Since education in Canada falls within the exclusive jurisdiction of the provincial legislatures by the Constitution Act of 1867, today's teachers' unions arose from professional associations that were founded under their respective provincial laws. The first provincial teachers' 
association in Canada was the Teachers' Association of Canada West, established in 1861 in Ontario. Its members included both teaching professionals and laymen. Though the association bore many of the attributes of a professional teachers' association, it was more of an educational organization rather than an organization of teachers representing other teachers for the purposes of maximizing their professional welfare (Giles and Proudfoot, 1994). Several other teachers' associations were formed soon afterwards in Quebec (1864), Prince Edward Island (1880), Newfoundland (1889), and Nova Scotia (1895) prior to the turn of the century. The major purposes of these associations were to provide opportunities for teacher in-service training and to provide a forum for educational concerns (Lawton et al., 1999).

The majority of current teachers' unions in Canada were founded prior to, and following, World War I. It was believed that the distressed economy, poor working conditions and unfair treatment experienced by teachers during that period spurred the development of the new-style teachers' associations. Teachers became unwilling to accept what they perceived as indignities and were determined to win recognition as professionals (Giles \& Proudfoot, 1994; Lawton et al., 1999). The new-style associations represented teachers' professional, political and economic interests and demands. The Saskatchewan Union of Teachers (1914), the Alberta Teachers' Alliance (1918), and the Manitoba Teachers' Society (1919) were among the first of these newly established teachers' associations.

The British Columbia Teachers' Federation came into being in this period of time under the Benevolent Society Act of 1917. Its major purposes included fostering and promoting the cause of education in British Columbia, improving teachers' economic and 
working conditions, raising the status of the teaching profession, and becoming an integral part of the educational hierarchy. In its early days, the BCTF had no power to bargain with either the local school boards or the Department of Education. However, two days of strike by the Victoria Teachers' Association in 1919 gained an implicit recognition of teachers' right to bargain from the Department of Education. This job action directly resulted in the amendment of the Public Schools Act (1919) by the British Columbia government to allow a school board to enter into agreement with its teachers. It also defined a form of dispute resolution—voluntary arbitration (Lawton et al., 1999). During the following decades, the BCTF played an important role in changing teachers' professional and economic status from that of unorganized and poorly paid individuals to that of well organized professionals with good compensation. In 1947, the British Columbia Teachers' Federation was officially recognized by the government, and through provincial legislation, teacher membership in the union was made automatic (Manzer, 1994).

One of the major changes that transformed labour relations between teachers' associations and school boards was the move to collective bargaining. The voluntary arbitration provided under the 1919 amendment to the Public School Act soon proved to be ineffectual due to lack of binding authority. A school board was not obligated to pay extra salaries awarded by the arbitration board since there were no provisions to enforce it. When arbitration was followed, it was seen simply as a privilege to local teachers' associations.

Finally in 1937, the British Columbia government passed an act that allowed compulsory arbitration in salary disputes. However, the teachers' unions did not obtain 
the full legitimate power to bargain for salaries with school boards until 1958. In that year, the British Columbia Teachers' Federation brought 58 school districts into arbitration because trustees had been granted the right to fix teachers' salaries. Such large-scale action led to another amendment to legislation by the government to provide teachers the explicit right to bargain collectively for salaries, albeit not working conditions (Lawton et al., 1999).

One notable event in the BCTF's history was the expulsion of principals and viceprincipals from the union in 1988. Until 1987, principals and vice-principals in British Columbia were members of the BCTF. Such is the pattern for principals and viceprincipals in most of the Canadian provinces. The exclusion of administrators from the BCTF sharpened the distinction between school leaders and the teachers and fueled the tension and antagonism between them.

Another notable event occurred in 1986 when the BCTF's Task Force on Bargaining and Professional Rights recommended an expanded scope of bargaining for teachers. The government viewed this move as a grab for greater union control of education, and responded with legislation, specifically Bill 19 and Bill 20, which were intended to destroy the union.

Bill 19, the Industrial Relations Reform Act, gave teachers increased bargaining rights and the option to either form local teacher associations or certify as local teacher unions to negotiate employment conditions. If teachers chose the union structure, they had full bargaining rights, including the right to strike or to be locked out. Meanwhile, the government removed compulsory membership in the BCTF for all public school teachers. In response to this legislation, the BCTF launched a million dollar campaign that resulted 
in the establishment of local teacher unions in each of the 76 school districts. 98 percent of teachers signed up voluntarily into the BCTF (Novakowski, 2000).

Ironically, the BCTF actually gained mandatory membership back in the majority of the districts through the same legislative package, which was really intended to decimate the union. Under the provincial legislation, if a local teachers' association chose unionization over professional structure, it could adopt the closed shop model that sets the union membership as a requirement for employment. The remaining 2 percent of the teachers who had not signed up for the BCTF membership were required subsequently to either join the union or be dismissed by their districts because their school boards accepted teacher union demands for the closed shop model in their collective bargaining. In Central Okanagan School District alone, 44 tenured teachers were forced to make a choice between the union membership and dismissal (Gunderson, et al. 1993; Lawton et al., 1999).

In speaking to the BCTF's stance of protecting tenured teachers from being dismissed for incompetence, Lawton et al. (1999) criticized the BCTF's approach towards teachers who refused to join the union,

It is evident that the primary motive of the $\mathrm{BCTF}$ was union power and control, not just quality of teaching or the welfare of the profession. Otherwise, it could have achieved its economic goals without forcing membership upon those who did not desire, for whatever reason, to become members. (p. 90)

At the same time, Bill 20, the Teaching Profession Act, created a new category of employees called Administrative Officers, made up of directors of instruction, principals and vice-principals. These people were identified as part of the management team in 
labour relations and therefore were automatically excluded from membership in local teacher unions. However, the legislation said nothing about their continued membership in the BCTF. After having considered five options forwarded by the BCTF Executive Committee, the BCTF Special General Meeting carried a motion to completely expel principals and vice-principals from active membership in the BCTF on October 10, 1987 (BCPVPA, 1996).

The new act (Bill 20) also created the British Columbia College of Teachers (BCCT) to be in charge of teacher certification, professional development and discipline. The government had intended to develop the College into an autonomous body separated from the BCTF. As such, the college would take charge of the professional needs of teachers. The BCTF, however, managed to limit the College's role to teacher certification and de-certification, with the BCTF members effectively in control of the College's governing council. The BCTF also regained responsibility for professional development from the College when a change in governing parties brought in the New Democratic Party (NDP) government. As it turned out, this new legislative package, Bills 19 and 20, set the stage for changes in educational labour relations in British Columbia for the following two decades, and did so in some ways unanticipated by the government. Political Perspectives

As early as 1909 , Chicago school superintendent and the first woman president of the National Education Association, Ella Flag Young, claimed that teachers were the great moving force, educating and developing the powers of the human mind, and that therefore, they should contribute to the power and efficiency of democracy (Sergiovanni et al., 1992). As teachers' unions have developed over time, their orientation has become 
more political than professional. Their presidents are considered as political leaders, and political campaigns have become an important focus (BCTF, 2001a; Lawton et al. 1999). In order to gain power and to be seen as a force with which to be reckoned, teachers' unions have also launched political lobbying and campaigns to influence public views, and to shape governmental policy-making.

Within this struggle for power and influence, the British Columbia government in 1983 introduced a legislative package of 26 bills designed to reduce public sector spending, allowing for the first time in the history, teacher layoffs and other public sector employee layoffs without cause. Teachers, together with the rest of the labour movement, created "Operation Solidarity" to fight the legislation. They participated in a three-day provincial strike to protest the government legislation. The job action led to successful negotiation of fair layoff and recall provisions in local contracts for teachers. This marked a significant step towards full collective bargaining for teachers in British Columbia, which they obtained in 1987 (BCTF, 2001a).

The original objectives of the BCTF have remained unchanged within the organization's constitution. One of the original objectives was to foster and promote the cause of public education in British Columbia. In order to achieve this objective, teachers' unions have been strong vocal opponents of public choice for schooling. The BCTF believes that providing choice for schooling, including school vouchers, charter schools, and supporting private schools with public funds, actually undermines public education. Further, they fear that if alternatives to public education become more widespread, they will lose their monopoly for negotiating on behalf of teachers (Lawton et al., 1999). The union's position is: 
"It is unacceptable for a government to starve public schools-which take in and provide services for all students, including those with special needs-while providing public tax dollars to private schools, which often reject them. The BCTF is opposed to using taxpayer dollars to fund private schools." (BCTF Education Funding Brief, 1998).

The union executive also called for teachers to fight further global integration of Canada's economy and to keep public education out of trade agreements, e.g., the North American Free Trade Agreement (NAFTA), the Free Trade Area of the Americas (FTAA), and the World Education Market. They were greatly concerned that social equity of education was at stake once public education became an industry that could be traded in the global marketplace. They strongly oppose privatization, commercialization, and corporate intrusion into public schools. "Public Education: Not For Sale" is their rallying slogan.

The BCTF has taken other strong political stances. They passionately opposed the school accreditation process as carried out by the government's ministry of education. In March of 2000, the BCTF launched the "Say No to School Accreditation" campaign. They used their boycott in an attempt to influence the British Columbia government to change its accreditation policy and also to build a case for collective bargaining.

A rally at the British Columbia legislature was held by seven hundred delegates from the BCTF's 85 ${ }^{\text {th }}$ AGM in April, 2001 just prior to a provincial election. The protestors declared that teachers would vigorously oppose the attempt of British Columbia Liberal Party to restrict teachers' democratic full collective bargaining rights through essential services legislation for schools. David Chudnovsky, BCTF President at 
that time, claimed at the rally that what is really essential for public education is improved pay for teachers and better learning conditions for students (Knickerbocker, 2001). In his letter to the BCTF members on June 15, 2001, Chudnovsky further argues, Essential-services legislation would constrain the one tool we have for leveling the playing field in negotiating with our employer. That crucial tool is our right to take strike action if we are forced to. Teachers have never chosen that course of action lightly or frivolously, but it is a fundamental and democratic right that we will do everything in our power to keep. The change Gordon Campbell proposes - unilateral action on the part of government that dramatically reduces teachers' bargaining rights-would create tension, conflict, and disruption. (p. 2) In addition, the BCTF also ran a TV advertisement to express publicly, its strong opposition to the government's proposed legislation that would designate education as an essential-service.

Despite opposition from the BCTF, education as an essential service was legislated by the government in 2001. In spite of the legislation, tens of thousands of teachers in British Columbia walked out of their classrooms and participated in a "day of political protest" when the Liberal government imposed a contract on teachers. By taking united action at 39 rallies around the province, even though the act was viewed as an illegal strike, the British Columbia teachers sent a strong message to the British Columbia Liberal government that they were furious with the forced settlement. They feared that the tool they believed to be the most important —-the collective agreement-had been taken away. 
The BCTF's political activities are not restricted to teachers' rights and public education. They also address a wider social and political agenda. For example, the BCTF has addressed social justice concerns through its Social Justice Program, providing workshops, resources, and grants. The Social Justice Program initiatives focus on gender equity and the status of women, antiracism and race relations, homophobia and heterosexism, First Nations, violence prevention and bullying, poverty, and child and youth issues. In 1999, the Surrey Teachers' Association launched a lawsuit against the Surrey School District over the Board's decision to remove three picture books on same sex parents from the library after receiving complaints from parents. In September of 2000, the BC Court of Appeal denied the Petitioners' request that the three books depicting same-sex parents be made learning resources for five and six year olds. The Court stated this invited a confrontation with the School Board, parents and teachers, where children would inevitably be drawn in. This example reflects the BCTF's stance in dealing with controversial issues such as homophobia and heterosexism within the British Columbia public school system. They oppose censorship, prejudices and stereotype, advocate sensitivity to sexual and minority issues, and promote the building of inclusive schools and communities.

\section{Socioeconomic and Professional Perspectives}

Promoting the economic welfare of the teachers and raising the social status of the teaching profession in British Columbia have always been the major agenda items of the BCTF. Almost all of the teachers' strikes were organized over the salary and pension disputes or tenure and employment rights (BCTF, 2001a). In a letter to BCTF members, Chudnovsky (2001) once again states, "The first priority for our BCFT in this round of 
negotiations is a significant salary increase for all members" (p. 1). The reasons for salary increase are the same as those stated in 1919-inflation and teacher shortages.

Recognition of teaching as a true profession is another issue for which the BCTF has fought. The Federation sought to achieve professional recognition by advocating high levels of teacher certification with increased professional standards, by promoting continuous professional development though a variety of in-service education activities, by establishing an ethical standard of conduct, and by enforcing a system of discipline within the teaching profession.

Although the professional concerns and economic welfare of teachers have been identified as equally important goals for the BCTF, from the very beginning of the $\mathrm{BCTF}$ (BCTF, 2001a), professional goals have either been overshadowed by its economic agenda, or used to legitimize teachers' social expectations and justify their economic demands (Lawton et al., 1999). Sometimes, in order to protect the welfare of teachers, the union damaged teachers' image as professionals. For example, the last BCTF bargaining proposals on procedures dealing with student/parent concerns appeared to be disturbing and offensive to the general public, and thus caused resentment from parents and the media (Collins, 2001). Under the title $A$ New Class of 'Untouchables', the BCTF was criticized by the British Columbia Confederation of Parent Advisory Councils (BCCPAC) and the media as wanting "to take control of the student/parent complaints process away from parents and administrators and put it in the hands of teachers and their unions" (Collins, 2001, p.8). The BCTF proposed to include procedures in a new contract that would give the teacher the right not to meet with the student and/or parent if they so choose; give the teacher the right to 
decide if the principal can become involved in resolving the issue... (Collins, 2001, p. 8)

These proposals were considered as “classic union protectionism, which isn't required by the vast majority of good employees, but can be used to great advantage by those whose performance and/or conduct is under question" (Collins, 2001, p. 10).

The BCTF was perceived as an upholder for "No performance measurement. No awards for excellence. No requirement to meet with parents. No interference by administration" (Collins, 2001, p. 10). It was a major concern that "the BCTF's complaints process proposals would ... lead to an increased perception that the education system is driven by processes protecting employees rather than what is best for students" (Collins, 2001, p. 10). The perception may consequently lead to a shaken public faith in the public education, the very cause the BCTF is striving to promote.

Sergiovanni points out (1992),

Professionals enjoy privileges because they can be trusted. It takes more than competence to earn trust - it takes virtue. Professionalism, therefore, is defined by competence plus virtue... In teaching, professional virtue is made up of four dimensions: a commitment to practice in an exemplary way; a commitment to practice toward valued social ends; a commitment not only to one's own practice but to the practice itself; a commitment to the ethic of caring. (p. 42) It is a pressing challenge to the BCTF and local teachers' associations to regain public trust, improve public perception, and strengthen public faith in the public education while achieving economic and professional goals. Professionalism, as defined by Sergiovanni and the emerging ideology of professional unionism articulated by 
Kerchner et al. $(1993,1997)$, may provide a solution to this challenge so that teachers' unions can promote public education and simultaneously protect employment rights of teachers.

Teachers' unions have had a profound influence on public education and educational labour relations, particularly in the province of British Columbia. Increases in teachers' salaries have helped increase teachers' social status and level of the public recognition. Through collective bargaining, unionism has altered the role of teachers, affected administrators' practices, and changed the nature of relationships between teachers and administrators. Meanwhile, unionism has played a major role in reshaping the political forces and context in educational policy-making at different levels.

\section{Educational Labour Relations}

Educational labour relations in British Columbia are governed and regulated by provincial labour and education legislation. The responsibilities for both education and labour relations are designated as exclusively provincial jurisdiction. Legislative acts define the nature of work, classify the roles of various parties in the educational arena, and design the framework for the educational labour relations. However, many other factors come into play to define how well the various parties in a given educational arena interact with each other. Those aspects will be examined through several strands of related literature in this section.

The Collective Bargaining and the British Columbia Legislation

In British Columbia, teachers are included in both the British Columbia Labour Relations Code 1992, c. 82 (Bill 84) and the Public Education Labour Relations Act, 1994, c. 21 (Bill 52) (Lawton et al., 1999). Passage of any new legislative bills always 
effects changes to educational labour relations despite resistance or rejections. For example, in 1987, the British Columbia government passed the Industrial Relations Reform Act and the Teaching Profession Act. These bills included teachers in the Labour Relations Code of British Columbia for the first time in history and made collective bargaining lawful for the teachers in British Columbia. Meanwhile, the Teaching Profession Act reinforced the industrial labour relation model—separateness of labour and management, teaching and administration - in the educational arena.

A system of coordinated local bargaining emerged after the 1987 legislation as teachers' unions obtained full collective bargaining rights. Local teachers' unions became the bargaining agents negotiating a collective agreement with their school boards on behalf of their teachers. The BCTF orchestrated all negotiating activities in locals by playing one school board against another as well as by providing technical support and negotiation training for teachers. As Burnham and O’Neill (1991) comment, The apparent BCTF strategy was to focus first on sympathetic, left-leaning districts, to gain all the concessions they could, and then use these as a whipsaw to force other boards to do the same. By the time mediators are called in, it's too late to change the pattern. (p. 39)

Since 1988, about 30 local teachers' strikes took place in an effort to achieve teachers' negotiation objectives. The resulting school closure time varied from one week to one month. The strikes ended with back to work orders for teachers and arbitration in favour of employees. As a result of the three rounds of collective bargaining, local teachers' unions achieved comprehensive collective agreements "that not only replaced the rights contained in legislation, but also enhanced and expanded those rights 
considerably" (BCTF, 2001a, p. 13). The cost to cover the collective agreements increased by 37 percent from 1988 to 1992 (Lawton et al., 1999).

According to the BCTF, "Teachers finally had an appropriate vehicle to exercise their collective will within the public school system" (2001a, p. 14). However, there was widespread dissatisfaction with the collective bargaining system from politicians of all stripes. In 1990, the province took over the complete control of education funding, which complicated the situation. School boards often found themselves unable to meet the contract obligations that they negotiated with teachers' unions because they did not have the financial authority to raise local taxes. The BCTF also recognized that the economic climate had changed and that the public was not as receptive to their cause as it had been in earlier rounds of negotiation (BCTF, 2001a; Lawton et al., 1999).

In 1994, the British Columbia government adopted several new legislative mandates designed to obtain the central control over collective bargaining and subdue turmoil within the public sector labour relations. Bill 52, Public Education Labour Relations Act (PELRA) and Bill 78, Public Sector Employers Act set up the current framework for provincial bargaining in which the BCPSEA bargains on behalf of all the school boards with the teachers' unions represented by the BCTF. Since then, three rounds of bargaining have taken place, yet not once have the two parties ever achieved a negotiated collective agreement. The first round took over 18 months with little progress made. Only four or five of more than 100 proposed clauses were agreed upon before the provincial government stepped in with some off-table bargaining. Eventually, both parties accepted the proposed three-year Transitional Collective Agreement, including a 2 
percent pay increase and an agreement to roll-over the provisions not covered by provincial agreement from local contracts.

The second round of negotiation started in September 1997 and was a repeat of the first round in many ways. Again, the government intervened after little or no progress was made, but this time the government entered directly into bargaining with the BCTF without the BCPSEA. In April 1998, a tentative three-year agreement was reached between the government and the BCTF. The new provincial teachers' contract contained a 2 percent salary increase and provisions for non-enrolling ${ }^{3}$ teacher/student ratio. Though the provincial agreement was ratified by teachers, it was rejected by 87 percent of the school boards because of their concerns over equity among school districts and because the agreement decreased flexibility in managing their schools (Lawton et al., 1999). The BCTF conducted an active campaign to promote the new contract to parents and the public, while the BCPSEA and the British Columbia Confederation of Parent Advisory Councils campaigned against the contract. The government then imposed the collective agreement by enacting Bill 39, the Public Education Collective Agreement Act, on July 30,1998 . The act legislated school districts to implement the agreement. All other provisions of the Transitional Collective Agreement not specifically changed were again rolled over. To financially support the agreement that the government negotiated and imposed, the government provided an additional $\$ 150$ million in funding over 3 years to keep up the non-enrolling teacher/student ratio and reduce the primary class size. However, due to the recession and concomitant deficit spending in the province, the government could not afford the agreement. "The agreement reduced still further the

Non-enrolling teachers include teacher librarians, counsellors, learning assistance teachers, special education resource teachers, and ESL teachers. 
ability of trustees, superintendents and principals to manage their districts. Their full-time job has become one of implementing the handiwork of the government and teachers' unions without encountering an excessive number of grievances" (Lawton et al., 1999, p. 97).

The following factors may account for the unsuccessful provincial bargaining. First of all, the two agents, the BCPSEA and the BCTF, did not share a mature working relationship (Lawton et al., 1999) and only came together for the purpose of negotiation. They were both remote from the school boards and teachers, and they could not fully represent their constitutes' interests. In addition, centralized bargaining could not effectively satisfy all the diverse needs of a wide range of school boards. The BCTF also found it hard to accommodate and represent competing internal interests of member locals.

Secondly, the bargaining approaches chosen by the two sides were radically different. The BCTF used 'positional bargaining' in which they proposed a master contract that was composed of over 100 'best' clauses from the existing collective agreements all over the province. The BCPSEA used 'interest bargaining,' in which it shared the key desires and needs of school boards, in the expectation that the other side would do the same (Lawton et al., 1999). This approach would not work unless the two parties had established a positive and healthy relationship.

Thirdly, the BCPSEA was not the ultimate financial authority (Lawton et al., 1999) since the government ultimately held financial power. The BCPSEA entered the bargaining with the knowledge that there were no more funds available for education other than what had been allocated to the schools by the government. This restricted the 
BCPSEA's negotiating power to bargain within the current budget. Consequently, as Lawton et al. (1999) describe:

... the Public Education Labour Relations Act must be viewed as a failure. In both rounds of bargaining to date, the province has undercut the employers' negotiating body by taking over bargaining and reaching a settlement. In the first instance, it provided funds that it previously had indicated were not available. In the second, it effectively joined with the leadership of the teachers' unions to implement a government policy that would have appeared quite modest in its direct benefit to teachers currently in the system but which set the provincial benchmark for salary settlements that the government desired. (p. 98)

The third round of bargaining started in April 2001 was destined for the same fate as the two previous rounds of bargaining. It ended with the introduction of legislation by the government, and an imposed "collective agreement". The difference in this particular round was the enactment of Bill 18, the Skills Development and Labour Statutes Amendment Act, whose purpose was to restore education as an essential service under the Labour Relations Code. The essential service designation for education had been removed by the NDP government in 1993. Though Bill 18 kept the employees' rights to collective bargaining and to strike, its fundamental purpose was to ensure that no child's right to education would be denied due to a labour dispute at schools.

When the third round of negotiation was making little progress, the BCTF called for job action under the new essential service act, with teachers' incremental withdrawal of services at 3 different phases. Just as the teachers' job action was about to enter Phase 3 (full withdrawal of services through partial, rotating or full strike action when the 
bargaining hit another impasse after 3 months' job action), the government once again brought forward legislation to end the contract dispute between the BCTF and the BCPSEA. Bill 27, Education Services Collective Agreement Act, concluded terms of the collective agreement and provided for the establishment of a commission to inquire into and make recommendations concerning provincial teachers' collective bargaining structures, processes and procedures. Bill 28, Public Education Flexibility and Choice Act, contained a series of amendments to the School Act. The amendments included class size and composition, teacher staffing levels, non-enrolling ratios, case loads or teaching loads, etc. The government claimed that the introduction of these two bills underscored its commitment to changing labour legislation in order to protect the public and restore flexibility and democratic rights to the workplace. The legislation certainly limited the scope of teachers' collective bargaining, and at the same time provided a mechanism for changes to the unsuccessful bargaining model that has frustrated all parties in the past.

However, the new legislation was considered by the BCTF as "the legislative hammer" that smashed their most important tool-the collective bargaining. "With the stroke of a pen, this government has eliminated the very provisions that ensure quality education for children... Bill 28, the 'Public Education Flexibility and Choice Act,' eliminates key provisions that teachers have negotiated over many years" (BCTF, 2002, p. 1). Under the direction of the BCTF, almost all of British Columbia's 45,000 teachers walked off the job on January 28, 2002 to protest their government-imposed contract. All the public schools were forced to close for one day across the province. Once again, the introduction of new legislation changed the playing field for educational labourmanagement relations and restructured the power distribution. Teachers' unions, school 
administrators, and school boards found themselves in a changed working environment that continues to present both opportunities and challenges.

Factors in Labour-Management Relations: Findings that Support the Theoretical Basis for the Study

Leadership Style as a Key Factor.

Fleishman and Harris (1962) published one of the most frequently cited articles of the 1960s-Patterns of Leadership Behavior Related to Employee Grievances and Turnover - based on their study of the relationships between the leadership behavior of industrial supervisors and the behavior of their group members (as cited in Fleishman, 1998). They utilized comprehensive constructs "consideration" and "initiating structure" to measure leaders' behaviour and attitude. Leaders scoring high in consideration were those who established a climate of mutual trust, rapport, and tolerance for two-way communication with their work groups. Foremen with a high level of structure tended to give the workers excessive instruction and strict directives in task performance. A very important finding from Fleishman's and Harris' study is that the leadership pattern of foremen with high structure and low consideration is related to high labour turnover, union grievances, worker absences and accidents, and low worker satisfaction. Furthermore, a significant correlation was found between each possible leadership pattern, (low in structure and high in consideration, high in both structure and consideration, low in both structure and consideration, and high in structure and low in consideration) and such indices as rated proficiency, grievances, turnover, and subordinate satisfactions. The study indicates that scoring low on both dimensions of leadership pattern is not desirable. The study also shows that some combined level of 
consideration and structure may be optimal for creating proficiency and favorable labour relations, with consideration as the dominant factor (Fleishman, 1998). In other words, foremen who showed high consideration had the lowest grievances and turn over regardless of the amount of structuring they were engaged in. Although the current research on leadership style has developed far beyond two dimensions, Fleishman and Harris spearheaded research on leadership in labour relations, and their findings provided grounding for subsequent studies in the field. Their findings have supplied an important piece to the conceptual framework of this study, bridging the study of leadership style with employee grievances and turnover. This link is extended to the educational arena.

Facing a perplexing and ever-changing unionized environment in the British Columbia public schools system, this study hypothesizes that leadership style has a key effect on labour relations. Fullan (2001) persuasively depicts the correlation between leadership and human relationships in the midst of the challenges of today's complex and changing world:

...the single factor common to every successful change initiative is that relationships improve. If relationships improve, things get better. If they remain the same or get worse, ground is lost. Thus leaders must be consummate relationship builders with diverse people and groups—especially with people different than themselves. (p. 5)

The leadership styles of school principals may have as significant an impact on the implementation of the collective agreement and dispute resolution as they have on school culture, student achievement or the success of school communities. As Andrews and Morefield (1991) indicate, numerous studies have shown that teachers' perceptions 
of the instructional leadership behaviour of their school principals have accounted for the most variance in student outcomes and school effectiveness (Andrews et al., 1986; Edmonds, 1979; Jantzi \& Leithwood, 1996; Leithwood \& Jantzi, 1999). In addition, a strong association has also been found between teachers' job satisfaction and the leadership of the school principal, their workplace conditions, and incremental growth in the performance of students (Andrews \& Morefield, 1991). It is therefore both logical and reasonable to assume that the leadership style of school administrators will correlate with dispute resolution in schools.

While the role of leadership in relation to teacher grievances remains the main focus of the investigation, the review of the related literature has suggested that other factors may also be attributable to the variation in the number of teacher grievances filed among schools.

\section{Gender as a Demographic Factor.}

Gender has emerged as a significant focus in research on educational leadership. Even though leadership traditionally has been studied using male norms such as masculinity and dominance as the standard, gender differences have contributed to the observed variation in leadership styles as more and more women have risen to leadership positions. Furthermore, gender differences in leadership have been acknowledged, confirmed and studied by more and more scholars (Chliwniak, 1997; Collard, 2001; Gilligan et al., 1988; Jantzi \& Leithwood, 1996; Miller, 1986). Women leaders are described as those who "place more emphasis on relationships, sharing, and process, while male CEOs, as per Mintzberg's studies, generally focus on completing tasks, achieving goals, hoarding of information, and winning" (Chliwniak, 1997, p. 3). Gilligan 
(1988) identified a separate developmental pathway that results in different value systems for women and men. For example, females tend to value personal and relational responsibility while males' highest value concerns legal justice for individuals. As described by several authors, men are more concerned with systems, rules and outcomes, while women are more concerned with processes, relations and atmosphere (Chliwniak, 1997). Jantzi's and Leithwood's (1996) research has suggested an association of the masculine traits with more authoritarian and non-transformational styles of leadership while female traits, such as individual consideration, inclusion, and nurturing, are associated with transformational leadership practices.

Other similar studies that included gender as the object of inquiry found gender to be significantly related to leaders' perceptions and beliefs, leadership styles, and behaviours or effects (Eagly \& Johson, 1990; Shakeshaft, 1989; Tabin \& Coleman, 1993). Quite often gender is treated more or less as a single independent variable in those studies. Collard (2001), however, in his reports on a broad-scale leadership and gender study of 400 principals in Victoria, Australia between 1996-99, confirms that significant gender differences exist in leadership, but he also acknowledges the importance of organizational cultures, value systems, and same-sex differences.

Significant relationships were also found in Jantzi's and Leithwood's (1996) study between leaders' gender and the teachers' perceived leadership styles of their school principals. The sample of teachers in their study rated women leaders at higher levels of transformational leadership than men. Nevertheless, Jantzi and Leithwood cautioned readers that there were additional plausible variables competing with gender differences to explain the results, such as school level and size. 
Bell and Chase (1995) challenged the idea that women are more likely to be interpersonally oriented rather than task oriented based on their interviews with 27 women school superintendents during the years 1986 to 1989 . They contend that an integrated conception of leadership and leadership strategies are shaped by the women superintendents' working contexts, especially by bureaucratic and male-dominated structures in educational administration, while gender is only one of these contingencies or contextual factors. Gamble's (2001) finding from her case study on the impact of principal leadership style and gender on elementary school climate supported Bell and Chase's assertion from another perspective. That is, gender based leadership traits, rather than the gender of the administrator, appear to be associated with school climate.

Some researchers also believe that differences exist in communication between genders (Booher, 1997; Scott, 2001). According to Booher (1997), "Neither men nor women are better communicators. They're just different" (p. 2). The differences lie in the use of questions, directness, purpose and engagement of conversations. Women use indirect channels such as asking questions to infer their positions, opinions or ideas to avoid confrontation. Their questions are also designed to solicit information and they tend to give fewer directives. Further more, women engage in casual conversations in order to build relationship with others. On the other hand, men's language tends to be more direct, powerful, and at times, offensive. Men generally give more directives and tend to view conversation as a means of exchanging information or solving problems (Booher, 1997). The differences may result in communication gaps. In addition, as Booher (1997) points out, “...the potential for gender communication gaps is widest in 
those organizations where one gender occupies most of the senior executive positions" (p. 1).

The gender interactions in any given organization create specific dynamics in that organization along with other factors. The gender differences in leadership styles and in communication can generate synergy as well as conflict in educational labour relations. As indicated by Gill (1998), "In practice, dichotomous sex differences typically are translated to mean that we should treat males one way and females the other way" (p.185).

\section{Leadership Experience as Demographic Factors.}

Leadership experience is often considered an independent variable in empirical studies (Jantzi \& Leithwood, 1996; Leithwood \& Jantzi, 1999; Mitchell, 1987). It is commonly assumed that experience and professional development on the job can help train educational leaders and foster their growth for their enormous responsibilities. For example, with experience, they will be able to develop their capacity to deal with diverse expectations from a wide range of constituent groups and resolve conflicts and problems among them and hopefully in the process, improve educational practice and students' achievements. As Daresh and Male (2000) report, based on their investigations of leadership experiences of newly appointed British headteachers and American principals, there is no better preparation for the leadership roles than on-the-job experience as a leader. Their findings support Jantzi's and Leithwood's (1996) proposition "that leaders' prototypes are strongly influenced by experience with those in formal leader roles, entry to such roles (especially in education) usually requiring lengthy periods of formal training and on-the-job experience" (p. 521). 
In British Columbia, in order for individuals to be selected as principals, they are required to have at least three to five years of teaching experience, a master's degree in educational administration from an accredited university, demonstrated abilities and a track record in instructional leadership, and strong communication and interpersonal skills.

School Type, School Level and School Size as Contextual Factors.

Rural schools have characteristics distinct from urban and suburban schools in terms of geographic, economic, racial, and cultural conditions. Elementary, middle and high schools are also different in their culture, structure, and operation. It is suggested that, in order to improve education and students' learning, the unique needs of rural, urban and suburban schools and the characteristics of elementary, middle, and secondary students must be understood and addressed (Andrews \& Morefield, 1992; Bloodsworth, 1993; Boyd \& Raffel, 1992; Jackson, 1990; Midgley et al., 1990; Worzbyt \& Zook, 1992). Therefore, School Type and School Level have been included in educational studies as important situational variables (Davis, 1998; Jantzi and Leithwood, 1996).

Rural schools in British Columbia tend to be situated in geographically large and less populated areas that concentrate their economic activity on farming, ranching, mining, sawmills and other forestry industry activities. They are quite often found to be associated with the following social challenges and conditions: poverty, diversity of culture, declining enrollment, small schools, split and multi-grade classes, a high cost of transportation, and a lack of access to a variety of cultural and educational opportunities. Embedded in those conditions are some advantages as well as challenges to rural educational leaders and their teaching staff. These small community schools are clearly 
important to their communities and often enjoy great parental rapport and community support. Smaller class size and low teacher/pupil ratios are favourable to students' learning. However, a scarcity of resources, inequities among the schools, operational inefficiencies, the ongoing threat of school closures, and school district restructuring are just part of the reality in rural education (Bloodsworth, 1993; Jackson, 1990). What rural school administrators and teachers have to deal with include staggering workloads, a shortage of staff development opportunities, a high rate of staff lay-offs and administrators' turnover, and difficulties attracting needed personnel and specialists (Worzbyt \& Zook, 1992).

Urban schools are located, in settings with a high density of diverse cultural and ethnic population, and accessibility to various facilities and resources. They are challenged by a predominantly minority enrollment, a high percentage of ESL students, urban minority poverty, high concentrations of disadvantaged students in inferior innercity schools, demands from parents and pressure form media (Boyd \& Raffel, 1992). There exist great gaps between poor and ethnic minority children and their affluent counterparts, and between inner-city schools and elite schools (Andrews, \& Morefield, 1992).

There is a growing recognition that elementary, middle, and secondary/high schools are different organizations with different school cultures, different school goals and different principal leadership styles (Midgley et al., 1990). According to Houts et al. (2001), secondary schools are usually larger than elementary schools and there is more departmentalization and more bureaucracy built into the secondary school system level than at the elementary level. As a result, secondary school principals are required to be 
strong curriculum leaders as well as managers and coordinators of a variety of activities while at the elementary level, principals have to be educational leaders capable of dealing with declining enrollment, reduction of resources, and increased responsibilities. Recent studies done by Tabin and Coleman (as cited in Jantzi \& Leithwood, 1996) also show there still exists a considerable gender disparity between secondary and elementary school principals, with secondary schools largely run by male principals. In addition, since elementary schools are often smaller than secondary schools, there are more opportunities for frequent and direct principal-teacher interactions in non-instructional related contact in elementary schools than in secondary schools. Consequently, the working relationships between elementary principals and their teachers tend to differ from that of secondary principals and their teachers.

Years of Teaching Experience as a Contextual Factor.

Years of employees' experience or tenure in their current organizations are often selected as an independent variable in studies on leadership and organization effectiveness. The results, however, are not consistent (Besson, 1999; Blank \& Weitzel, 1990; Jantzi \& Leithwood, 1996; Mitchell, 1987). Some studies found a significant correlation between employees' tenure and ratings of transformational leadership for leaders and managers (Besson, 1999); others found no correlation at all (Blank \& Weitzel, 1990; Jantzi \& Leithwood, 1996).

Years of teaching experience are also frequently included in studies on job satisfaction among teachers (Cencirulo, 2001; Dickinson, 2000; Galvez, 1998; Grill, 1999; Klecker \& Loadman, 1999; Mwamwenda, 1998). The findings of these studies turned out to be mixed. For example, Galvez (1998) examined the levels of job 
satisfaction and attitudes toward teaching from 120 regular elementary classroom teachers who serve special needs and special education students in nine elementary schools from Chesapeake City Public Schools in Chesapeake, Virginia. She claims that the number of years of experience is one of the factors that best predicts job satisfaction and attitude toward teaching. In her study of the relationship between leadership roles and job satisfaction among elementary teachers from a Florida school district, Grill (1999) also found significant differences in teachers' leadership due to their years of teaching experience. However, no significant correlation of years of teaching with job satisfaction emerged in studies by Klecker and Loadman, (1999) and Cencirulo (2001).

'Past job experience' is suggested as an important component of job maturity by Hersey and Blanchard (as cited in Blank \& Weitzel, 1990). The average years of teachers' experience may reflect the maturity of the teaching team at a school. A younger staff may be more energetic and less union-oriented while an older staff may be more mature and sophisticated. Dickinson's (2000) findings on job satisfaction and teacher union membership provide additional grounds for the inclusion of years of teachers' experience as a variable in my study. Unionized male teachers were more satisfied than their nonunionized peers; nonunionized teachers with the least years of experience were more satisfied than their unionized peers. The interaction of teaching experience and union status has a highly significant correlation with general job satisfaction.

Student Socio-Economic Status (SES) and Discipline as Factors.

Student socio-economic status (SES) has been historically regarded as the most powerful predictor of student success at school (Galloway, 1994; Leithwood \& Jantzi, 1999; Ma, 2000). The low SES students are usually behind their more advantaged peers 
in academic performance and high SES students, who appear academically more able, progress faster than low SES students in core subjects such as Math and Reading (D’Agostino, 2000; Liu \& Kaplan, 1992). SES still remains a strong determinant of the culture of learning within a school, which predicts students' school experience (D’Agostino, 2000; Duffield, 1998; Leithwood \& Jantzi, 1999). SES also has been shown to influence the form and style of principal leadership practices (Hallinger \& Murphy, 1986; Leithwood \& Jantzi, 1999).

However, Edmonds and Fredericksen (1978) report that SES per ce does not explain achievement differences because students achievement is affected by multiple factors such as teacher attitudes, instructional programs, parent involvement, student attendance, and expectations. It appears that SES is an influencing factor only when considered with other variables. For example, Brookover and Lezotte found that a significant amount of the variance in student achievement is explained by school climate, with race and SES as controlling factors (as cited in Bulach \& Lunenberg, 1995).

An increasing number of empirical studies have further developed assertions, indicating that school principals are critical in ensuring student academic achievement, especially for minority and low SES students (Andrews \& Morefield, 1991). In his report on the effects of school on students' longitudinal reading and mathematics achievements, D'Agostino (2000) contends that factors such as teacher collegiality, principal leadership, shared vision and goals, community support, effective instructional strategies, all have direct and interactive effects on students' success in reading and math, when controlling for SES. Grill's (1999) study, adding teachers' job satisfaction to the multiple regression equation, reveals a significant interaction of student SES and academic achievement with 
general job satisfaction and participation in teacher leadership roles. Significant differences in general job satisfaction were found related to student achievement, SES, and several demographic factors.

Student discipline and safety issues have become a major concern when bullying and violence became a common phenomena on school grounds (Klein, 1997). Discipline problems can be one of the sources of teachers' stress (Romano \& Wahlstrom, 2000). The combined effects of student SES and discipline can present great challenges to teachers' instruction and principals' leadership, through demands of more time, energy, and resources. Such demands can also raise stress levels in a school, and at times affect management and labour relationships.

\section{Labour Dispute: Grievance and Arbitration}

As Birnbaum (1981) maintains, grievances and dissatisfactions from employees in the beginning of the last century actually resulted in unionization, which in turn, led to collective bargaining. Now, grievances and arbitration are commonly used procedures to resolve contractual disputes; in fact, the dispute resolution mechanism is built into the teachers' collective agreements (Connors \& Bashore-Smith, 1991). In British Columbia, grievance procedures were among the first few provisions settled in the inaugural provincial transition agreement for teachers (1994-1997). The provincial teachers' collective agreement now provides detailed terms and conditions regarding grievances and arbitration. The agreement states the successive steps in the grievance procedure, with arbitration as the final step. The method of presenting and appealing the grievance and specific time limits for presentation, decision and appeal are clearly indicated at each step. If the grievance procedure is exhausted without resolving the dispute, either the 
local union chapter, the BCTF or the BCPSEA can advance the grievance to arbitration. Specific directions are given on the referral to arbitration with regard to provincial matters verses local matters (BCPSEA, 2000). As shown in Table 1, according to the annual report by the British Columbia Ministry of Skills Development and Labour (2000), grievance referrals for expedited arbitration by public primary and secondary sector peaked in 1997-1998 and declined through the 1999-2000 school year:

Table 1

$\underline{\text { Referrals for Arbitration by Public Primary and Secondary Schools }}$

\begin{tabular}{|c|c|c|c|c|c|}
\hline School Year & $1995-1996$ & $1996-1997$ & $1997-1998$ & $1998-1999$ & $1999-2000$ \\
\hline $\begin{array}{c}\text { Number of } \\
\text { Referrals }\end{array}$ & 37 & 31 & 109 & 82 & 45 \\
\hline
\end{tabular}

Each school district and local teachers' union has documentation on filed grievances and arbitration referrals.

District and school administrators as well as teachers' unions' representatives devote a large amount of their time to administering both the local and provincial teachers' collective agreements. To a certain extent, the climate of management and teachers' union relations is determined by the manner in which administrators and teachers' unions understand, apply the language and principles of the collective agreements, and react to conflicts that grow out of the implementation of collective agreements and day-to-day operations. Problems not resolved on the spot are generally resolved through the grievance procedure defined in the collective agreement, with final and binding resolution in arbitration (Connors \& Bashore-Smith, 1991; Knott, 1983). As Mitchell (1987) argues in his study on labour relations in California school districts, the number of formal grievances filed is a better predictor of weakened trust, and 
administrators find grievances more destructive to the working relationship than real or threatened work stoppage.

Nevertheless, the industrial labour relation model adopted in education has prescribed adversarial relationships for the district/school administration and teachers' unions (Knott, 1983). It takes more than formal grievance and arbitration procedures to resolve conflicts. A sound alternative to dispute resolution can provide a legitimate and natural framework for channeling differences of opinion, raising concerns not covered by existing contract language or policies, and resolve conflicts even before they turn to grievances or progress beyond grievances to arbitration (Knott, 1983). Mitchell (1987) indicates in his report that well managed schools and school districts are able to avoid teacher grievances. For these reasons, filed teacher grievances were used as the dependent variable in this study.

\section{Summary}

This chapter provided a review and critique of literature in three different and important areas of research: leadership/leadership styles, teachers' unions, and educational labour relations. First, a comprehensive review was conducted on various leadership theories to which transformational and transactional leaderships were either related or derived, including Maslow's motivation theories, McGregor's Theories X \& Y, social influence theory and contingency theory. Leadership styles were then examined through the results of empirical studies from organizational and educational perspectives.

Subsequently, teachers' unions, particularly the BCTF, as an important force in educational labour relations, were discussed from historical, political, socioeconomic, 
and professional perspectives. This part of the review consisted of the development, function and significant events in the history of the BCTF.

The role of legislation in educational labour relations, especially on collective bargaining and the current situation of the relationships between school principals, the school district administration and teachers' associations in the British Columbia public school system, was then examined. Finally, several factors, such as gender, leadership experience, student SES, were discussed individually through a review of related literature to provide a rationale for their inclusion in the study.

Together, these three components of literature review constructed a conceptual framework for the study. The following chapter will now present the methodology used in conducting the research. 


\section{CHAPTER III \\ RESEARCH DESIGN AND METHODOLOGY}

Introduction

This study used inferential and descriptive statistics to investigate factors related to labour dispute in British Columbia public schools. The purpose of this study was to determine the relationship between measures of leadership style and labour dispute. The overarching question that guided the study and directed the research design was: What is the relationship between measures of leadership style and labour dispute in British Columbia schools? Or put more specifically-why do some schools have fewer teacher grievances filed than other schools in the British Columbia?

This chapter begins with a detailed description of composition of the sample, survey instruments, and data collecting procedures. Then a presentation of the design of the study, including a discussion of the dependent and independent variables and their measures, is given. The chapter concludes with an explanation of the main analytic technique that was employed in answering the research questions.

\section{Participants and Sample}

Since the purpose of this study was to explore the relationship between measures of leadership styles and labour dispute in British Columbia public schools, the targeted population therefore included school principals in the British Columbia public school system. 
Although most of the school principals do not deal with grievances directly, their leadership styles and ways of implementing contracts exert an impact on labour relations by either reducing or increasing the likelihood of labour disputes. In addition, school principals' leadership styles may influence the ways and effectiveness of informal dispute resolution at school level before any dispute escalates to formal filed grievances.

A sample of school principals from each district was selected using a stratified random sample and surveyed online to gather data for the study. For the purpose of this investigation, participants must have served as principals at their schools in both the 2000-01 and 2001-02 school years. From each district, the precise number of school principals selected was based on the following stratification variables- - size of the district, school level and student population of the schools. Specifically, the student population of selected schools represented between 12 percent to 15 percent of the total student population in each school district, and the levels of the schools chosen from each district had to be representative of that district. For example, a certain number of secondary schools (that represented between 6 percent to 8 percent of the district student population) were first chosen from each district. Then elementary, and/or middle schools, or elementary junior high schools, were selected that had a total student population approximately equal to the population of selected secondary schools. As a result, small districts had as few as three schools selected, while large districts had as many as thirty schools and their principals selected. Consequently, a total of 460 school principals were selected to form the sample group; however, because an insufficient number of surveys were received, the mailing list from the BC Principals' and Vice-Principals' Association was used to supplement the sample. 


\section{Survey Instruments}

The survey instruments were chosen and adapted to fit the design of this study. The data were collected in two ways: a questionnaire and internet research for other demographic information about participating schools, specifically the socioeconomic status (SES) of the student population, school size as measured by student enrollment in the 2000-2001 and 2001-2002 school years, and teacher FTEs (Full Time Equivalences).

As for the questionnaire, there were three major components: demographics, leadership and grievance information.

1. Demographics. This part of the questionnaire collected the following demographic and contextual information: gender, years of leadership experience, school type, school level, average years of experience for teachers at the school, and student discipline (see Appendix A).

2. Leadership. This component of the survey collected data on the perceived leadership styles of the participants by using the Multifactor Leadership Questionnaire, Leader Form 5X-Short (see Appendix B).

3. Number of grievances that were filed during the two school years at that particular school.

The questionnaire was designed in an electronic format and was posted on a website with the password access so that the participants could do it online.

As noted above, the Multifactor Leadership Questionnaire (MLQ), Form 5XShort, (Bass \& Avolio, 2000) was used to measure leadership styles in this study. According to Hoyt and Melby (1999), the number of participants needed to achieve an adequate level of statistical power is a function of the reliability of the measure or rating 
system. In other words, the reliability and validity of the survey instruments would affect the actual number of participants required for the study. The lower the reliability, the higher the number of participants required. Fortunately, the MLQ is well established in terms of its reliability and validity through numerous testings across organizations, countries and cultures (Arter, 1990; Bass, 1997). The results of two comprehensive validation studies of an initial set of 9 samples and a replication set of 14 samples show that all of the leadership scales' reliabilities for the MLQ 5X were generally high (.63 to .92), exceeding standard values for internal consistency recommended in the literature (Bass \& Avolio, 2000). As a result, the MLQ (Leader Form, 5X-Short) was selected as the central component of the survey instrument for this study.

The Multifactor Leadership Questionnaire (Leader Form, 5X-Short) is based on the concepts of transformational, transactional, and laissez-faire leadership (Burns, 1978; Bass, 1985). It attempts to capture nine dimensions of leadership behaviors with 45 items that differentiate three styles of leadership. Five of the dimensions are either associated with or attributed to transformational leadership. In this study, they were merged into 3 higher order factors according to Bass and Avolio (2000):

\section{Charisma/Inspirational:}

- idealized behaviors - striving for a strong sense of shared vision and purpose for the organization with higher levels of moral and ethical standards (items 6, 14, 23, 34);

- idealized attributes - representing the highest level of transformational leadership with a high degree of credibility — respect, trust and faith—achieved by the transformational leaders through modeling (items 10, 18, 21, 25). 
- inspirational motivation-inspiring others through effective communication and articulation of challenging vision and mission as well as confidence (items 9, 13, $26,36)$

2. Intellectual Stimulation: stimulating others by challenging the conventional way of thinking and seeking different perspectives when solving problems (items 2, 8, 30 , $32)$;

3. Individualized Consideration: treating others as individuals by recognizing and meeting their level of maturity, capabilities and developmental needs with empathy and skills (items 15, 19, 29, 31);

In contrast to transformational leadership, transactional leadership is a process of transacting reward for performance, gaining compliance through contracts, and exchanging assistance for effort. Originally, there were three components in the MLQ measuring transactional leadership. However, recent studies have shown that passive management by exception, which is the third dimension of transactional leadership, correlates positively with laissez-faire items but negatively with all other dimensions of transformational and transactional dimensions (Hartog et al. 1997; Avolio \& Bass, 1999). Therefore, passive management by exception and laissez-faire items were collapsed into one higher order factor. Here are the remaining three factors, two factors for transactional leadership and one higher-order factor for passive avoidant leadership:

4. Contingent Reward: clarifying expectations, providing support in exchange for effort and trading reward for achievement (items 1, 11,16, 35); 
5. Active Management-by-Exception: concentrating full attention on task performance for any mistakes, complaints and failures, and correcting problems to maintain current performance levels (items 4, 22, 24, 27);

6. Passive Avoidant - passive or inactive leadership

- Passive Management-by-Exception: taking no action until complaints are received or problems become serious; in other words, “if it ain't broke, don't fix it” (items 3, 12, 17, 20).

- Laissez-faire leadership: avoiding getting involved when important issues emerge, in essence, failing to take action in response to conflicts or displaying no effort to follow up $(5,7,28,33)$.

Furthermore, items 37-45 on effectiveness, extra effort and satisfaction constitute a "quality of leadership" measure to further explain the effects of leadership styles on followers as well as on organizations. In other words, these items deal with outcomes of a leadership style on followers, leader effectiveness in meeting individual and organizational needs, and perceived satisfaction with the leadership.

\section{Design of the Study}

In this study, a series of models were developed to identify correlates of teachers' grievances in British Columbia public schools in order to explore answers to the research questions. The incidents of grievances are usually the results of a dynamic process of dispute resolution within a school. For example, school principals' leadership styles may account for a portion of the variation in filed grievances at school level. These leadership styles may influence the informal dispute resolution, and often, may decide whether or not disputes escalate to formal filed grievances. In the meantime, some other 
demographic factors may also come into play. Therefore, a series of school-based models were constructed to address the research questions. For these models, the unit of analysis was school site administrator-the School Principal.

\section{Data and Variable Selection}

The data pertaining to school principals were combined with the demographic and contextual information from their individual schools. Individual perceptions of one's own leadership style were also captured. The impact of school demographics, contextual factors, and the leadership styles of school principals on filed teacher grievances at the primary stage of dispute resolution were measured and then analyzed, allowing statistical comparisons among schools.

Since teachers' grievances are complex phenomena, the existing literature, informal interviews and discussions with professional practitioners such as superintendents, teachers' union presidents and school principals, helped identify the requisite independent variables.

\section{Data Collection for District Models}

The original design of the study included another set of district-based models developed to identify correlates of labour dispute in the British Columbia public school system. The settlement of teachers' grievances within a school district was another key measure of dispute resolution and labour relations. According to the Provincial Teachers' Collective Agreement, at least two employer representatives and two union representatives are required to attend grievance meetings. The leadership style of the superintendent may set the tone for the labour relations and consequently affect dispute resolution in the district. The leadership style of the district administrator in charge of 
labour relations, together with that of the union president and/or executive, may directly influence the process and results of dispute resolution. The interaction of district administrators and union officials' leadership styles may account for both the quantity and quality of internal grievance settlements.

Therefore, the invitation letters for participation were sent to these people in each of the 60 school districts. Specifically, the two representatives of district administration surveyed were the Superintendent and one district administrator who was in charge of labour dispute resolution. Two representatives surveyed from each of local teachers' associations included the President and one other executive dealing with dispute resolution and grievances. Unfortunately, after numerous emails, faxes and phone contacts, valid data from 23 school districts were finally obtained, of which there were only 13 teacher unions' responses. Because of the low return rate, the data was not sufficient for any subsequent analysis. As a result, the original plan to estimate districtbased models was dropped from the study.

Hierarchical Regression Models and Variables

As indicated above, a series of school-based models were used to address the research questions. In these models, hierarchical regression analysis was used to first examine the importance of principal demographics and school characteristics, and then in the second stage of the analysis, leadership variables were added (see Figure 3.1). In the next section, a detailed explanation of all the variables is provided for the basic and core hierarchical models. 
Basic School Demographic Model.

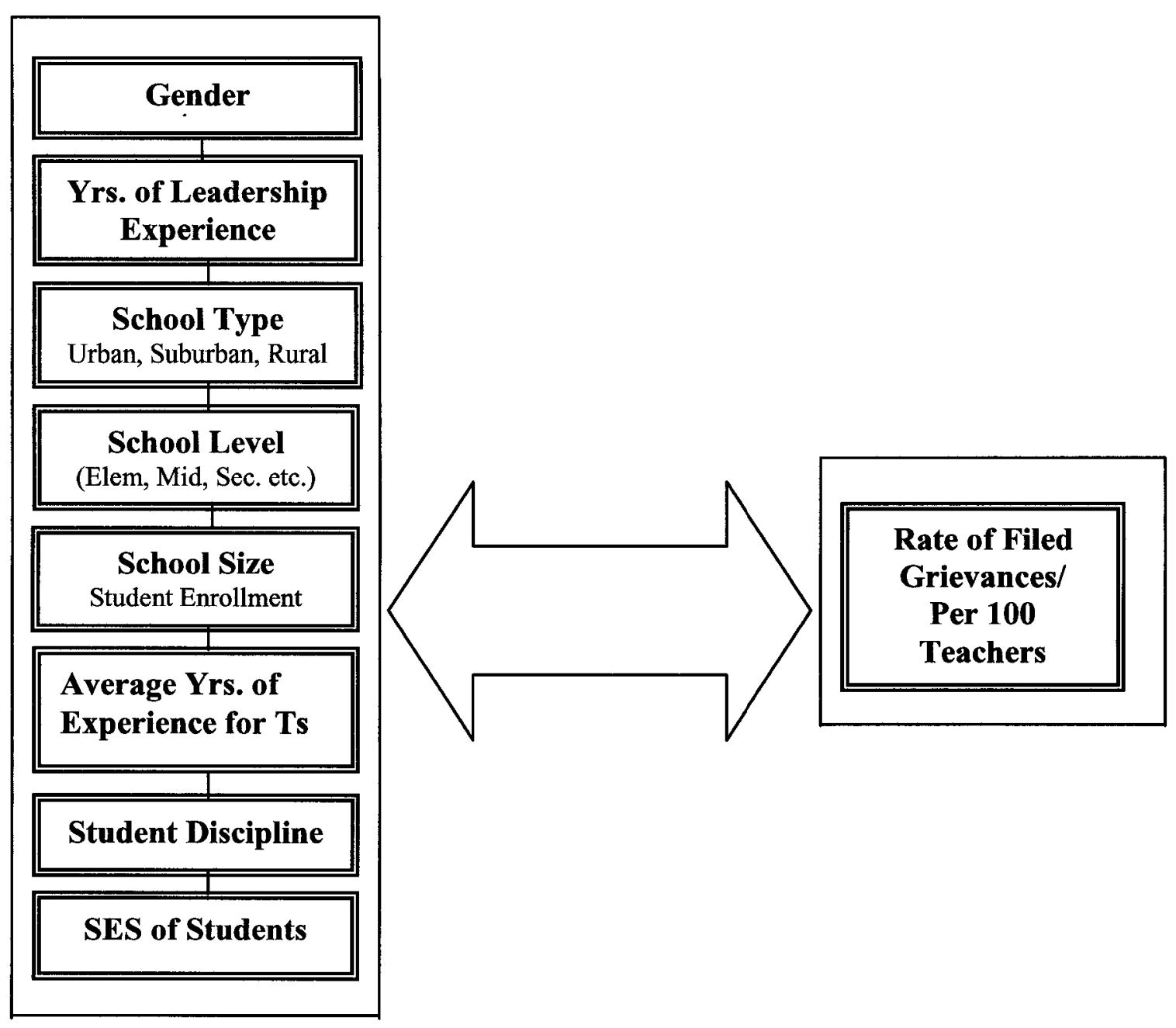

Figure 1: Basic demographic model

In the basic demographic model, (see fig. 3.1), there were originally eight independent variables. They were: Principal's Gender, Years of Leadership Experience for the Principal, School Type, School Level, School Size, Average Years of Experience for Teachers, Student Discipline, and Socio-Economic Status of Student Population (at school). The dependant variable represented one dimension of labour dispute-Number of Filed Grievances/Per 100 Teachers during the school years 2000-01 and 2001-02. In 
all of the hierarchical models, this variable was regressed on various subsets of independent variables described in detail in the next section.

Independent Variables and Measures: Demographics.

Gender is often chosen to be a demographic factor in research as it frequently has significant effects on the topic of investigation (Collard, 2001; Jantzi \& Leithwood, 1996; Mitchell, 1987; Pounders, 1996). The gender of the principal was included as an independent variable in this study because men and women might vary significantly in terms of leadership styles. They might also have distinct ways of handling conflict and dealing with disputes, which would affect the outcomes of the primary stage of dispute resolution. In all of the regression models, gender was operationalized as a dichotomous variable, with males coded with a one and females with a zero.

Years of Leadership Experience (YLE) referred to the number of years of leadership experience that the principal had in a unionized environment.

School Type was modeled as a dummy variable that indicated whether a school is located in an urban, suburban or rural area. The criterion to distinguish urban, suburban from rural schools was based on the proportion of rural population in the area where a school is located. The type of the school was reported by the participating principal. It served as a contextual variable since urban schools usually have characteristics distinct from rural schools. Three dummy variables were created in the following way with Suburban serving as the omitted variable:

Urban $=1$ if the school was urban, 0 otherwise;

Suburban $=1$ if the school was suburban, 0 otherwise;

Rural $=1$ if the school was rural, 0 otherwise. 
School Level (SL) was also modeled as a dummy variable for the demographic/leadership models. It indicated if a school was elementary, middle/junior high, secondary/senior high, elementary/junior high (K-9) or elementary/senior high (K12), or alternate/education center. Four dummy variables were used to model these five categories, with alternate/education center serving as the omitted variable.

Elementary $=1$, if the school was elementary, 0 otherwise;

Middle/Junior High $=1$, if the school was either a middle or junior high school, 0 otherwise;

Secondary/Senior High =1, if the school was either secondary or senior high, 0 otherwise;

K-9/K-12 School $=1$, if the school was either an elementary/junior high or an elementary/senior high school, 0 otherwise.

School Size stood for the student population. It was denoted by the average student enrollment for the school years 2000-2001 and 2001-2002.

Average Years of Experience for Teachers was another contextual variable that reflected school characteristics. This continuous variable was computed as the average years of teaching experience for all teachers on staff in the school.

Student Discipline was considered as an important indicator that reflected the school culture and learning environment. It was first denoted by the average rate of office referrals per school during the school years 2000-01 and 2001-02. In the preliminary analysis, it showed a consistently negative, though not yet statistically significant, effect on the number of filed grievance per one hundred teachers in all the basic and core models. Therefore, a group of dummy variables was created to further investigate the 
negative effects the single variable Student Discipline on the dependent variable and to compare the goodness of fit among a series of the regression models. Four dummy variables were constructed based on the quartiles of the single variable Student Discipline and were used for all the further regression analyses.

Ave. Office Referral Dummy $1=1$ if Ave. Off. Referrals $=0-48, \quad 0$ otherwise; Ave. Office Referral Dummy $2=1$ if Ave. Off. Referrals $=49-91,0$ otherwise; Ave. Office Referral Dummy $3=1$ if Ave. Off. Referrals = 92-225, 0 otherwise; Ave. Office Referral Dummy $4=1$ if Ave. Off. Referrals $>226,0$ otherwise. Ave. Office Referral Dummy 4 was omitted from the models as a reference variable.

Socio-Economic Status of Student Population (SES) was a continuous variable that was denoted by the percentage of families with income below $\$ 30,000$ in the school catchment area based on the 1996 census. The data was drawn from the most updated individual school's profile provided by the B.C. Ministry of Education, and it served as an indicator of the student population's SES.

Dependent Variable.

Rate of Filed Grievance Per 100 Teachers was the dependent variable in all the models, which provided objective information on the average unit rate of filed grievances per one hundred teachers. The rate of filed grievance per teacher was obtained by dividing the number of filed grievances by the total number of teachers at a school in the 2000-01 and 2002-02 school years respectively, then the sum of the two units were divided by 2 . The acquired score was then multiplied by 100 , which yielded the data for filed grievances per one hundred teachers. Instead of the Rate of Filed Grievance Per Teacher, this Rate of Filed Grievance Per 100 Teachers was used as the dependent 
variable since this scaling made it easier to display and interpret the results of regression analysis.

Usually, teachers' grievances arise as a result of their disagreement or complaints on administrative practice in the implementation of the collective agreement at a school site. Therefore, the investigation of this particular variable was conducted at the school level. Generally speaking, the number of teachers in a school is decided by two major factors: school size (based on student general enrollment) and revenue (including special funding such as special education and aboriginal education). By taking the rate of filed grievances per one hundred teachers as the unit, this figure provided a fair and equal measure for comparisons among schools, because both school size and revenue had been controlled for in this single continuous measure.

School Demographic/Leadership Model.

At the school level, school principals generally play a key role in dealing with labour relations. Their leadership style impacts their decision making process, communication mode, and human relations, which in turn may affect the actual rate of filed grievances. Therefore, Leadership Styles and Quality of Leadership were added in the second stage of the hierarchical regression analysis. As a result, the impact of leadership style on the rate of filed teacher grievances at the school level could be examined after controlling for demographic and school characteristics. 


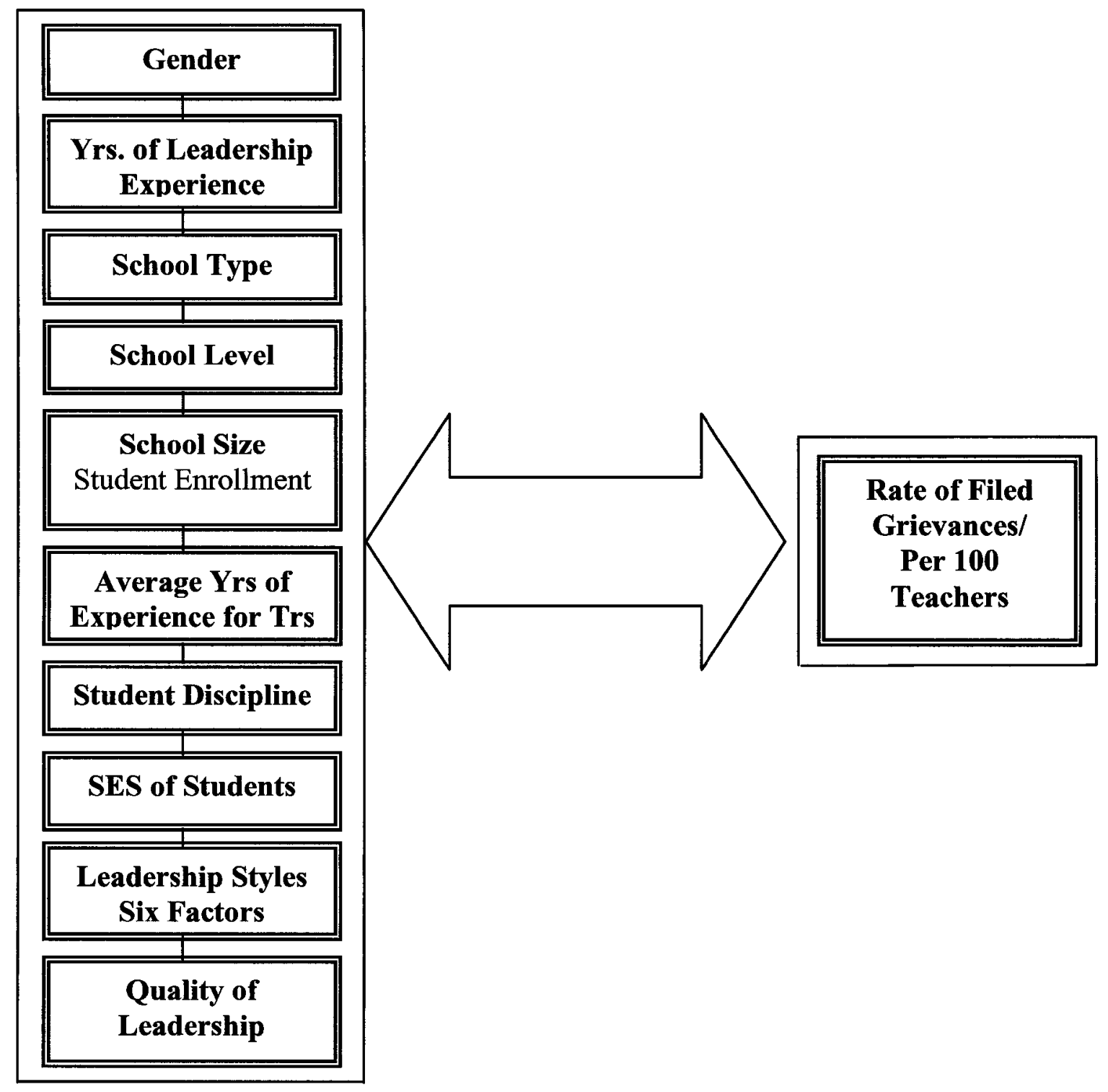

Figure 2: School demographic/leadership model

Additional Independent Variables and Measures: Leadership.

As shown in Figure 3.2, Leadership Style Factors were a group of independent variables added to the school demographic model in the second stage of analysis. Leadership is defined as a relationship between the leader and followers by Kouzes and Posner (1993). They believe that any study on leadership must focus on the dynamics of 
this relationship. "If there is no underlying need for the relationship, then there is no need for leaders." (Kouzes \& Posner, 1993, p. 1)

Given this perspective, it is highly likely that the leadership style of school principals would account for a significant portion of variation in filed teacher grievances, a measure of labour dispute at school level. Based on a conceptualization derived from several theories of leadership (Bass, 1990; Burns, 1978; Leithwood, 1995) and empirical evidence (Bass, 1997; Bass \& Avolio, 1996, 1999; Hartog, et al., 1997; Jantzi \& Leithwood, 1996; Leithwood, 1992a, 1992b; Lewis, 1993), Transformational and Transactional styles of leadership were selected initially to represent measures of leadership style for this study. Transformational leadership has been empirically shown to effect a collaborative, professional school culture, and school improvement (Leithwood, 1992a, 1992b). More importantly, transformational leadership alters power relationships between leaders and followers through empowerment, mutual aspirations, and shared values. (Backner, 1990; Leithwood, 1992b). As discussed before, the Multifactor Leadership Questionnaire, Leader Form 5X -Short, developed by Bass and Avolio (1995), was used to measure these specific leadership style variables.

The Transformational Leadership variables originally encompassed five dimensions: idealized attributes, idealized behaviors, inspirational motivation, intellectual stimulation, and individualized consideration. There were four types of leadership behaviours for each dimension (sample survey item for idealized behavior: "I talk about my most important values and beliefs"), and each behaviour was rated on a 4point-Likert frequency scale ranging from not at all ( 0 points) to frequently, if not always (4 points). According to the MLQ 5X scoring key (Bass \& Avolio, 2000), the maximum 
total score for each dimension was $16(4+4+4+4=16)$ - the sum of the highest possible scores for 4 types of leadership behaviours in each dimension. The average score for the items on each scale was then obtained by dividing the total score for each dimension by the number of types of the leadership behaviours that made up the dimension, e.g., $(16 / 4=4)$, which gave a maximum of 4 points for each scale.

Transactional Leadership was considered complementary to transformational leadership. In the 1995 MLQ test manual, transactional leadership comprised three dimensions (scales) with 12 types of leader behaviours: contingent reward, active management-by-exception, and passive management-by-exception (sample survey item for contingent reward: "I provide others with assistance in exchange for their efforts"). The same Likert scale of 4 points each was used for rating the frequency of leader behaviours.

Nevertheless, after numerous studies done on validity and reliability of leadership factors using MLQ 5X, Bass and Avolio (2000) recommended a six-factor model as it provided a more optimal fit than other alternative models (Avolio et. al., 1999). Due to the high intercorrelations found among idealized attributes, idealized behaviors, inspirational motivation (Avolio et. al., 1999; Bass \& Avolio, 2000), the three were merged into a single factor-Charisma/Inspirational. In addition, passive management by exception correlated positively and highly with laissez-faire leadership scale, which represented avoidant non-leadership. Each of these scales also correlated negatively with all the other factors. Therefore, another higher order factor Passive/Avoidant was constructed. As a result, the six-factor model included Charisma/Inspirational, Intellectual Stimulation, Individual Consideration, Contingent Reward, Active 
Management-by-Exception, and Passive/Avoidant. They were claimed to be conceptually and empirically distinct with proven discriminant validity (Bass \& Avolio, 2000, Howell \& Avolio, 1993).

When Jantzi and Leithwood (1996) adapted models of transformational leadership in non-educational contexts for schools, they used six separate dimensions of transformational leadership practice rather than a single leadership variable. In addition, Bass cautioned the inappropriateness of combining three dimensions of transactional leadership into one variable, indicating that "transactional leadership is complex. Contingent reward correlates higher with transformational scores than with other transactional scores; active and passive management by exception are independent of each other. Passive management by exception correlates with laissez-faire leadership. The two form a passive leadership factor" (Bass, personal communication, 2003). Therefore, after the preliminary regression analysis, which yielded insignificant results with two single Transformational and Transactional leadership variables, Bass's and Avolio's six-factor model was adopted for this study instead of the original design with only Transformational vs. Transactional. Again, each scale yielded a maximum of 4 points. The measurement indicated the intensity or the level of each set of leadership behaviour a school principal believed to display.

Quality of Leadership was a variable that measures the effectiveness, commitment and satisfaction of leadership. It supplied information about the outcomes of a leader's leadership style. According to Avolio et al. (1995), the quality of leadership measures were highly correlated with transformational leadership scales, positively correlated with transactional leadership style but less so than with the transformational leadership scales. 
Quality of Leadership contained three scales: 3 items for extra effort, 4 items for effectiveness and 2 items for satisfaction. Each item was rated on a 4-point-Likert frequency scale ranging from not at all (0) to frequently, if not always (4). It gave a maximum total of 12 points, which was the sum of the 3 scales' scores (e.g., $4+4+4=12$ ). The average score was then used for each school principal in the unrestricted schoolbased model.

\section{Hypotheses}

In order to address the first research question, "Why do some schools have fewer teacher grievances filed than other schools in the British Columbia?" two null hypotheses and corresponding alternative hypotheses were raised for the demographic and leadership models. It was expected that the null hypothesis would be rejected on the condition that there was statistically significant relationship between school principals' leadership styles and labour dispute in terms of filed teacher grievances at schools when controlling for school demographic and characteristic factors. In other words, it was hypothesized that different leadership styles accounted for some of the variation in the rate of grievances filed per one hundred teachers. For instance, transformational leadership may tend to create collaborative relationships between teachers and administrators and thus help to reduce tension and improve working relationship (Ristow, 1999). Specifically, the basic hypotheses for the demographic and leadership models are as follows:

$\mathbf{H}_{\mathbf{0}}$ 1: There is no statistically significant relationship between principals' leadership styles and filed teacher grievances at schools. 
$\mathbf{H}_{\mathbf{a}} 1$ : Leadership styles (as measured by 6 factors of transformational, transactional and laissez-faire leadership) have at least one non-zero effect on the measure of labour dispute at schools.

$\mathbf{H}_{0}$ 2: For other variables included in the study (such as gender, years of leadership experience, average years of experience for teachers, school type, school level, school size, student discipline and SES of student population), no statistically significant relationship exists between them and the rate of grievances filed per one hundred teachers at schools.

$\mathbf{H}_{\mathbf{a}}$ 2: There is at least one non-zero relationship between the demographic and contextual variables and rate of filed grievance per one hundred teachers at schools.

To test these two sets of hypotheses, a minimum confidence level of .05 was used for tests of significance so as to reduce the probability of a type 1 error.

Methods of Analysis

Hierarchical multiple regression analysis was used to analyze the data collected for the study after descriptive statistics were examined for all of the model's variables. The reason to employ the techniques of hierarchical multiple regression was twofold. First, it allows researchers to estimate the effect that each particular independent variable has on the dependent variable. Second, it allows the researcher to decompose the variation in the model's dependent variable into the general categories (demographics and leadership). And finally, it provides researchers with several goodness of fit measures that describe how much of the variation in the model's dependent variable was actually explained. 
For these reasons, hierarchical regression analyses were conducted in a series of models, including a series of unrestricted and restricted models ${ }^{4}$. First, the school demographic model was regressed against the dependent variable, average rate of filed grievances per one hundred teachers. After a final demographic model was arrived at through the deletion of variables that were statistically insignificant and theoretically unimportant, a second set of models was estimated that included leadership variables as well. The same procedure was repeated to arrive at a core or final demographic and leadership model. The goodness of fit for the design was tested by indices such as $R^{2}$ (the least-squares criterion), and adjusted $R^{2} . T$ scores and $F$-values were used to evaluate the statistical relevance of the independent variables that were included in the design. However, before this estimation procedure was used, a preliminary analysis was conducted that suggested that the student discipline variable could be more effectively modeled as a series of dummy variables. As a result, the models were strengthened and the goodness of fit increased.

The correction procedure employed to deal with missing values was done to exclude any observations that may have missing data in regression analyses. It appeared that the missing data occurred randomly due to unavailability of the information, such as record of office referrals and student SES (percentage of family income less than $\$ 30,000$ ), or questions either irrelevant or hard to respond (such as MLQ items) for certain participants. As such, any individual or school missing data was dropped from the regression analysis if the analysis required the use of the variable with the missing data.

\footnotetext{
${ }^{4}$ An unrestricted model is the one that contains all the independent variables used in the analysis. When an independent variable or a group of independent variables is removed from the unrestricted model, the model is then considered as a restricted model. The strategy is used to test statistical significance of the removed variable or set of variables on the dependent variable through the use of F-test.
} 
Unfortunately, since the cases with missing values were dropped from the regression analyses, the results were not as precise as they would be with the complete data.

\section{Summary}

In this section, a full discussion on the research design and methodology used for the study was provided, including an explanation of the data collecting procedure and the research models. The three components of the survey instruments were described in detail. In addition, independent and dependent variables selected for the two types of models were defined with specific measures. Finally, the reasons why hierarchical multiple regression was chosen as the statistical tool for the study were given, and the procedures to analyze data were explained. 
CHAPTER IV

\section{DISCUSSION AND INTERPRETATION OF THE FINDINGS}

Introduction

In this chapter, the researcher will report and discuss the results of the hierarchical multiple regression analyses from a series of models developed to identify correlates of grievances in the British Columbia public school system. First, the procedures used to gather the data will be reported, and the classification and measurement of all variables used in the school models will be presented in a table format. Second, the sample demographics will be depicted in detail with descriptive statistics for all the independent and dependent variables. Third, the results of the hierarchical multiple regression analyses will be presented in two stages of model development - construction of the core demographic model and the final model including both demographic measures and leadership variables. Thereafter, unrestricted and restricted models will be estimated within the hierarchical regression analysis structure. The restricted models will be sequentially compared with the unrestricted model using both $t$ and F-tests to evaluate the effects of each group of independent variables and test the corresponding null hypotheses. Finally, the general and specific effects of the independent variables on filed 
teachers' grievance will be discussed so as to answer the related research questions for the study.

\section{Survey Procedures}

As described in the previous chapter, participants for this study were public school principals in British Columbia. A sample of 460 school principals that met the sampling criteria was first selected randomly from each district, based on the information provided in the Public \& Independent Schools Book: A Complete Listing of British Columbia Schools and Principals.

The survey was posted on the website of the School District No. 36 (Surrey) with a password protection. Along with the website address and the password emailed to all the 460 participants on December 20,2002, a cover letter was provided, explaining the purpose and significance of the study, and ensuring the confidentiality of the respondent. Participants were given the opportunity to either submit their completed survey online or print the survey from the web and return their responses via fax. A sample of the cover letter is attached in Appendix A.

Two follow-up email messages were sent two, and three weeks after the initial invitation. Sixty responses out of 460 selected participants were received which gave only a 13 percent return rate. Since this sample size was still low for conducting a meaningful analysis, permission was obtained to send the invitation letter to all the school principals who belonged to the B.C. Principals and Vice-Principals Association (the BCPVPA), by using the BCPVPA's email mailing list. The BCPVPA had graciously granted its support to the study prior to the first survey. As a result, a total of 160 principals, which constituted approximately 10 percent of the population, returned their 
completed surveys either on the Internet or via fax over a time interval of one month and a half.

Among the 160 responses, however, there were a number of incomplete surveys. The correction procedure employed to deal with the missing values was to exclude any observations that had missing data required for the regression analyses. This way, the number of observations entered into each of the models in the hierarchical multiple regression analysis remained the same, although in the construction of some of the restricted models sample sizes were slightly larger. As a result, 103 valid cases were selected out of the 160 responses for use in the final stage of regression analysis.

\section{Classification and Measurement of All Variables}

The survey collected the data for the majority of the independent and dependant variables for the study. The data for two of the independent variables, i.e. School Size and Student SES, were gathered from the electronic school profiles found at the web site of the B.C. Ministry of Education. Since a detailed discussion was provided in Chapter III for all the independent and dependent variables, Table 1 provides a brief overview of the variables used in the data analysis, and is followed by a description of the sample characteristics and a full discussion of the findings. 
Table 1. Classification and measurement of all the variables in hierarchical models

\begin{tabular}{|c|c|c|}
\hline Variable Name & Dependent Variable & Measurement \\
\hline $\begin{array}{l}\text { Average grievances/ } \\
\text { per } 100 \text { teachers }\end{array}$ & Continuous & $\begin{array}{l}\text { rate of filed grievances per } 100 \\
\text { teachers for the } 2000-01 \& 2001-02\end{array}$ \\
\hline \multicolumn{3}{|c|}{ Demographic Variables } \\
\hline Gender & Dichotomous & male $=1$, female $=0$ \\
\hline Leadership Experience & Continuous & $\begin{array}{l}\text { total number of years in unionized } \\
\text { environment }\end{array}$ \\
\hline Urban School & Dichotomous & urban schools $=1$, else $=0$ \\
\hline Suburban School & Dichotomous & suburban schools $=1$, else $=0$ \\
\hline Rural School & Dichotomous & rural schools $=1$, else $=0$ \\
\hline Elementary & Dichotomous & elementary $=1$, else $=0$ \\
\hline Middle/Junior High & Dichotomous & middle/junior high $=1$, else $=0$ \\
\hline Secondary/Senior High & Dichotomous & secondary/senior high $=1$, else $=0$ \\
\hline $\mathrm{K}-9 / \mathrm{K}-12$ & Dichotomous & $\mathrm{K}-9$ or $\mathrm{K}-12=1$, else $=0$ \\
\hline Alternate/Education Centre & Dichotomous & alternate/education center $=1$, else $=0$ \\
\hline School Size & Continuous & $\begin{array}{l}\text { average of student enrollment in } \\
2000-01 \& 2001-02\end{array}$ \\
\hline Teachers' Teaching & Continuous & average years of total teaching \\
\hline Experience & & $\begin{array}{l}\text { experience of all teachers at the } \\
\text { school }\end{array}$ \\
\hline Student Discipline Dummy 1 & Dichotomous & $\begin{array}{l}\text { average office referrals for } 2000-01 \\
\& \text { 2001-02: 0-48=1, else }=0\end{array}$ \\
\hline Student Discipline Dummy 2 & Dichotomous & $\begin{array}{l}\text { average office referrals for } 2000-01 \\
\& 2001-02: 49=91, \text { else }=0\end{array}$ \\
\hline Student Discipline Dummy 3 & Dichotomous & $\begin{array}{l}\text { average office referrals for } 2000-01 \\
\& 2001-02: 92-225=1 \text {, else }=0\end{array}$ \\
\hline Student Discipline Dummy 4 & Dichotomous & $\begin{array}{l}\text { average office referrals for } 2000-01 \\
\& 2001-02: 226 \& \text { up }=1 \text {, else }=0\end{array}$ \\
\hline Student SES & Continuous & $\begin{array}{l}\text { percentage of families with income } \\
\text { below } \$ 30,000 \text { at the school }\end{array}$ \\
\hline
\end{tabular}


Table 1 (con't)

\begin{tabular}{|c|c|c|}
\hline & Leadership Variables & \\
\hline Charisma/Inspirational & Continuous & $\begin{array}{l}\text { average score of } 3 \text { scales (idealized } \\
\text { behaviours, idealized attributes } \& \\
\text { inspirational motivation) from MLQ }\end{array}$ \\
\hline Intellectual Stimulation & Continuous & scale score from MLQ \\
\hline Individualized Consideration & Continuous & scale score from MLQ \\
\hline Contingent Reward & Continuous & scale score from MLQ \\
\hline Management by Exception & Continuous & scale score from MLQ \\
\hline Passive/Avoidant & Continuous & $\begin{array}{l}\text { average score of } 2 \text { scales (passive } \\
\text { management-by-exception \& laissez- } \\
\text { faire leadership) from MLQ }\end{array}$ \\
\hline Leadership Quality & Continuous & $\begin{array}{l}\text { average score of } 3 \text { scales } \\
\text { (effectiveness, extra effort \& } \\
\text { satisfaction) from MLQ }\end{array}$ \\
\hline
\end{tabular}

Sample Demographics

A sample of 160 school principals participated in the survey, constituting over 10 percent of the population of 1546 principals in the B.C. public school system. The following discussion on the sample demographics will demonstrate evidently that the sample matched up well with the characteristics of the population that it was drawn from. To assist in this comparison, Table 2 shows the descriptive statistics for all the dependent and independent variables included in the school-based models. A table that shows the frequency and valid percent of all the dummy variables created out of School Type, School Level, and Average Office Referrals can be found in Appendix C. 
Table 2. Means and standard deviations of all the variables

\begin{tabular}{lrll}
\hline Variable Names & Valid N & Mean & Std. Deviation \\
\hline $\begin{array}{l}\text { Rate of filed grievances } \\
\text { per 100 teachers for 2 years }\end{array}$ & 146 & 3 & 9 \\
Gender & 160 & 0.64 & .48 \\
Leadership Exp. & 159 & 13.19 & 6.66 \\
School Type (location) & 160 & 1.97 & 0.76 \\
School Level & 160 & 1.53 & 1.02 \\
School Size & 159 & 404.26 & 358.69 \\
(two years' average) & & & \\
Av. Yrs of Teaching Exp. & 160 & 15.80 & 5.43 \\
for Teachers & & & \\
Student Discipline-- & 112 & 229.79 & 531.64 \\
Av. Office Referrals & & & \\
Student SES & 148 & 28.20 & 8.48 \\
Charisma/Inspirational & 142 & 3.32 & 0.41 \\
Intellectual Stimulation & 156 & 3.27 & 0.45 \\
Individualized Consideration & 152 & 3.45 & 0.41 \\
Contingent Reward & 149 & 3.01 & 0.62 \\
Management by Exception & 152 & 1.31 & 0.85 \\
Passive/Avoidant & 149 & 0.63 & 0.47 \\
Leadership Quality & 148 & 3.25 & 0.44 \\
& & & \\
\hline & & & \\
\hline
\end{tabular}

Table 2 also shows that the sample was truly diverse in terms of personal and school demographics. Among 160 school principals, there were 103 males and 57 females. The female to male ratio, $57 / 103=0.55$, equals exactly the actual female to male ratio of the principals in the province, which was $551 / 995=0.55$, according to the B.C. Ministry of Education (2003). Their years of leadership experience varied from one to thirty-five with an average of 13.19 years. Nevertheless, because of the sample selection 
criteria used in this study, the principals with leadership experience of less than 2 years were automatically deleted from the regression analyses. Fortunately, only a couple of principals with less than 2 years' leadership experience returned their surveys when the second invitation was sent out to all the principals in the BCPVPA.

School levels included elementary, middle/junior high, secondary/senior high, K9 or K-12, and alternate/education centre. Approximately, seventy-six percent of the participating schools were elementary and slightly more than fourteen percent were secondary/senior high schools. The percentages fairly accurately reflected the percentage distribution of elementary (69\%) and secondary/senior high schools (16\%) in British Columbia. Of all the participating schools, more were located in urban $(27.5 \%)$ or suburban (42.5\%) than rural (30\%). There was also a diverse social economic status among school student populations. For example, the percentage of families with annual income less than $\$ 30,000$ varied from as low as 6.7 percent for some schools to as high as 60.9 percent for others across the province. The average years of teaching experience for teachers at each school ranged from 2 to 28 years with a mean of 15.80 years.

The school principals' leadership styles were also varied, shown by the ranges and means of their leadership factor scores, as displayed in Table 2. The scores for Charisma/Inspirational Leadership ranged from a low of 1.92 to a high of 4.0 , which was the theoretical maximum score. The mean of 3.32 indicated the second highest score of the six leadership factors. This suggests that Charisma/Inspirational Leadership was one of the dominant leadership styles among many principals. The most dominant leadership style that many principals showed was apparently Individualized Consideration (mean = 3.45, the highest among the six factors). Passive/Avoidant was the least chosen 
leadership style, as the scores ranged from zero to 2.38 with a mean of .63. The largest variation occurred in Management by Exception-Active, where some principals scored zero and others scored as high as 3.50 . Its mean score of 1.31 , however, showed that Management by Exception-Active was another leadership style that was infrequently practiced among principals.

As indicated in Chapter III, the average number of filed grievances per one hundred teachers during the two school years (2000-2001 and 2001-2002) at each school site was used as the dependent variable in the regression models. For the school year 2000-2001, out of 160 school principals, 116 reported no grievances filed related to their school sites, accounting for 72.5 percent of the total cases, whereas 31 had grievances filed, accounting for 19.4 percent; the range of filed grievances for individual schools ranged from 1 to 30 , and eighteen principals reported more than one grievances filed in the year. Thirteen principals, 8.1 percent of the participants, did not provide the grievance information for the following reasons: a few new schools were not established yet until the 2001-2002 school year; some principals were working in different schools in the 2000-2001 school year; and a few felt uncomfortable in giving out their grievance information. These cases were excluded from the regression models and further data analysis.

For the school year 2001-2002, 109 out of 160 school principals reported no filed grievances, accounting for 68.13 percent of all the participants, whereas 45 of them had grievances filed against them or related to their school sites, accounting for 28.13 percent of the total cases. Seventeen principals had multiple grievances filed. The range of the filed grievances for individual schools was from 1 to 30 , which was similar to the 
previous school year. There were $6(3.75 \%)$ principals that failed to provide the grievance data.

The average filed grievances per teacher at a school for the two school years was first calculated to form the dependent variable. After the number of teachers from each school was factored in, there were altogether 146 valid cases out of the 160 , with 14 missing values $(8.75 \%)$. This was because out of six cases with missing values for the school year 2001-2002, one case had a missing value for the grievance data only for that school year, but not for the year before. Therefore, the total number of the observations with missing values for the two school years increased to 14. Ninety-six schools had zero filed teacher grievances, making up 60 percent of the total cases. Fifty schools had filed grievances - the number ranged from 0.01 to 0.88 per teacher, representing 31.25 percent of the sample. However, because the numbers of filed grievances per teacher were too small to yield any estimated coefficients that could be appropriately displayed or interpreted, the rate of filed grievances per teacher was scaled up to the rate of filed grievances per one hundred teachers by multiplying grievance rate per teacher by 100 .

Findings from the Hierarchical Regression Analyses

There were two stages of model development in the hierarchical regression analyses. In the first stage, preliminary hierarchical regression analysis was done to develop a core model with all the demographic variables that were either statistically significant or theoretically important. In the same manner, in the second stage leadership variables were added to the core demographic model to produce a final model for discussion purposes. In this section, the results of these regression analyses will be presented at both the preliminary and final stages in a series of models. Throughout the 
analyses, a series of restricted models will also be used to test for the existence of various effects, and inferential statistics used to identify the statistically significant variables. After this has been done, the discussion will then center on the significant variables themselves.

School Models: Demographics

Preliminary multiple regression analysis was conducted on several demographic models to examine the statistical significance and relevancy of select independent variables and to test the goodness of fit of the models. The basic demographic model, Model 1, evolved from the preliminary regression analysis with conversion of the single continuous variable, Student Discipline, into 4 dummy variables. As a single variable, Student Discipline had insignificant effects on the dependent variable in the original demographic model $(t=-.98$, and $p>.05)$. Results showed, however, that the use of dummy variables to measure various levels of Student Discipline — office referralsimproved the model with an increase in the number of included cases, and improvement in the adjusted $\mathrm{R}^{2}$ and the F-statistic. The use of dummy variables also resulted in a decrease in the standard error (see Table 3 in Appendix E), which increased the explained percentage of the variance in the dependent variable, Filed Grievances Per 100 Teachers, in Model 1. Table 3 shows how each independent variable in Model 1 affected the dependent variable as well as a summary of the relevant statistics. 
Table 3. Regression coefficients of independent variables for the basic demographic model, Model 1, (N=102)

\begin{tabular}{|c|c|c|c|c|}
\hline Variable Names & $\begin{array}{l}\text { Estimated } \\
\text { Coefficient }\end{array}$ & $\begin{array}{l}\text { Standard } \\
\text { Error }\end{array}$ & $\begin{array}{l}\text { Beta } \\
\text { Coefficient }\end{array}$ & t-Statistic \\
\hline (Constant) & -4.19 & 2.81 & & -1.49 \\
\hline Gender & -.06 & 1.01 & -.01 & -.06 \\
\hline Leadership Experience & .08 & .09 & .08 & .97 \\
\hline School Size & -.00 & .00 & .01 & .10 \\
\hline $\begin{array}{l}\text { Average Years of Teach } \\
\text { Experience for Teachers }\end{array}$ & $\begin{array}{ll}\text { hing } & \\
\mathrm{rs}^{2} & .02\end{array}$ & .09 & .02 & .18 \\
\hline $\begin{array}{l}\text { Student Discipline } \\
\text { Dummy } 1\end{array}$ & .65 & 1.40 & .04 & .46 \\
\hline $\begin{array}{l}\text { Student Discipline } \\
\text { Dummy } 2\end{array}$ & -.36 & 1.32 & -.02 & -.27 \\
\hline $\begin{array}{l}\text { Student Discipline } \\
\text { Dummy } 3\end{array}$ & 4.94 & 1.56 & .27 & $3.17^{* *}$ \\
\hline $\begin{array}{l}\text { Student SES (Family inc } \\
\text { less than } \$ 30 \mathrm{k} \text { per annun }\end{array}$ & $\begin{array}{l}\text { come } \\
\text { m) }\end{array}$ & .06 & .19 & $2.22^{*}$ \\
\hline Middle/Junior High & 2.96 & 2.55 & .09 & 1.16 \\
\hline Secondary/Senior High & .20 & 2.16 & .01 & .09 \\
\hline $\mathrm{K}-9$ or $\mathrm{K}-12$ & 17.72 & 2.36 & .62 & $7.50^{* * *}$ \\
\hline Rural Schools & .02 & 1.62 & .00 & .01 \\
\hline Urban Schools & .15 & 1.26 & .01 & .12 \\
\hline $\begin{array}{l}\text { R Square } \\
.52\end{array}$ & $\begin{array}{c}\text { djusted R Square } \\
.45\end{array}$ & \multicolumn{2}{|c|}{$\begin{array}{c}\text { Standard Error } \\
4.61\end{array}$} & $\begin{array}{l}\text { F Statistic } \\
7.30\end{array}$ \\
\hline
\end{tabular}

There were altogether 13 independent variables in this basic model, including three groups of dummy variables for School Level, School Type and Student Discipline. For each of the groups, one of the dummy variables was omitted from the regressions to serve as the reference variable against which the remaining effects could be evaluated. Note that Elementary was taken out from the model as a criterion dummy variable for 
School Level rather than Alternate/Education Centers. The latter had to be excluded from regression analysis because there were only four participants from alternate schools or education centers, with each one of them missing data that were required in the regression analyses. The results of regression analysis in Table 3 indicate that most of the independent variables had no statistically significant effects on filed teacher grievances among schools in this demographic model, except for the independent variable, SES of student population $(\mathrm{B}=.14, \mathrm{t}=2.22, \mathrm{p}<.05)$, Student Discipline Dummy 3 (with Average Office Referrals 92-225, $\mathrm{B}=4.94, \mathrm{t}=3.17, \mathrm{p}<.01$ ), and $K-9$ or $K-12$ Schools $(\mathrm{B}=17.72, \mathrm{t}=7.50, \mathrm{p}<.001)$.

Findings show that there were no gender differences among principals in the rate of filed grievances per one hundred teachers among schools. Another demographic factor, principals' Years of Leadership Experience, showed no significant effect on filed teacher grievances when the other independent variables were taken into account. The same was found to be true with three school demographic and contextual factors, Average Years of Teaching Experience for the Teachers, School Size or School Type (location).

However, students' socioeconomic status (denoted by the percent of families with incomes less than $\$ 30,000$ ) had a significant effect on the grievance rate. This finding means that schools that had higher percent of families with annual income less than $\$ 30,000$ appeared to have more grievances filed than those schools with a lower percent of low-income families. Specifically, a school with ten percent more low-income families would have approximately 1.4 percent more grievances filed per one hundred teachers than other schools. The variable with the strongest effect in the model, however, was $K-9$ or K-12 schools. When compared to its reference variable, Elementary Schools, K-9 or 
K-12 schools had approximately 18 more grievances filed per one hundred teachers. K-9 or K-12 schools also tended to have more filed teacher grievances than any other level of schools, holding other independent variables constant in the model. In contrast, elementary schools seemed to have the least filed teacher grievances among various levels of schools. Thus, findings show that it was School Level, not School Size or School Type (location), which played a significant role in accounting the rate of filed grievances.

Student discipline affected filed grievances only when office referral numbers were between 92 and 225. That suggests the principals who reported having between 92 to 225 office referrals seemed to have about 5 more grievances per one hundred teachers filed against them than schools with more office referrals, when all the other factors were taken into consideration.

Based on the results from several rounds of the preliminary regression analysis, a core demographic model, Model 2, was developed with the elimination of a few statistically insignificant variables from the basic model. They were two principals' demographic factors, Principal's Gender, Years of Leadership Experience for the Principal; and three school contextual/characteristic factors, School Type (a group of dummy variables including Urban, Suburban, and Rural Schools), School Size, and Average Years of Experience for Teachers. These variables had consistently shown no statistical significance on filed teacher grievances among schools. Fortunately, there was no existing literature suggesting that they were the determinants of filed teacher grievances; they were used in the preliminary model in an exploratory capacity only.

Once these independent variables were removed, the goodness of fit for the core demographic model, Model 2, proved to be better overall than that of Model 1, the basic 
demographic model (see Table 4). Although the $\mathrm{R}^{2}$ decreased slightly from .52 to .51 because of the deletion of the six independent variables, the adjusted $\mathrm{R}^{2}$ increased to .48 from .45, the F-score improved to 14.31 from 7.30 , and the standard error decreased to 4.47 from 4.61, suggesting that the core demographic model represents a real improvement in modeling accuracy.

Table 4. Regression coefficients of independent variables for the core demographic model, Model 2. ( $\mathrm{N}=103)$

\begin{tabular}{|c|c|c|c|c|}
\hline Variable Names & $\begin{array}{l}\text { Estimated } \\
\text { Coefficient }\end{array}$ & $\begin{array}{l}\text { Standard } \\
\text { Error }\end{array}$ & $\begin{array}{l}\text { Beta } \\
\text { Coefficient }\end{array}$ & t-Statistic \\
\hline (Constant) & -2.79 & .02 & & -1.64 \\
\hline $\begin{array}{l}\text { Student SES (Family in } \\
\text { less than } \$ 30 \mathrm{k} \text { per annu }\end{array}$ & $\begin{array}{l}\text { income } \\
\text { lum) }\end{array} .14$ & .05 & 19 & $2.59^{*}$ \\
\hline Middle/Junior High & 2.85 & 2.32 & .09 & 1.23 \\
\hline Secondary/Senior High & .24 & 1.36 & .01 & .18 \\
\hline $\mathrm{K}-9$ or $\mathrm{K}-12$ & 17.34 & 2.08 & .61 & $8.33^{* * *}$ \\
\hline $\begin{array}{l}\text { Student Discipline } \\
\text { Dummy } 1\end{array}$ & .64 & .01 & .04 & .52 \\
\hline $\begin{array}{l}\text { Student Discipline } \\
\text { Dummy } 2\end{array}$ & -.31 & 1.26 & -.02 & -.24 \\
\hline $\begin{array}{l}\text { Student Discipline } \\
\text { Dummy } 3\end{array}$ & 4.70 & 1.40 & .25 & $3.35^{* *}$ \\
\hline $\begin{array}{l}\text { R Square } \\
.51\end{array}$ & $\begin{array}{l}\text { Adjusted R Square } \\
.48\end{array}$ & \multicolumn{2}{|c|}{$\begin{array}{c}\text { Standard Error } \\
4.47\end{array}$} & $\begin{array}{l}\text { F Statistic } \\
14.31\end{array}$ \\
\hline
\end{tabular}

The estimated coefficients and accompanying statistics for Model 2 can be found in Table 4. Note that the valid cases for the core demographic model increased by one because six independent variables from Model 1 were removed. With fewer independent variables, there were fewer chances for an observation to have missing values. The number of the cases was 103 for all the core and final models. 
In the core demographic model, there were only 7 independent variables. Three of the seven independent variables, SES of Student Population, $(\mathrm{B}=.14, \mathrm{t}=2.59, \mathrm{p}<.05)$, Student Discipline Dummy 3 (with Average Office Referrals 92-225, $\mathrm{B}=4.70, \mathrm{t}=3.35, \mathrm{p}$ $<.01)$, and $K-9$ or $K-12$ Schools $(\mathrm{B}=17.34, \mathrm{t}=8.33, \mathrm{p}<.001)$, remained statistically significant at approximately the same level as in the basic model. The core demographic model explained nearly 48 percent of the variance in filed grievances per one hundred teachers among schools, and was used together with the leadership variables in the second stage in the hierarchical analysis.

\section{School Models: Demographics and Leadership Variables}

At the second stage of model development, the hierarchical multiple regression analysis was performed with the seven leadership variables added to the core demographic model. Subsequently, the insignificant leadership variables were removed from the model and a core demographic and core leadership model was established for the final regression analysis. The hierarchical demographic and leadership models were run to examine the estimated effect sizes of the significant demographic variables, to test the amount of variation in filed teacher grievances explained by the leadership variables, as well as to make a comparison between models in terms of the goodness of fit.

Core Demographic and Leadership Model.

When the six leadership variables and one leadership quality variable were added to the core demographic model, Model 2, the parameter estimates changed slightly and the key statistical values improved as well for the model (see Table 4 and Table 5). The following table provides the detailed estimated parameters in Model 3. 
Table 5. Regression coefficients of all independent variables for the core demographic and leadership model, Model 3, ( $\mathrm{N}=103)$

\begin{tabular}{|c|c|c|c|c|}
\hline Variable Names & $\begin{array}{l}\text { Estimated } \\
\text { Coefficient }\end{array}$ & $\begin{array}{l}\text { Standard } \\
\text { Error }\end{array}$ & $\begin{array}{l}\text { Beta } \\
\text { Coefficient }\end{array}$ & t-Statistic \\
\hline (Constant) & -8.12 & 4.82 & & -1.68 \\
\hline $\begin{array}{l}\text { Student SES (Family incom } \\
\text { less than } \$ 30 \text { k per annum) }\end{array}$ & .08 & .06 & .12 & 1.48 \\
\hline Middle/Junior High & 1.70 & 2.31 & .05 & .74 \\
\hline Secondary/Senior High & 1.04 & 1.51 & .06 & .69 \\
\hline $\mathrm{K}-9$ or $\mathrm{K}-12$ & 18.99 & 2.04 & .66 & $9.30 * * *$ \\
\hline $\begin{array}{l}\text { Student Discipline } \\
\text { Dummy } 1\end{array}$ & 1.19 & 1.22 & .08 & .98 \\
\hline $\begin{array}{l}\text { Student Discipline } \\
\text { Dummy } 2\end{array}$ & -.483 & 1.21 & -.03 & -.40 \\
\hline $\begin{array}{l}\text { Student Discipline } \\
\text { Dummy } 3\end{array}$ & 4.53 & 1.36 & .24 & $3.33 * *$ \\
\hline Charisma/Inspirational & 4.43 & 1.67 & .30 & $2.63^{*}$ \\
\hline Intellectual Stimulation & -.675 & 1.40 & -.05 & -.48 \\
\hline Individualized Consideratio & -2.84 & 1.38 & -.18 & $-2.06^{*}$ \\
\hline Contingent Reward & -.95 & .94 & -.09 & -1.01 \\
\hline Management by Exception & -.05 & .59 & -.01 & -.09 \\
\hline Passive/Avoidant & -.36 & 1.05 & -.03 & -.34 \\
\hline Leadership Quality & 2.17 & 1.55 & .16 & 1.40 \\
\hline $\begin{array}{l}\text { R Square } \\
.60\end{array}$ & $\begin{array}{l}\text { ted R Square } \\
.54\end{array}$ & $\begin{array}{r}\text { Standard. } \\
4.2\end{array}$ & & $\begin{array}{l}\text { F Statistic } \\
9.45\end{array}$ \\
\hline
\end{tabular}

First of all, the goodness of fit for Model 3, the core demographic and leadership model, improved over that of Model 2 with an increase in $\mathrm{R}^{2}$ from .51 to .60 . The standard error decreased from 4.47 in Model 2 to 4.21 in Model 3. Results show that the addition of the leadership variables increased the percentage of the variance in the dependent variable that Model 3 could explain. More specifically, Model 3 explained 54 
percent of the variance in the rate of filed grievances per one hundred teachers among schools, whereas Model 2, the core demographic model, explained 48 percent of the variance.

Secondly, two of the three significant demographic/contextual factors remained significant in Model 3 with similar effect sizes on the dependent variable as they were in other models. They were Student Discipline Dummy 3 (with Average Office Referrals 92225, $\mathrm{B}=4.70, \mathrm{t}=3.35, \mathrm{p}<.01$ in Model 2; $\mathrm{B}=4.53, \mathrm{t}=3.33, \mathrm{p}<.01$ in Model 3) and School Level Dummy $K-9$ or $K-12(\mathrm{~B}=17.34, \mathrm{t}=8.33, \mathrm{p}<.001$ in Model 2; $\mathrm{B}=18.99, \mathrm{t}$ $=9.30, \mathrm{p}<.001$ in Model 3). Meanwhile, the effect size of SES of Student Population $(\mathrm{B}=$ $.137, t=2.59, \mathrm{p}<.05$ in Model 2$)$ dropped in Model $3(\mathrm{~B}=.08)$ and became insignificant according to its $t$-statistic $(t=1.48, p>.05)$, when leadership factors were taken into the account. It was the only independent variable that showed an inconsistent effect on filed grievances in the process of hierarchical regression analysis.

Thirdly, two of the seven leadership factors in Model 3 appeared to be statistically significant in accounting for filed grievances per one hundred teachers among schools. They were Charisma/Inspirational $(\mathrm{B}=4.43, \mathrm{t}=2.61, \mathrm{p}<.05)$ and Individualized Consideration $(B=-2.84, t=-2.06, p<.05)$. Surprisingly, the directions of the effects of the two leadership variables were opposite, with Charisma/Inspirational showing a positive effect on the filing of teacher grievances and Individualized Consideration showing a negative effect on the filing of teacher grievances. This means that the stronger the Charisma/Inspirational leadership a principal believed that he/she had, the higher rate of filed teacher grievances was reported. To the contrary, the stronger the 
Individualized Consideration leadership a principal reported he/she had, the lower the rate of filed teacher grievances he/she seemed to have.

In addition, the other four leadership factors all showed a negative effect on the rate of filed grievances among schools, suggesting these leadership factors more or less influenced Filed Grievances Per 100 Teachers in the same direction as did Individualized Consideration. The magnitudes of the effects of the other four leadership factors, however, were too low to be statistically significant. In other words, how much leadership behaviour a school principal displayed in Intellectual Stimulation, Contingent Reward, Active Management by Exception or Passive/Avoidant did not account for any variation in the rate of filed grievances per one hundred teachers among schools.

Unexpectedly, Leadership Quality had a positive direction on its effect on the dependent variable, the same as Charisma/Inspirational, though it was not statistically significant. Leadership Quality was designed to measure leader effectiveness in motivating individuals and meeting organizational needs. It contained three scales: effectiveness, extra effort and satisfaction. School principals who try to achieve more by getting teachers to try harder and to do more than expected would not likely be seen as desirable from the perspective of the teacher unions, especially under the political circumstances of the 2001-2002 school year when the relationship between administrators and teachers' unions became very tense. The detailed discussion and interpretation of the significant effects of leadership factors will be provided in the final section of this chapter. 
In summary, the hierarchical regression analysis in Model 3 indicated that only a few school demographic/contextual factors and leadership factors had statistically significant effects on the dependent variable.

Core Demographic and Core Leadership Model.

In order to further increase the goodness of fit for the model within its theoretic framework, a final core demographic and core leadership model was developed by eliminating the insignificant or inappropriate leadership variables from Model 3. By doing so, the consistency of the effects of the predictors and the range of their effect sizes could also be measured.

It is important to note that the three demographic variables that were statistically significant in both the basic and core demographic models remained consistently significant in the core demographic and core leadership model. They were Student SES (B $=.12, \mathrm{t}=2.32, \mathrm{p}<.05$ ), Student Discipline Dummy 3 (with Average Office Referrals $92-225, \mathrm{~B}=4.22, \mathrm{t}=3.21, \mathrm{p}<.01)$, and School Level Dummy-K-9 or $K-12(\mathrm{~B}=18.44, \mathrm{t}$ $=9.41, \mathrm{p}<.001)$. It is interesting to note that the effect of Student SES that was not statistically significant when all the leadership variables were included in the model became significant again in Model 4. The two leadership variables that were statistically significant in the core demographic and leadership model were the only two out of the seven leadership factors that were included in Model 4. Both the direction and size of the effect of Individualized Consideration was similar in the two demographic and leadership models $(\mathrm{B}=-2.84, \mathrm{t}=-2.06, \mathrm{p}<.05$ in Model 3; $\mathrm{B}=-2.51, \mathrm{t}=-2.00, \mathrm{p}<.05$ in Model 4). Nevertheless, the magnitude of the effect of Charisma/Inspirational increased 
considerably in Model 4 whereas its direction remained the same $(B=4.43, t=2.61$, $\mathrm{p}<.05$ in Model 3; $\mathrm{B}=4.83, \mathrm{t}=4.06, \mathrm{p}<.001$ in Model 4).

Table 6. Regression coefficients of all independent variables for the core demographic and core leadership model, Model 4

\begin{tabular}{|c|c|c|c|c|}
\hline Variable Names & $\begin{array}{l}\text { Estimated } \\
\text { Coefficient }\end{array}$ & $\begin{array}{l}\text { Standard } \\
\text { Error }\end{array}$ & $\begin{array}{l}\text { Beta } \\
\text { Coefficient }\end{array}$ & t-Statistic \\
\hline (Constant) & -9.76 & 4.23 & & -2.31 \\
\hline \multicolumn{5}{|l|}{ Student SES (Family income } \\
\hline Middle/Junior High & 1.33 & 2.20 & .04 & .60 \\
\hline Secondary/Senior High & 1.07 & 1.29 & .06 & .83 \\
\hline $\mathrm{K}-9$ or $\mathrm{K}-12$ & 18.44 & 1.96 & .64 & $9.41 * * *$ \\
\hline \multicolumn{5}{|l|}{ Student Discipline } \\
\hline \multicolumn{5}{|l|}{ Student Discipline } \\
\hline \multicolumn{5}{|l|}{ Student Discipline } \\
\hline Charisma/Inspirational & 4.83 & 1.19 & .33 & $4.06 * * *$ \\
\hline \multicolumn{2}{|c|}{ Individualized Consideration -2.51} & 1.26 & -.16 & $-2.00^{*}$ \\
\hline $\begin{array}{l}\text { R Square } \\
.59\end{array}$ & $\begin{array}{l}\text { sted R Square } \\
.55\end{array}$ & $\begin{array}{r}\text { Standard } \\
4 .\end{array}$ & & $\begin{array}{l}\text { F Statistic } \\
14.65\end{array}$ \\
\hline
\end{tabular}

By and large, the modeling accuracy was improved for Model 4 , the final core demographic and core leadership model, with the adjusted $\mathrm{R}^{2}$ increased to .55 from .54 , the standard error dropped to 4.16 from 4.21 and the F-statistic raised to 14.65 from 9.45. Hypothesis Testing

The four models constructed for the hierarchical regression analyses also provided a framework for a series of F-tests designed to test the significance of groups of 
independent variables - specifically the demographic and leadership variables. As Hopkins et. al. (1987) indicate, "When the observed $F$-ratio is greater than the critical $F$ ratio, $H_{0}$ is rejected; when the computed $F$-ratio is less than the critical $F, H_{0}$ is not rejected and remains tenable" (p. 221). As such, this testing procedure will be followed in this section when used with a series of restricted and unrestricted models.

To test for the significance of the leadership variables, Model 3, the core demographic and leadership model was used as an unrestricted model and compared with the restricted Model 2 with all the leadership variables omitted.

Table 7. Comparison of the restricted and unrestricted hierarchical multiple regression models $(\mathrm{N}=103)$

\begin{tabular}{|c|c|c|c|c|c|}
\hline Model \# & $\mathrm{R}$ & $\mathrm{R}^{2}$ & Adjusted $\mathrm{R}^{2}$ & Standard Error & F-Statistic \\
\hline $\begin{array}{l}\text { Model } 3 \\
\text { (unrestricted) }\end{array}$ & .78 & .60 & .54 & 4.21 & $9.45^{* * *}$ \\
\hline $\begin{array}{l}\text { Model } 2 \\
\text { (restricted with }\end{array}$ & $\begin{array}{l}.72 \\
\text { aders }\end{array}$ & p) & .48 & 4.47 & $14.31^{* * *}$ \\
\hline
\end{tabular}

$* * * \mathrm{p}<.001$

As shown in Table 7, Model 3, the unrestricted model, explained 60 percent variation of filed teacher grievances among schools. Before the leadership variables entered into the model, the demographic/contextual variables in Model 2 explained 51 percent variation of the dependent variable. An F-test was conducted by comparing the $\mathrm{R}^{2}$ of the restricted Model 2 with the $\mathrm{R}^{2}$ of the unrestricted Model 3 according to the following formula:

$$
\frac{\left(\mathrm{R}^{2}{ }_{\mathrm{UR}}-\mathrm{R}_{\mathrm{R}}^{2}\right) / \mathrm{Q}}{\left(1-\mathrm{R}_{\mathrm{UR}}^{2}\right) /[(\mathrm{N}-(\mathrm{k}+1)]}
$$

where $R^{2}$ UR refers to the $R^{2}$ of the unrestricted model; $R^{2}{ }_{R}$ refers to the $R^{2}$ of the restricted model; "Q" stands for the number of the independent variables deleted to form the 
restricted model; "N" stands for the number of observations included in the analysis and " $\mathrm{k}$ " is the total number of variables entered into the unrestricted model. Substituting these values allows the relevant F-statistic to be calculated:

$$
\frac{\left(R_{U R}^{2}-R_{R}^{2}\right) / Q}{\left(1-R_{U R}^{2}\right) /[(N-(k+1)]}=\frac{(0.600-0.513) / 7}{(1-0.600) /[103-(14+1)]}=2.734
$$

Since 2.74 exceeds the critical value from the F-distribution of 2.25 , we can reject the first null hypothesis that suggests that the leadership variables have no effect on the dependent variable. These values along with the F-statistic from the demographics only regression are shown in Table 8.

Table 8. General effect by two groups of independent variables

\begin{tabular}{llcl}
\hline Categories of Variables & F-stats & F-critical value & Significant at 5\% level \\
\hline 1. Leadership Factors & $2.734^{*}$ & 2.25 & Yes \\
2. Demographic Factors & $7.30^{* * *}$ & 1.92 & Yes \\
\hline
\end{tabular}
${ }^{*} \mathrm{p}<.05,{ }^{* * *} \mathrm{p}<.001$

Given the above calculations, the first null hypothesis that there is no statistically significant relationship between principals' leadership styles and the measure of labour dispute at schools can be rejected, suggesting that there was a significant relationship between Leadership factors and the measure of labour dispute at schools.

Examining the F-statistic from Model 1 (7.30) also suggested that the demographic factors mattered since it exceeded the critical value of 1.92 . The same held true for Model 2, the core demographic, since its F-statistic (14.31) also exceeded the critical value. Clearly, demographic factors were statistically significant in explaining filed teacher grievances among schools. Therefore, the second null hypothesis was also rejected that for other variables included in the study (such as gender, years of leadership 
experience, average years of experience for teachers, school type, school level, school size, student discipline and SES of student population), no statistically significant relationships exist between them and the number of teacher grievances filed at schools. Nevertheless, only two leadership variables, Charisma/Inspirational and Individualized Consideration, and three categories of school demographic variables, School Level (K-9 or K-12), Student Discipline (Dummy 3), and SES of Student Population were found to be statistically significant in accounting for the variation of filed teacher grievances among schools based on their t-statistics. Surprisingly, rather than any of the Leadership factors, $K-9$ or $K-12$ turned out to be the most powerful independent variable in predicting the filed teacher grievances at schools.

\section{Discussion and Interpretation of the Findings}

The findings from all the basic and core hierarchical models have been statistically reported in reasonable details in the above sections. In this section, major findings will be further discussed in order to address the research question: Why do some schools have fewer grievances filed than other schools in the province? Meanwhile, the answer to the overarching research question — what is the relationship between measures of leadership style and labour dispute in British Columbia public schools?-will also be provided based on the results of the previously discussed analysis.

\section{Effects of School Demographic and Contextual Predictors}

Through the employment of hierarchical multiple regression analysis and the use of both $\mathrm{F}$ and $\mathrm{t}$-tests, three school demographic/contextual variables were found to be statistically significant predictors in accounting for the variation in filed grievances per 
one hundred teachers among schools. They are School Level (K-9 or K-12), Student Discipline (Dummy 3), and SES of Student Population.

School Level. Based on the t-statistic and the size of the estimated coefficient, it is apparent that the independent variable, $K-9$ or $K-12$ School was consistently the most powerful predictor out of all the independent variables. The positive signs for all three School Level coefficients indicated that all of the schools in the three remaining categories, Middle/Junior High, Secondary/Senior High, and K-9 or K-12, had higher rates of filed teacher grievances than Elementary Schools, although not all of these were significant in the final model. Of the four levels of B.C. public schools, K-9 or K-12 schools tended to have the highest rate of filed teacher grievances; specifically, K-9 or K12 schools had approximately 18 more grievances filed per one hundred teachers than elementary schools.

What interpretation can be drawn from the effects of $K-9$ or $K-12$ School then? First of all, it is interesting to note that there was a significant negative correlation $(r=-$ .18 ) between the K-9 or K-12 School Dummy and Average Years of Teaching Experience for Teachers. The absolute value for the $r$ was the highest among the various levels of schools. This suggests the teachers who worked in $K-9$ or $K-12$ schools were usually younger or had less teaching experience than the teachers who worked in other schools. In reality, they tend to be vulnerable to lay-offs when there is a budget cut, which in recent years has happened frequently in B.C. However, many young teachers prove themselves to be energetic, enthusiastic and actively involved in extra-curricular activities. School principals, parents and students find it hard to let them go. Therefore, it 
is assumed that there might be possibilities of the violation of a collective agreement in lay-off, recalling, hiring and posting provisions, which could result in a filed grievance.

Secondly, the positive and significant correlation coefficient with Rural Schools $(r=.31)$ indicated that K-9 or K-12 schools were mostly rural schools, covering large geographic areas. Rural Schools, though showing no statistical significance in the regression models when intervened by other factors, had a significant correlation with Filed Grievances Per 100 Teachers. Comparatively small student populations, which were implied by a negative correlation coefficient for School Size, caused the lack of resources for K-9 or K-12 schools, as B.C. public schools were funded according to student enrollment. This problem of lowered funding was normally compounded with the relatively high cost of bussing, low student/teacher ratios and the inefficiencies inherent in running small rural schools. As a result, there was less job security for teachers. The lay-offs and cut-backs usually hit harder and deeper for rural schools than for either urban or suburban schools. One of the rural school districts, for example, had to lay off teachers who had had more than 10 years of seniority, and afterwards recalled teachers only when positions were available. This lack of job stability caused more friction between teachers' unions and school/district administrations.

Thirdly, unlike any other levels of schools, $K-9$ or $K-12$ schools showed no significant relationship with any of the leadership variables. This result suggests that no particular pattern of leadership was prominent in K-9 or K-12 schools. Consequently, as a group, K-9 or K-12 school principals might not have the advantage of employing certain leadership skills, for instance-Individualized Consideration, to buffer or reduce the 
disadvantages and challenges faced by $K-9$ or $K-12$ schools in dealing with teachers' grievances.

Lastly, Elementary Schools, on the other end of School Level spectrum, had the lowest rate of filed grievances among all School Level categories. As indicated by the findings of previous research, elementary, middle, and secondary/senior high schools were different organizations with distinct school cultures and operations (Houts et al. 2001; Midgley et al., 1990). Elementary schools enjoyed many advantages as they were mostly smaller than middle or secondary schools, with students more closely bounded with their teachers within the homeroom configuration. Their organizational structure afforded more opportunities for principals to interact with teachers so as to establish positive relationship with fewer barriers (Houts et al. 2001). The correlation between Elementary Schools and leadership factors showed they were the least task oriented or bureaucratic among the four levels of schools. They also experienced fewer student discipline problems than other levels of schools (see Appendix D). K-9 or K-12 Schools, on the contrary, had the unique structures for elementary/junior high or elementary/senior high schools and also the challenges embedded in these structures. These challenges included different schedules for different grades, shared responsibilities between elementary and junior/senior high sections, higher requirements for coordination among staff, greater expectations of school principals' leadership, instructional and managerial expertise in both elementary and secondary curriculum and operation, greater possibility for staff and/or staff/administration conflicts due to differences in training, expertise, teaching methodology, and age span/differences of the student population. All these 
might have contributed negatively to the significant correlation between $K-9$ or $K-12$ Schools and Filed Grievances Per 100 Teachers.

Student Discipline Dummy 3 (Average Office Referrals: 92-225). Unexpectedly, Student Discipline Dummy 3 was the only Student Discipline dummy variable in the category that showed a positive significance $(B=4.22, t=3.21, p<.01)$ in the regression analysis. It seemed that the schools that reported office referrals between 90 to 225 appeared to have higher rate of filed grievances than the schools that reported otherwise. It is easy to understand why the comparatively high rate of office referrals would correlate to the higher rate of filed grievances. But why was the same not true with the office referrals greater than $225 ?$

The Pearson correlation coefficient $(r=.19)$ showed a significant correlation between Student Discipline Dummy 3 and Secondary/Senior High Schools, which suggests that most of the schools reported office referral rate within the 92-225 range were secondary or senior high schools. Even though the following estimates were not significant in their magnitudes, their negative direction provided additional information about Student Discipline Dummy 3. Those secondary/senior high schools that reported office referral rates within the $92-225$ range were mostly small to medium size schools with student enrollment less than 374 (the mean for School Size). Principals of these schools seemed to have relatively less leadership experience and their teachers had fewer years of teaching experience than other schools that reported lower office referral rates, particularly when compared with Student Discipline Dummy 4, office referrals more than 226 annually. Additional analysis was conducted afterwards for more information on Student Discipline Dummy 4. It showed that the schools reporting office referrals more 
than 226 annually were also mostly secondary/senior high schools $(r=.16)$ with large student population $(r=.29)$.

Small secondary/senior high schools were quite often not adequately funded due to lower student population and yet their same level of program and service requirements must be maintained. There might not be a vice-principal who could be in charge of student discipline in the school, or both principal and vice principal would have teaching loads due to smaller school size. Stress levels could be higher for both teachers and administrators than for their counterparts in larger secondary schools.

For large secondary/senior high schools, there were normally two to three viceprincipals, more school counsellors, and a better human resource support system in terms of student discipline. Therefore, even if the office referral rate was higher, there would be more professionals and administrators to share the responsibilities and carry the load, and thus would not result in higher rate of filed teacher grievances.

Office referral rate has been commonly used as an indicator of school culture and student learning environment. It reflects how well teachers handle the classroom management, how effective the school discipline system works, how supportive the school principal is to classroom teachers, and how the principal and teachers work together as a team. The high office referral rates imply the challenges of behaviour problem students, reactive rather than proactive discipline approach, and need in consistent school wide behaviour support system, which could result in high staff stress and low staff morale. A principal explained in response to the survey that the school's office referrals dropped from 300 in the 2000-2001 school year to 70 the next year because of the implementation of an Effective Behaviour Support (EBS) initiative at the 
school. In summary, Student Discipline had a significant effect on filed teacher grievances when there was a strain on both human and financial resources, and possibly a lack of an effective, school wide support system at work.

SES of Student Population. SES of Student Population was another school demographic/contextual variable that was statistically significant in predicting the filed teacher grievances at schools. Its estimated parameter $(\mathrm{B}=.14, \mathrm{t}=2.59, \mathrm{p}<.05)$ in the core demographic model, Model 2, indicated that when the percentage of families with income below $\$ 30,000$ increased, the rate of filed teacher grievances at a school tended to increase as well. Conversely, schools with families of higher income tended to have lower rate of filed teacher grievances.

As discussed in Chapter II, student socio-economic status (SES) has been historically regarded as the most significant predictor of student achievement at school (Galloway, 1994; Leithwood \& Jantzi, 1999; Ma, 2000). Students who come from lowincome families are more likely to have a deficit in early literacy, low family expectations and support in academic and social development. Many of them may have experienced physical, emotional, and psychological negligence and/or trauma, and have to survive with poor nutrition and scarce food. Due to their low economic status, many parents of those families were struggling for their own daily survival and there was little parental involvement either in their children's learning or school activities. All these factors may affect students' behaviour, performance and learning at school. Therefore, principals and teachers who work in the schools with high percent of students coming from low-income families require a high level of commitment to help those students improve their achievements. Principals and teachers are also facing greater challenges 
and definitely are under great pressure, as accountability has become a high priority for B.C. public schools. Challenges combined with pressure may explain why SES of Student Population showed a negative correlation with Average Years of Teaching Experience for Teachers $(r=-.19)$, suggesting that the teachers who worked in the schools with higher percentage of low-income families tended to be younger teachers with fewer years of teaching experience because of the relatively high turn-over in those schools. Thus, it is not hard to understand why there was a significant relationship between SES of Student Population and Filed Grievances Per 100 Teachers - greater challenges plus higher pressure led to higher stress and more conflicts.

However, the significant effect of SES of Student Population was reduced when all the leadership variables entered into the model $(B=.08, t=1.48, p>.05)$. In order to understand this change, it is necessary to explore the relationship between SES of Student Population and leadership variables. It had a significant positive correlation with Individualized Consideration $(r=.18)$ and a strong negative correlation with Passive/Avoidant $(r=-.28$ ). This finding showed, on the one hand, that principals who worked in the schools with higher percentage of students with low SES appeared to display a strong transformational style, focusing on understanding the needs of each follower and working continuously to get them to develop to their full potential. They tended to be more caring, supportive and facilitative. On the other hand, the same principals showed the least traits of laissez-faire style among all the leadership measures. The challenges they were facing at their schools would not allow them to take corrective action only when problems became serious or avoid making important decisions. At the same time, the significant positive correlation between SES of Student Population and 
Leadership Quality $(r=.31)$ indicated that these principals also reported to work harder and more effectively. This finding was consistent with the assertion made by Hallinger and Murphy (1986), and Leithwood and Jantzi (1999) that SES demonstrated to influence the form and style of principal leadership practices. Because Individualized Consideration showed a strong negative influence on Filed Grievances Per100 Teachers, its effect would have certainly reduced the magnitude of the variable, SES of Student Population.

In Model 4, the core demographic and core leadership model, however, SES of Student Population turned out to be significant again when five leadership variables were removed from the model. Its direction and magnitude $(\mathrm{B}=.12, \mathrm{t}=2.32, \mathrm{p}<.05)$ on the dependent variable was quite consistent after all. Therefore, the social economic status of students should still be considered as a significant predictor for the filed teacher grievances among schools

In summary, the discussion on the effects of school demographic and contextual predictors to this point has provided part of the answer to the first research question: why do some schools have fewer or no teacher grievances filed than other schools in the province? First of all, K-9 or K-12 schools tended to have more filed teacher grievances than other levels of schools simply because they had limited resources, lack of stability and job security for teaching staff, a demanding configuration and the challenges embedded in their organizational structures. In contrast, elementary schools were more likely to foster a positive people relationship with their advantageous configuration, people-oriented way of operation, and caring and supportive school culture, tended to resolve conflicts between administration and teachers informally and thus had fewer or 
no filed teacher grievances. Secondly, schools that had a high rate of office referrals, that lacked in human and financial resources, and that needed an effective positive behaviour support system as well as a safe and supportive school culture, had a higher rate of filed teacher grievances than other schools that had fewer student discipline problems. On the contrary, some large schools had even more office referrals, but they had a lower rate of filed teacher grievance because they had an adequate human resource support system, and possibly, a school wide behaviour support system in place. Finally, schools with a higher percentage of low income families were more likely to have a higher rate of filed teacher grievances as well, due to the great challenges and pressure that principals and teachers had to work under. Nevertheless, leadership factors seemed to reduce the undesirable effect of SES of Student Population to a certain extent. Effects of Leadership Predictors

Out of seven leadership variables, two turned out to be statistically significant predictors for Filed Grievances Per 100 Teachers. They were Charisma/Inspirational and Individualized Consideration, which are both dimensions of transformational leadership. However, it was unexpected to find that these two variables had just the opposite effects on Filed Grievances Per 100 Teachers. In addition, the magnitude of Charisma/Inspirational increased considerably in Model 4 when other five leadership variables were removed from the model, becoming the second most powerful predictor for the dependent variable in the model.

As discussed in Chapter II, transformational leadership has been considered the real mover and shaker of the world (Howell \& Avolio, 1993). Research results illustrating that transformational leadership makes a positive difference in organizational 
change and followers' performance are substantial and consistent in noneducational organizations (Bass \& Avolio, 2000; Howell \& Avolio; 1993, Leithwood, 1992a, 1992b). Although there have not been many studies done on transformational leadership in educational settings, significant relationships between transformational leadership and positive changes in teachers' instructional behavior, school improvement and student engagement have been thoroughly reported (Jantzi \& Leithwood, 1996; Leithwood, 1992a \& 1992b; Leithwood \& Jantzi, 1999). Contrary to the previous research, the finding from this study indicated a negative relationship between Charisma/Inspirational and labour dispute, denoted by a positive sign for filed teacher grievances. This suggests that when school principals showed more Charisma/Inspirational Leadership behaviour, there seemed to be higher rates of filed teacher grievances at their schools (specifically, about five more grievances filed per one hundred teachers). Detailed discussion and interpretation are as follows.

Charisma/Inspirational. This higher order factor has been considered as a construct essential to transformational leadership style (Howell \& Avolio, 1993). Transformational leaders with strong Charisma/Inspirational leadership traits are seen to display a high level of self-confidence, self-determination and a strong sense of purpose. They articulate their beliefs and values with enthusiasm and convey a compelling vision of the future. Abundant evidence is available showing that Charisma/Inspirational, as with the other transformational leadership factors, enhances motivation of the followers, and thus positively predicts high level of commitment and performance (Bass \& Avolio, 2000; Howell \& Avolio, 1993; Leithwood, 1992a, 1992b). It was somewhat surprising to find it otherwise in this study of labour dispute in B. C. public schools. However, several 
possibilities could help explain this discrepant result. First, the dependent variable for all the models in this study was Filed Grievances Per 100 Teachers. Its content and outcome were completely different from other dependent variables in the previously cited studies, such as unit performance, or organizational commitment of teachers. The variable, Filed Grievances Per 100 Teachers, was used in this study to provide a measure or index for labour dispute between school administration and teachers. A higher rate in Filed Grievances Per 100 Teachers reflected a higher rate of labour conflicts that failed to be resolved through informal channels. Therefore, based on findings from this study, the question is raised as to whether the leadership behaviour that fostered performance and commitment is effective in resolving labour conflicts at schools.

Second, the context for this study was different and complicated. The time period of this study covered two school years, the 2000-2001 and 2001-2002 academic years. In April, 2001, the public school employers (the BCPSEA) and the teachers' association (the BCTF) started the bargaining for a new provincial teachers' collective agreement. The process was full of obstacles and impasses. The second year of negotiation witnessed three stages of teachers' job actions across the province, and a new teachers' collective agreement imposed by the government through legislation. The relationship between administrators and teachers' associations deteriorated and the aftermath of the job actions affected school culture in many of public schools. The BCTF launched protests against the government for striping the existing teachers' contract and encouraged its members to restrain from volunteering in extra-curricular activities or any school committees (BCTF, $2002 b$ ). It was possible that the nature of the timing of this study in the context of intense labour tension meant that Charisma/Inspirational leadership was less influential than it 
might have been in a less emotional and political setting or time. If school principals promoted their beliefs and vision for schools with a focus on improving student achievements, they may have been seen by teachers as simply attempting to fulfill the government agenda to increase accountability. Teachers might perceive their school principals' effort to motivate teachers to a higher level of commitment and performance in the best interests of students as trying to put more pressure on teachers to do more with less. In this extraordinary time and context, Charisma/Inspirational leadership style might be somewhat counterproductive in regard to labour dispute.

Finally, other contextual factors that were not included in the model might have mitigated the impact of Charisma/Inspirational leadership on the rate of Filed Grievances Per 100 Teachers. Teachers' unions had a different mandate than did school and district administrations. One of the main purposes of the unions was to protect teachers' economic interests and working conditions. Charisma/Inspirational leadership might be seen as manipulative, and employer's/administrators' attempt to raise expectations of teachers, put more restrictions on teachers, and drive teachers to work harder with reduced budget and resources, beyond what was required by their collective agreement. Informal interviews conducted with teachers' unions' executives also revealed that the provincial political context played a huge role in the grievance procedures and dispute resolution. Some of the grievances were policy related provincial issues, such as class size and inclusion. Such grievances could not be resolved informally or even formally in the district. 
Given the politically and emotionally volatile context of the setting for the study, the finding of Charisma/Inspirational leadership might mirror a negative reaction from teachers' unions to the current political situation and labour relation in the province.

Individualized Consideration. Individualized Consideration was another factor out of the three constructs for transformational leadership that was found statistically significant in this study. As expected, its relationship with Filed Grievances Per 100 Teachers was negative. That means the more Individualized Consideration Leadership Style a school principal displayed, the less chance he or she had any filed grievances at the school. Transformational leaders with strong Individualized Consideration Leadership Style are regarded as those who are able to focus on understanding the different needs, abilities and aspirations of individuals, and help them develop their full potential through facilitating, coaching and supporting. Given the unusual time and context discussed above, it was not surprising to see that Individualized Consideration Leadership Style had a desirable negative effect on teachers' grievances. Within an extremely challenging context, Individualized Consideration was apparently the most appropriate and effective leadership style to work with teachers, who felt frustrated, astonished, angry and betrayed by the government's imposed settlement. Understanding individual teachers' feelings and needs might help maintain the respect and trust between school principals and teachers, especially during the negotiation process and job action periods. Teachers needed to be treated as individuals, not just as members of a group or team, as they worked in a school setting with much autonomy. Direct personal interaction and communication are crucial to any positive and healthy relationship, and particularly so with teaching professionals. Influencing teachers with a broader perspective and 
shared common interests would then assist in rebuilding the relationship after imposition of legislated contract, and refocusing teachers' professional commitment to improving student achievements. This finding supported the results of previous research that Individualized Consideration Leadership Style, one construct of transformational leadership, had a significant desirable effect on the dependent variables of various studies (Bass \& Avolio, 2000; Howell \& Avolio, 1993; Jantzi \& Leithwood, 1996; Leithwood, 1992a \& 1992b; Leithwood \& Jantzi, 1999).

The discussion on effects of leadership predictors has made it more clear why some schools have fewer or no teacher grievances filed than other schools in the province. At the same time, it depicted the relationship between measures of leadership style and labour dispute in the British Columbia public school system. In summary, school principals who displayed strong Charisma/Inspirational leadership, focusing on motivating teachers to a higher level of commitment to accomplish goals, but neglected teachers' individual needs, feelings or readiness, were most likely to have a higher rate of filed teacher grievances at their schools. In contrast, school principals who demonstrated Individualized Consideration leadership, showing respect for teachers' feelings and concern for their needs with understanding and support, and working continuously to get them to develop to their full potential, tended to have a lower (or zero) rate of filed teacher grievances at their schools. Part of these findings was the result of the unusual time and complicated political/labour context. Although leadership predictors did not have the strongest effects over and above all the other school contextual predictors as expected, they did moderate the effects of SES of Student Population in the study. 


\section{Summary}

This chapter reported the survey procedures and presented the results of data analyses and findings from the sample of 160 B.C. public school principals. The hierarchical regression analysis was conducted at two stages of model development. The results were examined and compared in a series of hierarchical multiple regression models that used both $\mathrm{t}$ and F-tests. The last section of the chapter provided a discussion and interpretation of the findings based on the data analyses.

The results provided by the hierarchical multiple regression analyses indicated that the core demographic and core leadership model (Model 4) used in this study explained 55 percent of the variance in filed teacher grievances among schools. The major findings of this study revealed that there was a strong statistical relationship between three demographic/contextual variables, School Level Dummy-K-9 or $K-12$ Schools, Student Discipline Dummy 3 (Average Office Referrals: 92-225), SES of Student Population and Filed Grievances Per 100 Teachers. There were approximately 18 more grievances filed per one hundred teachers in K-9 or K-12 schools than elementary schools. The principals who reported to have average office referrals between 92 to 225 seemed to have about 4 more grievances per one hundred teachers filed either against them than schools with more than 225 office referrals. A school with ten percent more low-income families would have approximately 1.2 percent more grievances filed per one hundred teachers than other schools.

Out of the seven leadership variables, Charisma/Inspirational leadership and Individualized Consideration leadership were the only two included in the final model, Model 4. When principals reported stronger Charisma/Inspirational leadership, they 
tended to have about 5 more grievances filed per one hundred teachers than other principals. In contrast, principals who showed higher Individualized Consideration would have approximately 3 fewer grievances filed per one hundred teachers than those who did not. Apparently, School Level Dummy-K-19 or K-12 Schools and Charisma/Inspirational leadership are the most powerful predictors of filed teacher grievances at schools, whereas Individualized Consideration leadership was the only significant predictor that can help reduce or avoid filed teacher grievances. 


\section{CHAPTER V \\ CONCLUSION AND RECOMMENDATIONS OF THE STUDY}

Introduction

The purpose of this study was to determine the relationship between measures of leadership style and a measure of labour dispute, filed grievances per 100 teachers, and to identify correlates of teacher grievances among public schools in British Columbia, Canada. The first chapter provided the background information with the introduction of the research questions. The review of the literature established a theoretic framework for the study by examining the existing literature related to leadership and labour relations, as well as labour relations specifically connected to the context of schools. The research design and methodology employed in the study were then outlined in Chapter Three, and Chapter Four reported the results of the data analysis and hypotheses testing.

The findings showed that two transformational leadership traits, Charisma/Inspirational and Individual Consideration, were statistically significant predictors of the rate of grievances filed per 100 teachers, with each trait having opposite effects on the number of filed grievances. Charisma/Inspirational leadership showed a direct relationship to the rate of grievances filed, while Individual Consideration showed an inverse relationship to the rate of grievances filed. Chapter 4 also gives a detailed discussion and interpretation on the findings within the context of the B.C. educational labour relations during the school years of 2000-2001 and 2001-2002. As such, this 
chapter will present an executive summary of the study in the form of four sections:

summary of the findings, theoretical implications, practical solutions, and recommendations for further studies.

\section{Summary of the Findings}

The study was designed to answer the overarching research question: What is the relationship between measures of leadership style and a measure of labour dispute in British Columbia public schools? Or put more specifically—why do some schools have fewer grievances filed per teacher than other schools in the province?

To answer these questions, data was gathered from two sources: electronic files of the B.C. Ministry of Education, and an internet survey of 160 public school principals in British Columbia, Canada. Hierarchical multiple regression analysis was used to analyze these data in a series of models at two stages. Results reveal that Contextual variables, $K$ 9 or K-12 Schools, Average Office Referrals, SES of Student Population, and Leadership variables, Charisma/Inspirational leadership and Individualized Consideration leadership were the major determinants of filed teacher grievances among B.C. public schools in 2000-2001 and 2001-2002. The most powerful predictor of filed grievances per 100 teachers at schools turned out to be the contextual variable, $K-9$ or $K-12$ Schools. Two factors of principals' leadership style had statistically significant effects on the rate of filed teacher grievances at schools, but the magnitudes of their effects were not as great as the contextual variable, $K-9$ or $K-12$ Schools.

Thus, schools that tended to have more filed teacher grievances than others were those 
- that were K-9 or K-12 schools; those that had a considerable number of office referrals and student discipline problems;

- those that had comparatively large percentage of their student population from lower income families; or

- those whose principals practiced more Charisma/Inspirational leadership rather than Individualized Consideration leadership.

In contrast, other conditions being equal, schools that had no or fewer filed teacher grievances were likely to be those that were

- elementary schools;

- had fewer student discipline problems, or had more than 225 office referrals yet developed strong positive behaviour support systems or programs with better human resources;

- had lower percentage of the student population of lower income families, or

- had principals who exercised Individualized Consideration leadership as a strong trait of their leadership style.

Only two measures of principals' leadership style, Charisma/Inspirational leadership and Individualized Consideration leadership, showed statistically significant effects on the number of filed teacher grievances at schools. Though both dimensions of these leadership styles fall into the transformational leadership measure, they exerted the opposite effects on filed teacher grievances in the context of the B.C. public educational labour relations. There were no statistically significant relationships found in this study between filed teacher grievances at schools, and other dimensions of transformational leadership, transactional leadership or laissez-faire leadership. 


\section{Theoretical Implications of the Findings}

Three important theoretical implications arise from the findings of this study. First, the results reveal that not all the dimensions of transformational leadership had desirable effects on filed teacher grievances in B.C. public schools. As a matter of fact, only one dimension of transformational leadership displayed by principals, Individualized Consideration leadership, appears to facilitate informal dispute resolution and help reduce filed teacher grievances. A most distinctive factor of transformational leadership, Charisma/Inspirational leadership, on the other hand, turned out to have a direct effect on labour dispute in the context of the B.C. public educational labour relations. This finding on transformational leadership is in disagreement with a claim by Leithwood, (1992b) that "the evidence on transformational educational leadership to be quite limited but uniformly positive" (p. 20). However, the finding aligns with the argument put forward by Goleman et. al. (2002) that visionary leadership style (comparable to Charisma/Inspirational leadership), although it is powerful and a natural part of transformational leaders, does not work in every situation. The finding supports and illustrates the perception that authentic transformational leaders switch between the various leadership styles depending on the situation they are in, just as golf pros picks the right golf club from the array of clubs based on the demands of the shot (Bass, 1977; Goleman et. al., 2002). Charisma/Inspirational leadership may be very effective in organizational change and improvement, but not necessarily in the context of tense educational labour relations, whereas Individualized Consideration leadership is the most appropriate leadership quality needed to rebuild trust between school administrators and teachers in the current political situation in the province of B.C.. 
The finding regarding leadership style also partially supports Fleishman's and Harris' claims (as cited in Fleishman, 1998) that the leadership pattern of supervisors with high structure and low consideration is related to high labour turnover, union grievances, worker absences and accidents, and low worker satisfaction; and that consideration is the dominant leadership factor to reduce union grievances and create favorable labour relations.

Secondly, principals' gender showed a significant correlation with measures of leadership style. Women principals displayed more Charisma/Inspirational style-traits of transformational leadership, whereas men principals more Active Management by Exception-transactional leadership. This result supports the findings regarding significant gender differences in leadership by other scholars (Chliwniak, 1997; Collard, 2001; Eagly \& Johson, 1990; Gilligan et al., 1988; Jantzi \& Leithwood, 1996; Miller, 1986; Shakeshaft, 1989; Tabin \& Coleman, 1993). Nevertheless, Jantzi and Leithwood (1996) caution researchers to take into account a wider array of other plausible variables when conducting leadership studies with a focus on gender, as gender may not be as critically important as some of the researchers claim. It was true that in this study, gender had no statistical significant effect on the dependent variable, filed teacher grievances, when examined together with other demographic and/or leadership variables.

A third theoretical implication of the study is related to the SES of Student Population. Student socio-economic status (SES) was found to be statistically significant in relation to the number of grievances filed. This finding is in agreement with many other researchers who have found socio-economic factors to be powerful predictors of student achievement and school culture (D’Agostino, 2000; Duffield, 1998; Galloway, 
1994; Leithwood \& Jantzi, 1999; Ma, 2000). At the same time, the significant correlation of SES of Student Population with leadership style also confirms the theory that that SES influences the form and style of principal leadership (Hallinger \& Murphy,1986;

Leithwood \& Jantzi,1999). Findings show that principals' leadership style intervened and reduced the effect of SES of Student Population on filed teacher grievances. This finding strengthens the assertion that SES per se does not explain the variation in dependent variables (Bulach \& Lunenberg, 1995; Edmonds \& Fredericksen, 1978), and that other factors, especially principal leadership and effectiveness, have important direct and interactive effects as well (Andrews \& Morefield, 1991; D’Agostino, 2000).

\section{Recommendations for Change in Practice and Policy}

The findings of the study provide the opportunity to propose solutions that might better meet the needs of teachers and educational leaders in the context of a politically charged education system in British Columbia, Canada. Therefore, based on the findings, the following changes in policy and practice are proposed.

First, the findings show that K-9 and K-12 schools are more likely to have higher numbers of filed teacher grievances than other levels of schools, especially elementary schools. The data further show that K-9 and K-12 schools are mostly small rural schools that have inadequate resources, higher operating expenses, less job security, and more challenges embedded in their structure. Therefore, in order to improve dispute resolution at the school level, one recommendation for change is for the government to develop a flexible funding formula to meet the unique needs of small rural K-9 and K-12 schools so that they will be able to offer the best possible educational services and programs to their students, as well as to provide higher job satisfaction to their teachers. A supporting 
recommendation is for the school districts and teachers' associations to work together to explore ways to provide better job security and stability to teachers working in K-9 and K-12 schools, because of the unique challenges facing K-9 and K-12 schools.

A second recommendation for change relates to the finding that student discipline and office referrals is correlated to a higher number of teacher grievances. It is recommended that teachers and administrators in all schools have a clear, school-wide behavioural support plan tailored to meet their specific needs. Classroom management and student discipline are always important factors in quality instruction and school culture. The number of office referrals is often an indicator of effectiveness of teachers' classroom management, the existence of a student discipline program, and principals' leadership. The higher the number of office referrals, the higher the stress level for both teachers and principals, and the higher the possibility for teachers to file grievances, especially when teacher stresses are compounded by inadequate human resources. Teaching students expected behaviors, using B.C. Social Responsibility Performance Standards to implement anti-bullying programs, and establishing school wide effective behavioural support systems (EBS) are recommendations that address the issue of high numbers of students being referred to the office. Many successful stories from B.C. schools have shown that these approaches are working in improving students' behaviour and discipline (the B.C. Safe Schools and Communities Centre, 2004).

A third recommendation for change is related to the finding that two factors of principals' leadership style had statistically significant effects on the number of filed teacher grievances at schools. It is recommended that administrators put forth a concerted effort to strengthen positive, working relationships with their teachers. In order 
to enhance informal dispute resolution and improve educational labour relations at school levels, principals need to develop full range of transformational leadership skills to strengthen their leadership capacity. In particular, the skill of Individualized Consideration needs to be developed. Fullan (2001) agrees with Goleman that "elements of different leadership styles must be learned and used in different situations (p. 46)". Charisma/Inspirational leadership, although showing an direct effect on the rate of filed teacher grievances, can be crucial when schools need clear vision and directions for change, and when schools implement their growth plans. However, when pressure, anxiety and stress are high, principals have to combine their leadership skills with emotional intelligence- to show teachers empathy, pay attention to individual needs, control damage, and repair rifts. In short, principals need to develop and strengthen positive relationships with teachers. Fullan (2001) emphasizes, “... successful strategies always involve relationships, relationships, relationships" (p.70). Without improving relationships, vision cannot be converted to internal commitment nor can initiated change be sustained. Charismatic principals need to understand teachers' perspectives and address their teachers' emotional needs. A leader who ignores people's dilemmas and distresses will lose the ability to influence and inspire them. In the meantime, if high standards of work performance and change are still demanded, results are likely to be counterproductive, causing additional negative emotions and resistance. Feelings of betrayal and distrust will erode mental ability and productivity. Therefore, principals need to utilize the power of emotional intelligence to be able to lead effectively in a context of change. 
A fourth recommendation for change is for districts to provide more leadership development opportunities and moral support to principals in K-9 and K-12 schools or schools with large, low-income populations. There is a higher need in these schools for principals to practice the emotional art and craft of leadership. At the same time, district leadership should establish a culture that encourages best practices of appropriate leadership styles for different situations.

A fifth and final recommendation for change, though not a direct implication from the results of this study, relates to teachers' associations. Based on the literature regarding the best practices in educational labour relations (Chase, 1997; Kerchner et al. 1997, 1998), it would be productive if school leaders and union leaders abandoned the adversarial educational labour relation model to search for new ways to fulfill their mandate and to join the forces with their educational partners in advancing the cause of quality public education.

During the two school years on which this study focused, 2000-2001 and 20012002, B.C. public school teachers who were members of teachers' associations, were under great pressure and stress, being torn between the dilemma of conforming with their professionalism for the best interests of students, and on the other hand supporting their unions' strong stands on their behalf. The need to present a united front in a clearly adversarial environment led the majority of teachers, voluntarily or involuntarily to chose to firmly back their union leadership. The unexpected finding in which Charisma/Inspirational leadership correlated with higher numbers of filed teacher grievances reflects this conflict between common purpose and collective self-interests. It 
is an indicator that teachers viewed charismatic/inspirational leadership as representative of "the other side".

Common to all parties involved in public education is the responsibility to serve the needs of students and their parents. Schools have to clarify their purpose and explore new ways to increase their accountability for the common good. Teachers are critical players in this cause. Teachers' union leaders will also have to reexamine their purpose, and identify the existing shared common grounds with administrators, employers, and the government. The old models of adversarial educational labour relations and unsuccessful provincial collective bargaining require change to transform the constant conflicts between the BCTF and the Ministry of Education. A fresh look at educational funding is needed to look for ways to address inadequacies. It is high time for all leaders in B.C. education to search for new ways to fulfill their mandate and to join the forces with their educational partners in advancing the cause of quality public education. Perhaps union leaders in particular have a wonderful opportunity to take the lead in restoring confidence to public education. The experience of their counterparts in the United States can lend some reference as to what is possible for our teachers' associations in B.C.

\section{Recommendations for Future Research}

Two suggestions for additional research are made in this section. One concerns a modification of the demographic/leadership model used in this study while the other is about investigating dispute resolution at the district level, rather than at the school level.

After numerous rounds of preliminary regression analyses, three categories of demographic/contextual variables (with two groups of dummy variables) and two leadership variables were selected for the final core demographic and core leadership 
model. This model, however, could be modified to further study the direct and indirect effects of the independent variables by using Communication as an intervening variable on labour dispute, since communication plays a crucial role in educational labour relations. In fact, all the people that were informally interviewed indicated that there seemed to be a strong correlation between communication and dispute resolution at all levels. As such, it may be appropriate to consider communication as a set of skills that can be separated from either demographic or leadership variables, hopefully resulting in an increase in the predictive power of the model.

The findings of this research strongly suggest that leadership and labour dispute require further study at the district level. As the result of this study, there is a better understanding of the relationship between measures of principals' leadership style and filed teacher grievances at school level. However, some closely related questions still remain unanswered. For example, after teachers' grievances are filed, what factors come into play in terms of resolving the grievance? Why are some school districts able to resolve grievances more effectively than other school districts in the British Columbia public school system? To answer these questions, a district model could be built on the basis of the hierarchical demographic/leadership model. All the variables could be measured at the district level instead of a school level, and the unit of analysis could be the district. Because grievance settlement involves two parties-district administration and teachers' unions, participants could be superintendents or assistant superintendents, directors of human resources or their designates, teachers' union presidents and executives/grievance officers. The purpose of such a study may be to further determine 
the relationship between measures of leadership style and labour dispute, and to identify correlates of dispute resolution among school districts. 


\section{References}

Anderson, J., Gunderson, M., \& Ponak, A. (1989). Union-management relations in Canada. Don Mills, Ontario: Addison-Wesley Publishers.

Andrews, R. \& Morefield, J. (1991). Effective leadership for effective urban schools. Education \& Urban Society, 23(3), 270-279.

Andrews, R., Soder, R., \& Jacoby, D. (1986, April). Student achievement, other in-school variables and principal behavior. Paper presented at the annual meeting of the American Educational Research Association, San Francisco, CA.

Arter, J. (1990). Assessing leadership and managerial behavior. Portland, Ore: Northwest Regional Educational Library.

Avolio, B., \& Bass, B. (1999). Re-examining the components of transformational and transactional leadership using the multifactor leadership questionnaire. Journal of Occupational \& Organizational Psychology, 72(4), 441-463.

Avolio, B., Bass, B. Jung, D. (1995). MLQ multifactor leadership questionnaire: Second edition, sampler set. Redwood City, CA: Mind Garden.

Bacharach, S., \& Mitchell, S. (1983). Labour relations in school systems: Attitudes toward teachers unions across school hierarchies. New York: State University of New York. (ERIC Document Reproduction Service No. ED243180)

Baron, R. M., \& Kenny, D. A. (1986). The moderator-mediator distinction in social psychological research: Conceptual, strategic, and statistical considerations. Journal of Personality and Social Psychology, 51, 1173-1182.

Bascia, N. (1991, April 3-7). Teachers' union and notions of professional community. Paper presented at the $75^{\text {th }}$ Annual Meeting of the American Educational Research Association, Chicago, Il. (ERIC Document Reproduction Service No. ED338601)

Bass, B. (1990). From transactional to transformational leadership: Learning to share the vision. Organizational Dynamics, 19(3), 19-32.

Bass, B. (1997). Does the transactional-transformational leadership paradigm transcend organizational and national boundaries? American Psychologist, 52(2), 130-137.

Bass, B. (1999). On the taming of charisma: A reply to Janice Beyer. Leadership Quarterly, 10(4), 541-554. 
Bass, B., \& Avolio, B. (1995). MLQ multifactor leadership questionnaire: Technical report. Redwood City, CA: Mind Garden.

Bass, B., \& Avolio, B. (1996). Transformational leadership, transactional leadership, and non-transactional leadership. Retrieved July 24, 2000 from the World Wide Web: http://205.231.84.242/demo/intro/tformlead.html\#behave.

Bass, B., \& Avolio, B. (2000). MLQ multifactor leadership questionnaire: Second edition, sampler set. Redwood City, CA: Mind Garden.

B.C. Safe Schools \& Communities Centre, (2004). Effective Behaviour Support (E.B.S). Retrieved January 18, 2004 from the World Wide Web: http://www.safeschools.gov.bc.ca/ebs.html.

Beckner, W. (1990). The why and how: Commitment and leadership. Bulletin: The Journal for Middle Level and High School Administrators, 74(529), 4-10.

Bell, C., \& Chase, S. (1995). Gender in the theory and practice of educational leadership. Journal for a Just \& Caring Education, 1(2), 200-223.

Bennis, W., \& Nanus, B. (1985). Leaders: strategies for taking charge. New York : HarperCollins.

Bennis, W., \& Nanus, B. (1997). Leaders: strategies for taking charge. New York : HarperBusiness.

Besson, Y. (1999). A comprehensive assessment of leadership using triangulation of qualitative and quantitative methods. Binghamton: State University of New York at Binghamton.

Birnbaum, R. (1980). Creative academic bargaining: Managing conflict in the unionized college and university. New York: Teachers College, Columbia University.

Blank, W., \& Weitzel, J. (1990). A test of the situational leadership theory. Personnel Psychology, 43(3), 579-598.

Bloodsworth, G. (1993). Rural education and the urban reform movement. Retrieved March 18, 2002 from the World Wide Web: http://ericae.net/ericdb/ED366590.htm

Bolman, L., \& Deal, T. (1997). Reframing organizations: Artistry, choice, and leadership. ( $2^{\text {nd }}$ Ed.). San Francisco: Jossey-Bass.

Booher, D. (1997). Gender benders. Retrieved February 24, 2002 from the World Wide Web: http://www.dianna-booher.com/booher. 
Boyd, W., \& Raffel, J. (1992).Urban education today. Journal of Planning Literature, 5(1), 22-28. Abstract from: http://ericae.net/ericdb/ED360445.htm

British Columbia Ministry of Education, (2003). British Columbia Ministry of Education Data Reports. Retrieved July 22, 2003 from the World Wide Web: http://www.bced.gov.bc.ca/k12datareports/other_reports.htm

British Columbia Ministry of Skills Development \& Labour, (2002). British Columbia Ministry of Skills Development \& Labour Annual Report 1999/2000. Retrieved May 6, 2001 from the World Wide Web: http://www.gov.bc.ca/sdl/annrep/ar9900/caab.htm

British Columbia Principals' \& Vice-Principals' Association, (1996). The Claim for Assets: 1988-1995. Retrieved May 6, 2001 from the World Wide Web: http:// www.bcpvpa.bc.ca/reports/claimhist.html.

British Columbia Public School Employers' Association, (2000). Administrative Manual of Provincial Teachers Collective Agreement. Retrieved May 23, 2000 from the World Wide Web: http://www.bcpsea.bc.ca/Database/Teacher/PAC_Admin_Manual/HTML_Manual

British Columbia Public School Employers' Association, (Summer, 2001). NewsLink. Retrieved March 22, 2002 from the World Wide Web: http://www.bcpsea.bc.ca/public/publications/newlink/2001 summer.pdf

British Columbia Teachers' Federation, (2000). School Staff Alert, September 18, 2000.

British Columbia Teachers' Federation, (2001a). History of BCTF. Retrieved July 10, 2001 from the World Wide Web: http://www.bctf.ca/About/MembersGuide/history.html

British Columbia Teachers' Federation, (2001b). Provincial bargaining themes and objectives. Teacher: Newsmagazine of the B.C. Teachers' Federation, 13(4), 4.

British Columbia Teachers' Federation, (2002). School Staff Alert, February 7, 2002.

British Columbia Teachers' Federation, (2002). School Staff Alert, February 26, 2002.

British Columbia Teachers' Federation, (2002). Teachers are furious after Liberals gut collective agreements and wipe out protections for quality of education. Retrieved January 28, 2002 from the World Wide Web: http://www.bctf.ca/NewsReleases/archive/2002/2002-01-25.html

Bulach, C. \& Lunenberg, F. (1995). The influence of the principal's leadership style on school climate and student achievement. People \& Education, 3(3), 333-351. 
Burnham, R. \& O’Neill, T. (March 18, 1991). British Columbia Report,_37-39.

Burns, J. (1978). Leadership. New York: Harper \& Row.

Cencirulo, R. S. (2001). The relationship between hardiness and job satisfaction in elementary school teachers. Dissertation Abstracts International, 62(4-A), 1279. (University Microfilms No. AAM9831984)

Chase, B. (1997). New unionism: Working together for children's sake. Speech made at the National Press Club.

Chliwniak, L. (1997). Higher Education Leadership: Analyzing the Gender Gap. ERIC Digest. Retrieved February 23, 2002 from the World Wide Web: http://www.ed.gov/databases/ERIC Digests/ed410846.html

Chudnovsky, D. (2001). A letter to members. Issue Alert, British Columbia Teachers' Federation, 13(2), 1-2.

Cole, C. (2000). Negotiating practices \& trends in the Abbotsford School District. Unpublished manuscript.

Collard, J. (2001). Leadership and Gender: An Australian Perspective. Educational Management \& Administration, 29(3), 343-55.

Collins, R. (2001, July 10). A new class of 'untouchables'? Teachers are better than this. The Chilliwack Progress. p. A8 \& A10.

Connors, E. K. \& Bashore-Smith, B. (1991). Employment dispute resolution in the United States: An overview. Canada -- United States Law Journal, 17, 319-336.

Cooper, B. (Ed.). (1992). Labour relations in education: An international perspective. Westport, Conn.: Greenwood.

Cornes, A. (2001). Standing on the shoulders of teachers who have gone before: Providing a legacy for those who follow us. Retrieved May 15, 2001 from the World Wide Web: http://www.bctf.bc.ca/Publications/ezine/Archive/200004/support/05Gaining-full.html.

Costley, D., \& Todd, R. (1991). Human relations in organizations. $\left(4^{\text {th }}\right.$ Ed.). New York: West Publishing Company.

D'Agostino, J. (2000). Instructional and social effects on students' longitudinal reading and mathematics achievements. School Effectiveness and school improvement, 11(2), 197-235. 
Daresh, J., \& Male, T. (2000). Crossing the border into leadership: Experiences of newly appointed British headteachers and American principals. Educational Management \& Administration, 28(1), 89-101.

Davis, S. (1998). Superintendents' perspectives on the involuntary departure of public school principals: The most frequent reasons why principals lose their jobs. Educational Administration Quarterly, 34(1), 58-91.

Dickinson, G. K. (2000). Job satisfaction and teacher union membership. Dissertation Abstracts International, 61(6-A), 2118. (University Microfilms No. AAI9975482)

Duffield, J. (1998). Learning experiences, effective schools and social context. Support for Learning, 13(1), 3-8. England: Blackwell Publishers Ltd.

Eagly, H., \& Johnson, T. (1990). Gender and leadership syle: A meta-analysis. Psychological Bulletin, 108, 233-256.

Eberts, R., \& Stone, J. (1986, April 16-20). The effects of teachers' unions on American education. Paper presented at the $70^{\text {th }}$ Annual Meeting of the American Educational Research Association, San Francisco, CA. (ERIC Document Reproduction Service No. ED018483)

Edmonds, R. (1979). Effective schools for the urban poor. Educational Leadership, 37(1), 15-27.

Ellis, M., \& Chartrand, J. (1999). Advanced quantitative methods in counselling psychology: Synthesis. Counseling Psychologist, 27(4), 579-678.

Fiedler, F. (1967). A theory of leadership effectiveness. New York: McGraw-Hill.

Fiedler, F., \& Chemers, M. (1974). Leadership and effective management. Glenview, Ill: Scott, Foresman.

Fleishman, A. (1998). Patterns of leadership behavior related to employee grievances and turnover: Some post hoc reflections. Personnel Psychology, 51(4), 825-35.

Fullan, M. (1998a). Education reform: Are we on the right track? Education Canada, 38(3), 4-7.

Fullan, M. (1998b). Leadership for the $21^{\text {st }}$ century: Breaking the bonds of dependency. Educational Leadership, 55(7), 6-10.

Fullan, M. (2001). Leading in a culture of change. San Francisco: Jossey-Bass. 
Galloway, F.J. (1994). The importance of high school related skills in the primary and secondary labour market. Unpublished doctoral dissertation. Harvard University.

Galvez, L.A. (1998). Job satisfaction and attitudes toward teaching of elementary regular education teachers who serve special needs and special education. Dissertation Abstracts International, 58(8-A), 3092. (University Microfilms No. AAM9806398)

Gamble, C. (2001). The impact of principal leadership style and gender on elementary school climate: A case study. Retrieved March 18, 2002 from the World Wide Web: http://wwwlib.umi.com/dissertations/fullcit/3011891.

Giles, T., \& Proudfoot, A. (1994). Educational Administration in Canada. Calgary, AB: Detselig Enterprises Ltd.

Gill, D. L. (1998). Gender and competitive motivation: From the recreation center to the Olympic arena. In Nebraska Symposium on Motivation, 45, 173-207. Lincoln, Neb.: University of Nebraska Press.

Gilligan, C., Ward, V., \& Taylor, M. (Eds) (1988). Mapping the moral domain: A contribution of women's thinking to psychological theory and education. Cambridge, Mass.: Harvard University Press.

Global B.C./the Canadian Press, (2002). Teachers take protest to the streets. Retrieved January 28, 2002 from the World Wide Web: http://www.canada.com/vancouver.

Goleman, D. (2000). Leadership that gets results. Harvard Business Review, 78(2), 7890.

Goleman, D., Boyatzis, R., \& McKee, A. (2002). Primal leadership: Realizing the power of emotional intelligence. Boston, Mass: Harvard Business School Press.

Grill, P.A. (1999). The relationship between leadership roles and job satisfaction among elementary teachers. Dissertation Abstracts International, 60(2-A), 340. (University Microfilms No. AAM9919571)

Gunderson, M., \& Riddle, C. (1993). Labour market economics. $\left(3^{\text {rd }}\right.$ ed.). Toronto: McGraw-Hill Ryerson.

Haar, C. (1996). The teachers' unions: Roadblocks to reform. American Enterprise, 7(5), 35-37.

Haar, C. (1998). The teachers' unions. Crisis in Education, Feb. 39-40. 
Hallinger, P., \& Murphy, J. (1986). The social context of effective schools. American Journal of Education, 94(3), 328-355.

Hartog, D. N., Muijen, J. J., \& Koopman, P. L. (1997). Transactional versus transformational leadership: An analysis of the MLQ. Journal of Occupational and Organizational Psychology, 70, 19-34.

Henderson, J. E. (1993, March 25-27). Quality through involvement: A school-based decision-making success story. Paper presented at the National Conference on Creating the Quality School, Oklahoma City, OK. (ERIC Document Reproduction Service No. ED359012).

Hendricks-Lee, M., \& Mooney, T. (1998). A teacher union's role in systemic educational reform. Contemporary Education, 69(4), 218-222.

Hersey, P. (1984). The situational leader. New York: Warner Books.

Hersey, P., and Blanchard, K. (1977). The management of organizational behavior. $\left(3^{\text {rd }}\right.$ Ed.) Upper Saddle River, NJ: Prentice Hall.

Herzberg, F. (1966). Work and the nature of man. Cleveland, Ohio: World.

Hopkins, K., Glass, G., \& Hopkins, B. (1987). Basic statistics for the behavioral sciences. Englewood Cliffs, NJ: Prentice-Hall.

House, R. (1971). A path-goal theory of leadership effectiveness. Administrative Science Quarterly, September, 321-332.

House, R. (1987). Retrospective comment. In Boone, L. \& Bowen, D. (Eds.) The great writings in management and organizational behavior. $\left(2^{\text {nd }}\right.$ Ed. $)$ New York: Random House.

Houts, P., Koerner, T., \& Krajewski, R. (2001). View from the bridge: A discussion. Theory into Practice, 18(1), 2-7.

Howell, J. M., \& Avolio, B. J. (1993). Transformational leadership, transactional leadership, locus of control, and support for innovation: Key predictors of consolidated business unit performance. Journal of Applied Psychology, 78(6), 891-902.

Hoyle, J., English, F., \& Steffy, B. (1990) Skills for successful school leaders. Arlington, VA: American Association of School Administrators.

Hoyle, J., English, F., \& Steffy, B. (1998) Skills for successful $21^{\text {st }}$ century school leaders. $\left(2^{\text {nd }}\right.$ Ed.) Arlington, VA: American Association of School Administrators. 
Hoyt, W., \& Melby, J. (1999). Dependability of measurement in counseling psychology: An introduction to generalizability theory. The Counseling Psychologist, 27(3), 325-352.

Jackson, D. (1990). Rural Education in Iowa: A Collection of Papers from the Invitational Rural Education Conference (Cedar Falls, IA, April 7-9, 1989). Retrieved March 18, 2002 from the World Wide Web: http://ericae.net/ericdb/ED329402.htm

Jantzi, D., \& Leithwood, K. (1996). Toward an explanation of variation in teachers' perceptions of transformational school leadership. Educational Administration Quarterly, 32(4), 512-538.

Johnson, Jr. A. C., Johnson, M. B., \& Buse, R. C. (1987). Econometrics: Basic and applied. New York: MaCmillan Publishing.

Johnson, S. (1990). Teachers at work: achieving success in our schools. New York: Basic Books, Inc.

Kerchner, C., \& Caufman, K (1993). Building the airplane while it's rolling down the runway. In Kerchner, C., \& Koppich, J. (Eds.). A Union of professionals: labour relations and educational reform. New York: Teachers College Press.

Kerchner, C., \& Koppich, J. (1993a). A Union of professionals: labour relations and educational reform. New York: Teachers College Press.

Kerchner, C., \& Koppich, J. (1993b). A Union of professionals: Unions and management in turbulent times. New York: Teachers College Press.

Kerchner, C., Koppich, J., \& Weeres, J. (1997). United mind workers: unions and teaching in the knowledge society. San Francisco: Jossey-Bass Publishers.

Kerchner, C., Koppich, J., \& Weeres, J. (1998). Taking charge of quality: how teachers and unions can revitalize schools: an introduction and companion to United mind workers. San Francisco: Jossey-Bass Publishers.

Kerlinger, F.N., \& Pedhazur, E.J. (1973). Multiple regression in behavioural research. New York: Holt, Rinehart and Winston.

Klecker, B. M., \& Loadman, W. E. (1999). Male elementary school teachers' ratings of job satisfaction by years of teaching experience. Education, 119(3), 504-603.

Klein, M. (1997). Helping teachers stick with it. American Demographics, 19(10), 39.

Knickerbocker, N. (2001). It's about time! Teacher: Newsmagazine of the B.C. Teachers' Federation, 13(6), 1. 
Knott, I. (1983-84). Collective bargaining can enhance quality of worklife. Community \& Junior College Journal, 54(4), 18-21.

Kotter, J. (1988). The leadership factor. New York: Free Press.

Kouzes, J., \& Posner, B. (1987). The leadership challenge: How to get extraordinary things done in organizations. San Francisco: Jossey-Bass.

Kouzes, J., \& Posner, B. (1993). Credibility: How leaders gain and lose it, why people demand it. San Francisco, CA: Jossey-Bass.

Lawton, S., Bedard, G., MacLellan, D. \& Li, X. (1999). Teachers' Unions in Canada. Calgary, AB: Detselig Enterprises.

Leithwood, K. (1992a). The move toward transformational leadership. Educational Leadership, 49(5), 8-12.

Leithwood, K. (1992b). Transformational leadership: Where does it stand? Education Digest, 58(3), 17-20.

Leithwood, K. (Ed.). (1995). Effective school district leadership: Transforming politics into education. Albany, N.Y.: State University of New York Press.

Leithwood, K., \& Jantzi. D. (1999). Transformational school leadership effects: A replication. School Effectiveness and School Improvement, 10(4), 451-479.

Lewis, A. (1993). Leadership styles. CA: American Association of School Administration.

Lieberman, M. (1997). The teachers unions: How the NEA and the AFT saborage reform and hold parents, students, teachers and taxpayers hostage to bureaucracy. New York: Free Press.

Liu, X., \& Kaplan, H. (1992). Decomposing the reciprocal relationships between academic achievement and general self-esteem. Youth \& Society, 24(2), 123-149.

Ma, X. (2000). Socioeconomic gaps in academic achievement within schools: Are they consistent across subject areas? Educational Research \& Evaluation, 6(4), 337356.

Manzer, R. (1994). Public schools and political ideas: Canadian educational policy in historical perspective. Toronto: University of Toronto Press.

Maple Ridge \& Pitt-Meadows School District No. 42, British Columbia. (2000, February 19). Elementary/Secondary School Principals. Vancouver Sun, p. E4. 
Maslow, A. (1954). Motivation and personality. New York: HarperCollins.

McAdams, R., \& Zinck, R. (1998). The power of the superintendent's leadership in shaping school district culture: Three case studies. ERS Spectrum, 16(4), 3-7.

McCabe, D. M. (1984, April 5-7). The labour-management communication process: Current developments in labour-management cooperation. In Ramsay, R. D. (Ed.) Professional communication in the modern world: Proceedings of the American Business Communication Association Southeast Convention. pp. 193-198. Hammond, LA. (ERIC Document Reproduction Service No. ED259359).

McGregor, D. (1960). The human side of enterprise. New York: McGraw-Hill.

McMahon, D. O. (1987, February 20-23). Getting to yes. Paper presented at the Annual Meeting of the American Association of School Administrators, New Orleans, LA. (ERIC Document Reproduction Service No. ED280188).

Midgley, C. (1990). A preliminary assessment of school level differences in instructional leadership, school culture, and student commitment. Urbana, IL: Illinois Univ., Beckman Inst. for Advanced Science and Technology (BBB28361).

Miller, J. (1986). Toward a new psychology of women. Boston: Beacon Press.

Mitchell, D. E. (1987). Labour relations in California as seen by members of the Association of California School Administrators: A survey conducted by the Far West Laboratory. San Francisco, CA: Far West Lab. for Educational Research and Development.

Mwamwenda, T. S. (1998). Teaching experience, job security, and job satisfaction among secondary school teachers in South Africa. Psychological Reports, 82_(1), 139-142.

Nelson, F., \& Rosen, M. (1996). Are teachers' unions hurting American education? A state-by-state analysis of the impact of collective bargaining among teachers on student performance. Milwaukee, Wisconsin. (ERIC Document Reproduction Service No. ED375496).

Novakowski, K. (2000). Gaining full bargaining rights. Retrieved May 15, 2001 from the World Wide Web: http://www.bctf.bc.ca/bargain/negotiations/rights/CornesArticle.html.

Ouchi, W. (1981). Theory Z. Reading, Mass.: Free Press.

Ouchi, W. (1982). Theory Z: How American business can meet the Japanese challenge. New York: Avon Publishing. 
Pejza, J. (1994, April 4-7). Lead, follow, or get out of the way: Transformational leadership. Paper prepared for the $91^{\text {st }}$ Annual Meeting of the National Catholic Educational Association, Anaheim, CA. (ERIC Document Reproduction Service No. ED018483).

Pindyck, R., \& Rubinfeld, D. (1981). Econometric models and economic forecasts. New York: McGraw-Hill.

Podgursky, M. (2002). The Teacher Unions (Book). Journal of Labour Research, 23(2), 333-334.

Pounders, B., Acker-Hocevar, M., \& Bishop, H. (1996, November 6-8). A study of superintendents' power and leadership styles as perceived by local teacher association representatives and secondary school principals in Alabama public school districts in Illinois. Paper presented at the Annual Meeting of the MidSouth Educational Research Association, Tuscaloosa, AL. (ERIC Document Reproduction Service No. ED 403642).

Pounder, D. (1999). Teacher teams: Exploring job characteristics and work-related outcomes of work group enhancement. Educational Administration Quarterly, 35(3), 317-349.

Pyrczak, F., \& Bruce, R. (2000). Writing empirical research reports: A basic guide for students of the social and behavioral sciences. ( $3^{\text {rd }}$ Ed.). Los Angles, CA: Pyrczak Publishing.

Quintana, S., \& Maxwe.., s. (1999). Implications of recent developments in structural equation modeling for counseling psychology. Counseling Psychologist, 27(4), 485-527.

Raham, H. (2000). Policy watch: Reinventing teacher contracts. Education AnalystSociety for the Advancement of Excellence in Education, (Fall) 4-5.

Reddin, W. (1970). Managerial effectiveness. New York: McGraw-Hill.

Rinehart, J. S., Short, P. M., Short, R. J., \& Eckley, M. (1998). Teacher empowerment and principal leadership: Understanding the influence process. Educational Administration Quarterly, 12 (Suppl. 34) 630-649.

Ristow, W. (1999). The impact of selected education labour relations decisions on the policies and practices of selected public school districts in Illionis. Chicago, IN: Loyola University of Chicago.

Rost, J. (1994, April). Moving from individual to relationship: A postindustrial paradigm of leadership. Paper presented at the $78^{\text {th }}$ Annual Meeting of the American Educational Research Association, New Orleans. 
Scott, K. (2001). Learning sex-equitable social skills. Theory into Practice, 25(4). 243249.

Seder, R. (1998). Organizing principal. Reason, 29(8), 52-56.

Sergiovanni, T. (1987). The theoretical basis for cultural leadership. In Schoenheit, M. \& Sheive, L. (Eds.) Leadership: Examining the elusive. Alexandria, VA: Association for Supervision and Curriculum Development.

Sergiovanni, T. (1992). Moral leadership: Getting to the heart of school improvement. San Francisco, CA: Jossey-Bass.

Sergiovanni, T. (1992). Why we should seek substitutes for leadership. Educational Leadership, 49(5), 41-45.

Sergiovanni, T. (1994). Organizations or communities? Changing the metaphor changes the theory. Educaitonal Administration Quarterly, 30(2), 214-217.

Sergiovanni, T., Burlingame, M., Coombs, F., \& Thurston, P. (1992). Educational governance and administration. ( $3^{\text {rd }}$ Ed.) Boston: Allyn and Bacon.

Shafritz, J., \& Ott, J. (1996). Classics of organization Theory. New York: Harcourt Brace College Publishers.

Shakeshaft, C. (1989). The gender gap in research in educational administration. Educational Administration Quarterly, 25, 324-337.

Shedd, J. (1990). Teacher unions: Participation through bargaining. In Bacharach, S. (Ed.). Education reform: Making sense of it all. Boston: Allyn and Bacon.

Smaller, H. (1998). Canadian teacher unions: A comparative perspective. Contemporary Education, 69(4), 223-227.

Smith, J. (2003, September 12). Edmonton's schools 'lead continent': US management professor's study praises city's schools for offering choice. National Post, p. E12.

Steinberg, E. (1990). Teachers unions handling tricky turns on the road to reform. School Administrator, 47(8), 26-28, 30-31.

Straut, D. (1998). Negotiations in interesting times: The impact of interest-based negotiations on educational labour relations. Boston: Cornell University.

Strube, M., \& Garcia, J. (1981). A meta-analytic investigation of Fiedler's contingency model of leadership effectiveness. Psychological Bulletin, 90, 307-321. 
Tabachnick, B., \& Fidell, L. (1996). Using multivariate statistics. (3 ${ }^{\text {rd }}$ ed.). New York: HarperCollins.

Tabin, Y., \& Coleman, P. (1993). From the dollhouse to the schoolhouse: The changing experience of women principals in British Columbia, 1980 to 1990. Canadian Journal of Educaiton, 18, 381-397.

Taylor, P. (1994). Educational leadership. Emergency Librarian, 21(3), p. 9-18.

Turvey, R. (1999). The effects of leadership style on the total quality management implementation. Rolla, MS: University of Missouri.

Uline, C., Miller, D., \& Tschannen-Moran, M. (1998). School effectiveness: The underlying dimensions. Educational Administration Quarterly, 34(4), 462-481.

Vroom, V., \& Yetton, P. (1973). Leadership and decision making. Pittsburgh: University of Pittsburgh Press.

Wang, Y. (1991). A demographic study: The case of functional literacy of non-English speaking immigrants in Canada. Unpublished master thesis, Memorial University of Newfoundland, St. John's, Newfoundland, Canada.

Wedge, C. (2001). Essential services designations under the Labour Relations Code. Teacher: Newsmagazine of the B.C. Teachers' Federation, 13(Special Iss.), 7.

Weiner, L. (1996). Teachers' unions and school reform: examining Margaret Haley's vision. Educational Foundation, 10(3), 85-96.

Worzbyt, J. \& Zook, T., (1992). Counselors who make a difference: Small schools and rural settings. School Counselor, 39(5), 344-350.

Yandle, S. (2001). Bargaining rights: The problems with essential services legislation. Retrieved May 15, 2001 from the World Wide Web: http://www.bctf.bc.ca/bargain/negotiations/rights/. 
Appendix A: Cover Letter the Principal Survey 


\section{Cover Letter for the Principal Survey}

\section{Dear Principal,}

I am currently a doctoral candidate at the University of San Diego and an elementary principal with Surrey School District. I am writing to invite you to participate in a survey for my dissertation-related research - The Relationship between Leadership Styles and Dispute Resolution in the British Columbia's Public School System. The purpose of this study is to determine the relationship between measures of leadership style and dispute resolution. Through your timely completion of the survey online, you will provide very important information about what effect leadership styles have on educational labour relations. With your valuable help, this study will yield findings that will foster positive labour relations between school administration and the teachers' associations. This relationship is so vital to the improvement of schools and students' learning.

Please take about 5 minutes to complete the survey by clicking: http://www.sd36.bc.ca/cgi-bin/rws2.pl?YWANG2 The required password for restrict access is yw2002. Please be assured that this research has gained support from the British Columbia Principal and Vice-Principals' Association, and all your responses will remain confidential. The reports prepared from these responses will protect the anonymity of the respondents. Submit the completed survey on line please, or print and fax it to the following number by February 15, 2003: (604) 581-9424, c/o Ms. Yanping Wang.

Should you have any questions or concerns about the survey or the study, please feel free to contact me via any of the following:

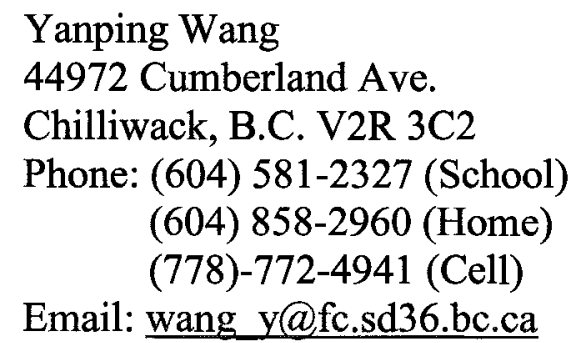

$\begin{array}{ll}\text { Or } & \text { Nian Zhu } \\ & \text { 44972 Cumberland Ave. } \\ \text { Chilliwack, B.C. V2R 3C2 } \\ \text { Phone: (604) 795-9226 (School) } \\ \text { (604) 858-2960 (Home) } \\ \text { (604) 793-5501 (Cell) } \\ \text { Email: nzhu98@yahoo.com }\end{array}$

If you would like a copy of the final report of this study, please provide me with your mailing address and I will be happy to send you a copy upon completion of the study.

Please accept my sincere thanks in advance for your support and contribution to this endeavor, especially at this special time of the year.

Sincerely yours,

Yanping Wang 
Appendix B: Principal Electronic Survey 


\section{Principal Electronic Survey}

All replies to this questionnaire will be confidential and any reports prepared from these replies will protect the anonymity of the respondent. If you have any questions or concerns about this questionnaire, please contact the researcher, Ms. Yanping Wang by email at wang_y@fc.sd36.bc.ca or telephone 604-581-2327 (school), 604-8585-2960 (home) or 778-772-4941 (cell).

What is your gender?

O Male

O Female

What district do you work in?

How many years have you worked in your current position?

$O$ Less than 2 years

$\mathrm{O}$ more than 2 years

How many years of leadership experience do you have in labour relations/dispute resolution in a unionized environment (including principalship)? (Type in.)

What school do you work in? (Type in.)

How would you characterize the location of your school?

O Rural O Suburban O Urban

From your knowledge of your school, please provide the following information (Type in):

- Number of office referrals (student discipline incidents) at your school in 20002001:

- Number of office referrals (student discipline incidents) at your school in 20012002:

- Number of teachers (FTE) at your school as of September 2000:

- Number of teachers (FTE) at your school as of September 2001:

- Average years of teaching experience for all teachers at your school:

- Number of filed teacher grievances related to your school in the 2000-2001 school year:

- Number of filed teacher grievances related to your school in the 2001-2002 school year: 
The following questions are sample questions from the MLQ Multifactor Leadership Questionnaire Leader Form (5x-Short) Copyright 1995 by Bernard $\mathrm{m}$. Bass and Bruce J. Avolio.

All rights reserved.

Not at all $0 \quad$ Once in a while $1 \quad$ Sometimes $2 \quad$ Fairly often 3 Frequently, if not always 4

I provide others with assistance in exchange for their efforts..............

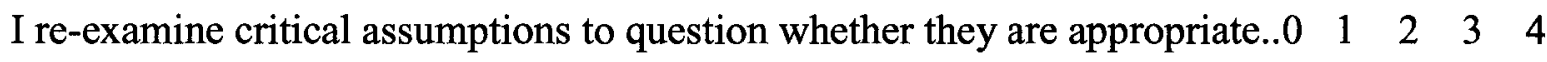

I talk enthusiastically about what needs to be accomplished...............

I focus attention on irregularities, mistakes, exceptions, and deviations

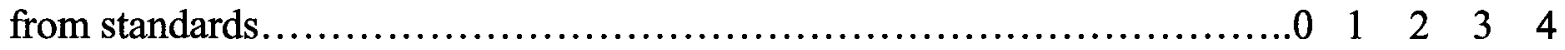

I avoid getting involved when important issues arise .......................

I specify the importance of having a strong sense of purpose.................

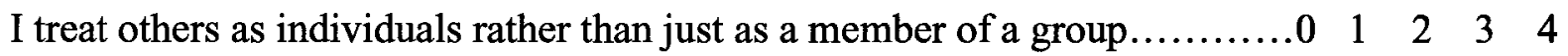


Appendix C: Frequency and Valid Percent of the Dummy Variables 
Table $\mathrm{C} 1$. Frequency and valid percentage of independent dummy variables

\begin{tabular}{|c|c|c|c|}
\hline I.V. Names & Dummies & Frequency & Valid Percent \\
\hline \multirow[t]{3}{*}{ 1. Gender** } & Male & 102 & $64.2 \%$ \\
\hline & Female* & 57 & $35.8 \%$ \\
\hline & Total & 159 & $100 \%$ \\
\hline \multirow[t]{6}{*}{ 2. School Level } & Elementary & 121 & $75.6 \%$ \\
\hline & Middle/Junior High & 7 & $4.4 \%$ \\
\hline & Secondary/Senior High & 23 & $14.4 \%$ \\
\hline & $\mathrm{K}-9$ or $\mathrm{K}-12$ & 5 & $3.1 \%$ \\
\hline & Alternate/Edu. Centre* & 4 & $2.5 \%$ \\
\hline & Total & 160 & $100 \%$ \\
\hline \multirow[t]{4}{*}{ 3. School Location } & Rural & 48 & $30 \%$ \\
\hline & Suburban* & 68 & $42.5 \%$ \\
\hline & Urban & 44 & $27.5 \%$ \\
\hline & Total & 160 & $100 \%$ \\
\hline \multirow[t]{5}{*}{ 4. Student Discipline } & Ave. Office Referrals 0-48 & 28 & $25 \%$ \\
\hline & Ave. Office Referrals 49-91 & 27 & $24.1 \%$ \\
\hline & Ave. Office Referrals $92-225$ & 29 & $25.9 \%$ \\
\hline & Ave. Office Referrals $>226^{*}$ & 28 & $25 \%$ \\
\hline & Total & 112 & $100 \%$ \\
\hline $\begin{aligned} \text { Note: } & * \text { Served as cr } \\
& \text { models. }\end{aligned}$ & iterion variables and were omi & tted as refer & e regression \\
\hline
\end{tabular}


Appendix D: Correlation Coefficients, Means, and Standard Deviations of All the Variables 
Table D1: Correlation coefficients, means, and standard deviations for all the variables $(\mathrm{N}=102)$

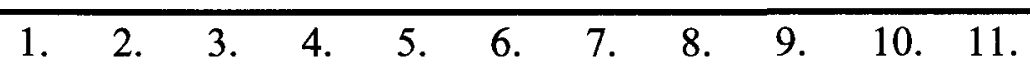

1. Grievances/Per $100 \mathrm{~T}$

2. Student SES $.27 \quad--$

3. Leadership Exp. $-.02 \quad .03 \quad--$

4. Av. Yrs of Tchg. Exp. for Teachers $\begin{array}{llll}-.17 & -.19 & .03 & --\end{array}$

5. School Size $\begin{array}{lllll}-.10 & -.00 & .12 & -.15 & --\end{array}$

6. Gender $\begin{array}{llllll}.02 & -.06 & .019 & -.04 & .08 & --\end{array}$

7. Elementary

$\begin{array}{llllllllll}-.31 & .08 & .14 & .13 & -.40 & -.08 & --\end{array}$

8. Middle/Junior High $\begin{array}{llllllll}.02 & -.06 & -.07 & .01 & .06 & -.05 & -.37 & --\end{array}$

9. Secondary/Senior High $\begin{array}{llllllllll}-.04 & -.15 & -.07 & -.05 & .55 & .07 & -.74 & -.08 & --\end{array}$

10. K-9 or K-12

$\begin{array}{llllllllll}.64 & .14 & -.10 & -.18 & -.16 & .08 & -.42 & -.05 & -.09 & --\end{array}$

11. Rural Schools $\begin{array}{lllllllllll}.21 & .10 & -.19 & .10 & -.37 & .15 & -.29 & -.04 & .18 & .31 & --\end{array}$

12. Urban Schools $\begin{array}{lllllllllll}.03 & .17 & .12 & -.07 & .11 & -.04 & .06 & .22 & -.11 & -.14 & -.44\end{array}$

13. Student Discipline Dummy 1

$\begin{array}{lllllllllll}-.01 & .01 & .06 & -.00 & -.25 & -.03 & .21 & -.10 & -.20 & .00 & .31\end{array}$

14. Student Discipline Dummy 2

$\begin{array}{lllllllllll}-.07 & -.03 & .09 & .02 & -.10 & .09 & .13 & .04 & -.19 & .01 & -.13\end{array}$

15. Student Discipline Dummy 3

16. Charisma/Inspirational $\begin{array}{lllllllllll}.28 & .01 & -.13 & -.14 & -.10 & -.07 & -.15 & -.08 & .19 & .05 & .03\end{array}$

17. Intellectual Stimulation $\begin{array}{lllllllllll}.21 & .16 & .04 & -.11 & .06 & -.29 & .04 & .18 & -.08 & -.10 & -.15\end{array}$ $\begin{array}{lllllllllll}.14 & .07 & -.03 & -.03 & .09 & -.12 & -.18 & .03 & .17 & .06 & -.03\end{array}$

18. Individualized Consideration

19. Contingent Reward

$\begin{array}{lllllllllll}.02 & .17 & .01 & -.10 & -.05 & -.10 & -.03 & .02 & .03 & -.01 & .04\end{array}$

20. Management by Exception $\begin{array}{lllllllllll}.12 & -.00 & -.03 & -.04 & .17 & -.13 & -.23 & .15 & .17 & .02 & -.02\end{array}$

21. Passive/Avoidant $\begin{array}{lllllllllll}-.02 & -.10 & .06 & .04 & .25 & .25 & -.33 & .18 & .32 & -.02 & .12\end{array}$

22. Leadership Quality $\begin{array}{lllllllllll}-.10 & -.29 & .01 & .03 & -.08 & .09 & -.00 & -.13 & .04 & .07 & .20\end{array}$ Means $\begin{array}{lllllllllll}.19 & .30 & .05 & -.03 & .11 & -.15 & -.09 & .04 & .12 & -.06 & -.01\end{array}$

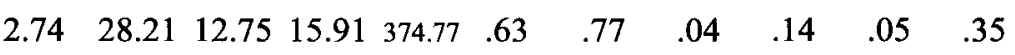
Standard Deviations \begin{tabular}{lllllllllll}
6.21 & 8.61 & 5.68 & 5.60 & 342.73 & .49 & .42 & .20 & .35 & .22 & .48 \\
\hline
\end{tabular} 
Table D1 (cont'd)

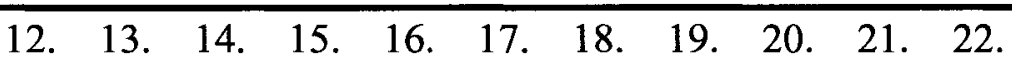

1. Grievances/Per $100 \mathrm{~T}$

2. Student SES

3. Leadership Exp.

4. Av. Yrs of Tchg. Exp. for Teachers

5. School Size

6. Gender

7. Elementary

8. Middle/Junior High

9. Secondary/Senior High

10. K-9 or K-12

11. Rural Schools

12. Urban Schools

13. Student Discipline Dummy 1

14. Student Discipline $\begin{array}{llll}\text { Dummy } 2 & .01 & -.23 & --\end{array}$

15. Student Discipline Dummy 3 $\begin{array}{llll}-.03 & -.19 & -.18 & --\end{array}$

16. Charisma/Inspirational $\begin{array}{llllll}.10 & -.07 & -.00 & .00 & --\end{array}$

17. Intellectual Stimulation $\begin{array}{llllll}.05 & .06 & -.02 & -.09 & .55 & --\end{array}$

18. Individualized Consideration $\begin{array}{lllllll}.05 & .10 & -.10 & -.09 & .47 & .53 & --\end{array}$

19. Contingent Reward $\begin{array}{llllllll}.08 & .02 & .00 & .04 & .52 & .34 & .28 & --\end{array}$

20. Management by Exception

21. Passive/Avoidant $\begin{array}{llllllllll}-.08 & -.27 & .02 & .04 & -.01 & -.10 & -.12 & .24 & --\end{array}$

22. Leadership Quality $\begin{array}{llllllllll}-.21 & .02 & -.03 & .08 & -.34 & -.22 & -.24 & -.12 & .25 & --\end{array}$

Means $\begin{array}{lllllllllll}.07 & .03 & .02 & -.11 & .66 & .63 & .53 & .46 & -.02 & -.39 & --\end{array}$

Standard Deviations $\begin{array}{lllllllllll}.26 & .20 & .18 & .13 & 3.34 & 3.24 & 3.46 & 2.99 & 1.29 & .61 & 3.25\end{array}$ \begin{tabular}{lllllllllll}
.44 & .40 & .38 & .34 & .41 & .44 & .39 & .58 & .86 & .47 & .46 \\
\hline
\end{tabular} 
Appendix E: Regression Coefficients of All Independent Variables

in Various Model Specifications 
Table E1. Regression coefficients of independent variables for original school demographic model $(\mathrm{N}=71)$

\begin{tabular}{|c|c|c|c|c|}
\hline Variable Names & $\begin{array}{l}\text { Estimated } \\
\text { Coefficient }\end{array}$ & $\begin{array}{l}\text { Standard } \\
\text { Error }\end{array}$ & $\begin{array}{l}\text { Beta } \\
\text { Coefficient }\end{array}$ & t-Statistic \\
\hline (Constant) & -2.83 & 3.14 & & -.90 \\
\hline Gender & .20 & 1.27 & -.02 & .16 \\
\hline Leadership Exp. & .05 & .10 & .05 & .51 \\
\hline School Size & -.00 & .00 & -.14 & -.95 \\
\hline $\begin{array}{l}\text { Av. Yrs of Teaching Exp. } \\
\text { for Teachers }\end{array}$ & -.01 & .11 & -.01 & -.11 \\
\hline $\begin{array}{l}\text { Student Discipline-- } \\
\text { Av. Office Referrals }\end{array}$ & -.00 & .00 & -.11 & -.98 \\
\hline $\begin{array}{l}\text { Student SES (Family incon } \\
\text { less than } \$ 30 \mathrm{k} \text { per annum) }\end{array}$ & .21 & .07 & .32 & $2.92 * *$ \\
\hline Middle/Junior High & -1.70 & 4.85 & -.03 & -.35 \\
\hline Secondary/Senior High & 3.98 & 2.58 & .22 & 1.54 \\
\hline $\mathrm{K}-9$ or $\mathrm{K}-12$ & 18.24 & 3.12 & .60 & $5.85 * * *$ \\
\hline Rural Schools & -1.29 & 1.74 & -.10 & -.74 \\
\hline Urban Schools & -.64 & 1.53 & -.05 & -.42 \\
\hline $\begin{array}{l}\text { R Square } \\
.53\end{array}$ & $\begin{array}{l}\text { ted R Square } \\
.44\end{array}$ & $\begin{array}{r}\text { Standard } \\
4 .\end{array}$ & & $\begin{array}{l}\text { F Statistic } \\
5.94\end{array}$ \\
\hline
\end{tabular}

${ }^{*} \mathrm{p}<.05,{ }^{* *} \mathrm{p}<.01,{ }^{* * *} \mathrm{p}<.001$ 
Table E2. Regression coefficients of all independent variables for original demographic and leadership model $(\mathrm{N}=71)$

\begin{tabular}{|c|c|c|c|c|}
\hline Variable Names & $\begin{array}{l}\text { ated } \\
\text { icient }\end{array}$ & $\begin{array}{l}\text { Standard } \\
\text { Error }\end{array}$ & $\begin{array}{l}\text { Beta } \\
\text { Coefficient }\end{array}$ & t-Statistic \\
\hline (Constant) & -2.54 & 7.69 & & -.33 \\
\hline Gender & .85 & 1.31 & .07 & .65 \\
\hline Leadership Exp. & .04 & .11 & .04 & .35 \\
\hline $\begin{array}{l}\text { School Size } \\
\text { Av. Yrs of Teaching Exp. } \\
\text { for Teachers }\end{array}$ & $\begin{array}{l}-.00 \\
-.02\end{array}$ & .00 & $\begin{array}{l}-.13 \\
-.02\end{array}$ & $\begin{array}{l}-.89 \\
-.17\end{array}$ \\
\hline $\begin{array}{l}\text { Student Discipline-- } \\
\text { Av. Office Referrals }\end{array}$ & -.00 & .00 & -.14 & -1.21 \\
\hline $\begin{array}{l}\text { Student SES (Family incom } \\
\text { less than } \$ 30 \mathrm{k} \text { per annum) }\end{array}$ & .20 & .081 & .30 & $2.64^{*}$ \\
\hline Middle/Junior High & -.59 & 5.15 & -.01 & -.11 \\
\hline Secondary/Senior High & 6.07 & 2.74 & .33 & $2.22 *$ \\
\hline $\mathrm{K}-9$ or $\mathrm{K}-12$ & 18.56 & 3.22 & .61 & $5.76 * * *$ \\
\hline Rural Schools & -1.08 & 1.77 & -.09 & -.61 \\
\hline Urban Schools & -.48 & 1.54 & -.04 & -.31 \\
\hline Charisma/Inspirational & 5.56 & 2.57 & .34 & $2.16^{*}$ \\
\hline Intellectual Stimulation & -1.23 & 2.04 & -.08 & -.60 \\
\hline Individualized Consideration & -3.87 & 1.84 & -.24 & $-2.11^{*}$ \\
\hline Contingent Reward & -1.35 & 1.37 & -.11 & -.99 \\
\hline Management by Exception & -5.89 & .84 & -.08 & -.70 \\
\hline Passive/Avoidant & .35 & 1.40 & .03 & .25 \\
\hline Leadership Quality & .93 & 2.08 & .06 & .45 \\
\hline $\begin{array}{l}\text { R Square } \\
.60\end{array}$ & $\begin{array}{l}\text { ted R Square } \\
.46\end{array}$ & \multicolumn{2}{|c|}{$\begin{array}{c}\text { Standard Error } \\
4.54\end{array}$} & $\begin{array}{l}\text { F Statistic } \\
4.30\end{array}$ \\
\hline
\end{tabular}


Table E3. Regression coefficients of all independent variables for original demographic and leadership model ( $\mathrm{N}=102)$

\begin{tabular}{|c|c|c|c|c|}
\hline$\overline{\text { Variable Names }}$ & $\begin{array}{l}\text { Estimated } \\
\text { Coefficient }\end{array}$ & $\begin{array}{l}\text { Standard } \\
\text { Error } \\
\end{array}$ & $\begin{array}{l}\text { Beta } \\
\text { Coefficient }\end{array}$ & t-Statistic \\
\hline (Constant) & -12.11 & 5.88 & & -2.06 \\
\hline Gender & 1.20 & 1.03 & .09 & 1.16 \\
\hline Leadership Exp. & .05 & .08 & .05 & .61 \\
\hline School Size & -.00 & .00 & -.04 & -.30 \\
\hline $\begin{array}{l}\text { Av. Yrs of Teaching Exp. } \\
\text { for Teachers }\end{array}$ & -.03 & .09 & -.03 & -.45 \\
\hline $\begin{array}{l}\text { Student SES (Family incom } \\
\text { less than } \$ 30 \mathrm{k} \text { per annum) }\end{array}$ & .09 & .06 & .13 & 1.42 \\
\hline Middle/Junior High & 1.97 & 2.50 & .06 & .79 \\
\hline Secondary/Senior High & 1.46 & 2.30 & .08 & .64 \\
\hline$K-9$ or $K-12$ & 19.20 & 2.33 & .67 & $8.24 * * *$ \\
\hline Rural Schools & -.04 & 1.60 & -.00 & -.03 \\
\hline $\begin{array}{l}\text { Urban Schools } \\
\text { Student Discipline }\end{array}$ & .38 & 1.18 & -.03 & -.32 \\
\hline Dummy 1 & 1.11 & 1.42 & .07 & .79 \\
\hline $\begin{array}{l}\text { Student Discipline } \\
\text { Dummy } 2\end{array}$ & -.65 & 1.26 & -.04 & -.52 \\
\hline $\begin{array}{l}\text { Student Discipline } \\
\text { Dummy } 3\end{array}$ & 4.70 & 1.52 & .25 & $3.08 * *$ \\
\hline Charisma/Inspirational & 5.21 & 1.85 & .34 & $2.81 * *$ \\
\hline Intellectual Stimulation & -.88 & 1.48 & -.06 & -.59 \\
\hline Individualized Consideration & -2.94 & 1.44 & -.18 & $-2.04^{*}$ \\
\hline Contingent Reward & -.87 & .98 & -.08 & -.89 \\
\hline Management by Exception & -.31 & .64 & -.04 & -.49 \\
\hline Passive/Avoidant & -.02 & 1.13 & -.00 & -.02 \\
\hline Leadership Quality & 2.21 & 1.61 & .16 & 1.37 \\
\hline R Square & ted R Square & Standard 1 & & F Statistic \\
\hline .60 & .46 & 4.5 & & 4.30 \\
\hline
\end{tabular}

Table E4. Comparison of the original models 


\begin{tabular}{|c|c|c|c|c|c|c|c|}
\hline Model \# & $\mathrm{N}$ & $\mathbf{R}$ & $\mathrm{R}^{2}$ & Adjusted $\mathrm{R}^{2}$ & Std. Error & $\mathrm{F}$ & Sig. \\
\hline Model O1 & 71 & .73 & .53 & .44 & 4.64 & 5.94 & $.000 * * *$ \\
\hline \multicolumn{8}{|c|}{ (original demographic model with Student Discipline Single) } \\
\hline $\begin{array}{l}\text { Model } 1 \\
\text { (basic dem }\end{array}$ & $\begin{array}{l}102 \\
\text { aphic }\end{array}$ & .72 & .52 & .45 & 4.61 & 7.30 & $.000 * * *$ \\
\hline Model O2 & 71 & .77 & .60 & .46 & 4.54 & 4.30 & $.000 * * *$ \\
\hline \multicolumn{8}{|c|}{ (original demographic \& leadership model with Student Discipline Single ) } \\
\hline $\begin{array}{l}\text { Model B2 } \\
\text { (basic dem }\end{array}$ & $\begin{array}{l}102 \\
\text { aphic }\end{array}$ & $\begin{array}{l}.78 \\
\text { leac }\end{array}$ & $\begin{array}{c}.62 \\
\text { ship } 1\end{array}$ & $\begin{array}{r}.52 \\
\text { del) }\end{array}$ & 4.30 & 6.46 & $.000 * * *$ \\
\hline
\end{tabular}

Note: Model O1 is the original demographic model; Model 1 is the basic demographic model; Model $\mathrm{O} 2$ is the original demographics and leadership model; and Model B2 is the basic demographics and leadership model. 